\title{
Skin Color and Identity Formation
}

Perceptions of Opportunity and Academic Orientation among Mexican and

Puerto Rican Youth

\section{Edward Fergus}

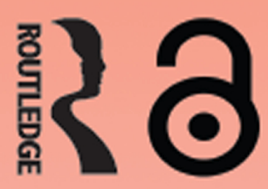




\title{
LATINO COMMUNITIES
}

\section{EMERGING VOICES}

Political, Social, Cultural, and Legal Issues

\author{
Edited by
}

Antoinette Sedillo Lopez

University of New Mexico

A ROUTLEDGE SERIES 


\section{LATINO COMMUNITIES: EMERGING VOICES}

Antoinette Sedillo Lopez, General Editor

CHICANO PROFESSIONALS

Culture, Conflict, and Identity

Tamis Hoover Renteria

RESISTING GENTRIFICATION

AND DISPLACEMENT

Voices of Puerto Rican Women of the Barrio

Vicky Muniz

CHICANO EMPOWERMENT

AND BILINGUAL EDUCATION

Movimiento Politics in Crystal

City, Texas

Armando L.Trujillo

CREATING A LATINO

IDENTITY IN THE NATION'S

CAPITAL

The Latino Festival

Olivia Cadaval

THE DEVELOPMENT OF A

LATINO GAY IDENTITY

Bernardo C.Garcia

LATINO FICTION AND THE MODERNIST IMAGINATION

Literature of the Borderlands

John S.Christie

VOICES OF GUATEMALAN WOMEN IN LOS ANGELES

Understanding Their Immigration Gabrielle Kohpahl

SPANISH AND ACADEMIC ACHIEVEMENT AMONG MIDWEST MEXICAN YOUTH

The Myth of the Barrier

Patricia MacGregor Mendoza
CHICANO EDUCATIONAL ACHIEVEMENT

Comparing Escuela Tlatelolco, A

Chicanocentric School and a

Public High School

Elena Aragon de McKissack

LATINOS AND LOCAL

REPRESENTATION

Changing Realities, Emerging

Theories

Florence Adams

PUERTO RICAN NEWSPAPER

COVERAGE OF THE PUERTO

RICAN INDEPENDENCE

PARTY

A Content Analysis of Three

Elections

Maria Cristina Santana

COLEGIO CESAR CHAVEZ,

1973-1983

A Chicano Struggle for

Educational Self-Determination

Carlos S.Maldonado

LATINOS IN ETHNIC

ENCLAVES

Immigrant Workers and the

Competition for Jobs

Stephanie Bohon

TELLING OUR STORIES

The Lives of Midwestern Latinas

Theresa Barron McKeagney

DOMINICANS IN NEW YORK

CITY

Power From the Margins

Milagros Ricourt 
LATINO NATIONAL

POLITICAL COALITIONS

Struggles and Challenges

David Rodriguez

CREATING TROPICAL

YANKEES

Social Science Textbooks and U.S.

Ideological Control in Puerto

Rico, 1898-1908

Jose-Manuel Navarro

BROWN EYES ON THE WEB

Unique Perspectives of an

Alternative U.S. Latino Online

Newspaper

Maggie Rivas-Rodriguez

PREGONES THEATRE

$A$ Theatre for Social Change in

the South Bronx

Eva C.Vásquez

CARIBBEAN SPANISH IN THE METROPOLIS

Spanish Language among

Cubans, Dominicans, and Puerto

Ricans in the New York City Area

Edwin M.Lamboy 


\section{SKIN COLOR AND \\ IDENTITY FORMATION}

Perceptions of Opportunity and Academic Orientation among Mexican and Puerto Rican Youth

Edward Fergus

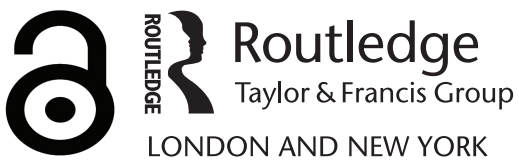


First published 2004 by Routledge

Published 2017 by Routledge

2 Park Square, Milton Park, Abingdon, Oxon OX14 4RN

711 Third Avenue, New York, NY 10017, USA

Routledge is an imprint of the Taylor \& Francis Group, an informa business

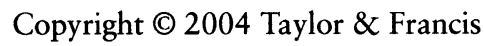

First published in paperback 2012

The Open Access version of this book, available at www.tandfebooks.com, has been made available under a Creative Commons Attribution-Non Commercial-No Derivatives 4.0 license.

Library of Congress Cataloging-in-Publication Data

Fergus, Edward, 1974-

Skin color and identity formation : perceptions of opportunity and academic orientation among Mexican and Puerto Rican youth / Edward Fergus.

p. cm. - (Latino communities)

Includes bibliographical references and index.

ISBN 0-415-94970-X (hardback : alk. paper)

1. Mexican Americans-Education (Secondary)-Michigan-Detroit-Case studies. 2. Puerto Ricans-Education (Secondary)-Michigan-Detroit-Case studies. 3. Mexican American youth-Race identity-Michigan-Detroit-Case studies. 4. Puerto Rican youth-Race identity-Michigan-Detroit-Case studies. 5. Mexican American youth-Michigan-Detroit-Attitudes. 6. Puerto Rican youth-Michigan-Detroit-Attitudes. 7. Urban high schools-Michigan-Detroit. 8. Human skin color-Social aspects-United States. I. Title. II. Series.

LC2688.D48F47 2004

$373.1829^{\prime} 6872073-\mathrm{dc} 22$

2004005188

ISBN 13: 978-0-415-65171-4 (hbk) 
This book is dedicated to everyone that has been a sanctuary, a pillar of strength and an anchor of love.

Besos y abrazos para todos. 


\section{Contents}

List of Tables ix

Preface $\mathrm{x}$

Acknowledgments xii

Introduction xiii

Chapter One Mapping Explanations of Academic 1

Variability and Racial/Ethnic Identification

$\begin{array}{lll}\text { Chapter Two Methods } & 19\end{array}$

Chapter Three Portraits of Self-Identification 35

Chapter Four Negotiating Identification with Other 63

Students and Teachers

Chapter Five Perceptions of Life Chances 81

Chapter Six Conceptualizing and Navigating the School 105 Space

Chapter Seven Toward an Understanding of the 129

Educational Implications of Skin Color

Variation

Appendix A

Appendix B 155

Appendix C 157

Appendix D 159

Appendix E 161

Appendix F 163 
viii

$\begin{array}{ll}\text { Appendix G } & 165\end{array}$

$\begin{array}{ll}\text { Appendix } \mathrm{H} & 167\end{array}$

$\begin{array}{ll}\text { Appendix I } & 169\end{array}$

$\begin{array}{ll}\text { Notes } & 171\end{array}$

Bibliography 175

$\begin{array}{ll}\text { Index } & 185\end{array}$ 


\section{List of Tables}

Table 1 Percentage of National and Detroit Latino/a Groups 21

Table 2 Identification of Respondents 24

Table 3 Participant Background 25

Table 4 District Student Population by Ethnic Group 27

Table 5 Metropolitan Achievement Test Scores (MAT) 28

Table 6 Schools' Student Ethnic Composition 28

Table 7 Schools' Faculty and Staff Ethnic Composition 29

Table 8 Schools' Average Test Scores 30

Table 9 Student Origin and Identification 38

Table 10 Ethnic Identification and Other's Identification 66

Table 11 Student Achievement and Aspirations 108 


\section{Preface}

This topic is near and dear to my heart. Just like many of the students I interviewed, I continue to live my life shifting my identity from one context to another. This is not to imply that I am unsure of who I am, nor that the students in this book do not know who they are. However, when you operate within a societal context that uses skin color to situate everyone, you become aware of what you can and cannot be. For example, when I was an undergraduate, I was Black to a majority of the students and professors on campus and Panamanian to the handful of Latino/as on campus. Even in graduate school, I was required to be Black for the research projects I was on and the classrooms I was in, but I was Panamanian only to myself, family and friends. It was not until I worked in Washington Heights (a community that was $100 \%$ Latino and mostly Dominican) that I could be Panamanian $100 \%$ of the time. It is these realities that have reminded me of the significance of race, ethnicity and skin color. I separate race, ethnicity and skin color not because I believe they are distinct constructs but rather because I understand them as operating in unique but symbiotic ways. These ways of operating also resonate with the realities of the students I interviewed.

The discussion in this book touches on the nature of race and ethnicity on various levels. I approach this discussion of race and ethnicity from the vantage point of the students. They catalog race as a biological construct within the United States because Americans use skin color as a proxy for identifying race. However, the students also interpret race as a cultural/ethnic construct because, as many students stated, they defined White to mean White American and Black as Black/ African American. Both terms in their mind reference a cultural/ethnic group. Such a perspective purports that race and ethnicity are distinct yet connected constructs. However, my focus in writing about the experiences of these students is not to make a value judgment on whether these are valid constructs or if they are one in the same or separate. It is difficult to make such a decision when even academia, 
reference texts (e.g., dictionaries), the census and state governments, continue to vacillate back and forth with regards to whether race and ethnicity are distinct or similar constructs. Thus, what I focus on is the students' discussion of skin color as a proxy for both race and ethnicity. In most instances, I will therefore reference the se constructs as race/ ethnicity in the effort to signify its dual usage. However when the students are making an evident distinction between race and ethnicity the constructs will be separated out, and I will elucidate upon the students' understanding of the term(s) in those instances.

Another construct that I contend with in this book is the notion of identity and identification. Much of the educational research on academic variability among ethnic minority groups has focused on race/ ethnicity as a finite identity. Part of my contention in this book is that by focusing on the race/ethnicity of an individual as a finite construct we overlook the shifting nature of race/ethnicity, the impact of society's definition of race/ethnicity, and the significance it plays in an individual's lived experience. Thus, my approach to exploring race/ ethnicity is through the identification that individuals invoke. By intention, I focus on the selection of a racial/ethnic affiliation as a shifting process that is herein referred to as identification. 


\section{Acknowledgments}

The development of this book is due to the support of several entities in my life: family, friends, and dissertation committee. My family (nuclear, extended, and in-laws) has been an ever-present champion of this work and what I do. I am grateful for my parents, brother, Manuel (Manny), my super supportive extended family in Panama, and in-laws-Todos siempre seran parte de mi vida. Amongst my many friends, there are several that I consider my true inspirations-Virgil (Kihika), Tiffany, and Pearl. The three of you have shown me the beauty of discovering and exploring one's intended path. (You will always be in my heart, my prayers, my thoughts, and an everlasting part of my soul. Jah bless!)

The last seven years of looking at this work would not be possible without the love and support of my family-Lorelei, Javier, and Sofia. The day Lorelei and I committed ourselves to each other was the day we promised to be each other's biggest fans and toughest adversaries. (Lorelei-I always sit in awe of how beautiful of an individual you are, and I am ecstatic about being your partner through your life journey.) Finally, I cannot talk about my partnership with Lorelei without talking about the spirits that have illuminated our lives in the last 4 years. Javier and Sofia have brought new meaning and inspiration to my life in ways that I could never put into words.

Finally, Carla O'Connor, Alford Young, Jr., Virginia Richardson, and Frances Aparicio, my dissertation committee, have provided not only the academic support but also the intellectual space and freedom to explore this area of interest. I especially would like to thank Carla who has pushed the intellectual boundaries of this work and its substantive worth in the field of education. 


\section{Introduction}

I guess I'm Puerto Rican, but Puerto Ricans to me are mutts. There is no such thing as $100 \%$ Puerto Rican. Some have more than others like my family has a lot of African, Indian, we got Taino Indian, we got a little European, we got French and we got Spaniard. It depends because my father looks Arab, but my mother looks Black, so it's a mixture. And my sister looks White... When somebody asks me I tell them yeah, I'm Puerto Rican, but when they see me, they say I can pass as anything. So some people think I'm a lightskin Black girl or I'm Indian or Arab or something Mexican. It don't bother though but I just tell them where I'm from.

Samantha, 12th grade, second generation Puerto Rican

The Opportunity and Achievement literature traditionally interpreted the ethnic and racial identification of minority students as a self-imposed categorization process. Minority students are presumed to select an ethnic or racial identification from a list of discrete categories, such as Black, White, Asian, Native American or Other. Each category is then imagined as being bound to specific histories of discrimination and privilege that have been identified as guiding students' perceptions of opportunity and its relation to their academic orientation. These undergirding presumptions regarding how individuals become identified with one racial/ethnic category rather than another have driven much of the research that explains why some minority students perform poorly and why others are able to be academically successful. However, Samantha's passage above prompts us to re-examine whether this presumption is necessarily accurate. Samantha's description of her racial/ ethnic composition and how she perceives others view her ethnic or racial identification based on her skin color raises the following questions: Is ethnic or racial identification solely a self-ascribed 
process? What does it mean for Samantha that she identifies as Puerto Rican, but due to her "light-skin," possibly hair texture and facial features, she believes others identify her as Black? How do these external interpretations of her identification relative to her own understanding of her identification affect her perceptions of opportunity and subsequent academic orientation? In other words, are her perceptions of opportunity a function of her self-identification as Puerto Rican or her external identification as African American or Black? Further, what is likely to determine whether it is self rather than external identifications that drive perceptions of opportunity and therefore the extent to which Samantha engages in school? Or is there an interaction between self and external identifications that moderate perceptions of opportunity and academic orientation? It is these questions that are at the center of this book.

The stories of the 17 students interviewed for this book are significant because in the last 25 years researchers have demonstrated that marginalized students perceive the opportunity structure as limited for people like them and subsequently disengage from school. Their perceptions of the opportunity structure as limited are driven by a disbelief in the dominant theory of "making it." This theory purports that in America individuals can make it if they work hard and display individual effort. Marginalized students, on the other hand, are said to believe that the distribution of social rewards is inequitable and that social structures (e.g., institutional racism) constrain the opportunity and chances of individuals like themselves. They consequently interpret their own life chances as limited. These interpretations result in marginalized students developing pessimistic perspectives about their future. They subsequently conclude that it is not worth it to work hard in school because they will not be rewarded comparably for their efforts. Ethnic affiliation, also implicated in their rejection of school norms and expectations, and limited perceptions of the opportunity, involves, in part, a cultural frame of reference that operates on the premise that oppression is pervasive; therefore people like them cannot make it. In response to such a perceived environment, minority students have been catalogued as assuming non-conducive or resistive behavior that disengages them from the schooling process.

Such findings have been best captured by the research of John Ogbu (e.g., 1978, 1987). Ogbu's cultural ecological model (CEM) centers its analysis on the extent to which a student's interpretation of the relationship between schooling and social outcomes inform his/her relative engagement or disengagement from school. In accordance with this model, students are likely to disengage from school when they 
believe that members of their racial or ethnic group (compared to whites) will not reap comparable economic and social rewards for their performance in school. On the other hand, academic engagement is a function of student belief that their racial or ethnic group will be equitably rewarded for their efforts in school.

To date, however, this cultural model and subsequent typologies has not lent sufficient attention to the distinction between the ethnic group with which individuals identify (i.e., self-identification) and those with whom they are identified (i.e., external interpretations of identity). Much of the research has wholly ignored this distinction. Instead, researchers predeterrnine the racial and ethnic identification of respondents and conduct their investigations as if the respondents would necessarily situate themselves within these same racial/ethnic categories. Consequently, ethnic identification becomes both an objective and static cultural characteristic with which individuals can be readily categorized and analysis proceeds along the lines introduced.

Prominent investigations of immigrants and their generational status provide evidence regarding the variation in and significance of racial/ ethnic identification in the adaptation process (e.g., Portes, 1994; Portes \& MacLeod, 1996a \& 1996b; Rumbaut, 1994). This research finds that each generation of immigrants adopts differing identities, which correlate with a generational stage in the adaptation process. These generational shifts in identification correlate with educational attainment. This work points to CEM's construction of Latino/a immigrant groups as limited, however, this immigration research itself has not interrogated the within-group variations (e.g., skin color and language) that can also shift and/or alter the adaptation process of Latino/a immigrants, regardless of generation.

The few studies that have systematically explored skin color variations within Latino/a groups establish a correlation to social acceptance, educational attainment and selection of identification. Research on phenotype differences among ethnic minority groups, especially African Americans and Latino/as, notes that individuals with lighter skin tone fair better than those with darker-skin tone and, in some instances, are considered more attractive (Arce, Murguia, \& Frisbie, 1987; Gomez, 2000; Hughes \& Kertel, 1990; Keith \& Herring, 1991). For example, several correlational studies of Chicano and Mexican men in the Southwest demonstrate that darker skin color is correlated with lower educational attainment and, in turn, has implications in social mobility (Murguia \& Telles, 1996; Telles \& Murguia, 1990). Similarly, various survey and qualitative studies assert that in some instances Latino/a groups shift their ethnic identification to 
the U.S. racial categories based on how they perceive others situate them (Oboler, 1991; Rodriguez, 1992, 2000; Rodriguez \& Cordero-Guzman, 1992). Overall, such phenotype research, along with sociological constructs of racial/ethnic identification, provides a framework from which to explore 1) how students like Samantha negotiate their racial/ ethnic identification alongside other's perceptions of their skin color, and 2) how these negotiations moderate perceptions of opportunity and influence (if at all) academic orientation. Such an exploration complicates Ogbu's cultural ecological model and subsequent typologies by placing emphasis on the internal and external subjective nature of racial/ethnic identification as moderating why and how some ethnic minority students succeed in school and others fail. Further, by exploring the relevant impact of self-identification and external interpretations of identification on perceptions of opportunity and academic orientation, we can begin to consider micro-level versus macro-level explanations for academic variability.

In sum, by accounting for variation in skin color this book explores ethnic identification as reflective of both a self-identification and external interpretations of identification. Portes and MacLeod (1996) describe it as, "what they think your ethnicity is influences what you think your ethnicity is, to say nothing of what they think you think your ethnicity is" (p. 527). By approaching race/ethnicity from such a vantage point moves away from the static and objective considerations of race/ethnicity as having a universal definition and marker(s). Instead, by looking at race/ethnicity through the process of identification versus a circumscribed identity we are able to explore "the way people are discursively interpolated into certain positions, and the process by which people are brought to invest in or context their assigned positions" (Evans, 1998, p. 100). This book demonstrates that, irrespective of how these 17 Mexican and Puerto Ricans students constructed their own identifications, they were aware that others construct their identifications in other ways based on their phenotype. What this book focuses on is the relative influence the students' negotiation of their self-identifications and external interpretations of identification had on their perceptions of opportunity and academic orientation.

The aforementioned was examined over the course of six months. Interviews were conducted with 17 high school students from the same community who attended three different high schools. The students participated in a local community center that provided the site where I interviewed students. The interviews focused on discerning: 1) how the students defined their own racial/ethnic identification as well as how 
they perceived others define them; 2) how they discussed the opportunities available for the social group with which they identified as well as the social group with which they believed others situated them; and 3) how the students' academic orientation (which reflected their educational aspirations, participation in co-curricular activities, and accommodation to schooling norms) related to their experiences of racial and ethnic identification and their perceptions of opportunity.

\section{OVERVIEW OF CHAPTERS}

In chapter one, I situate the traditions in educational research that examine the academic variability of marginalized students. I also offer a theoretical framework that complicates such previous explanations by exploring racial/ethnic identification as both an internal and external phenomenon. That is, the framework focuses on identification as a process that involves agency behavior (i.e., self-identification) but contains various mandatory boundaries dictated by external markers (i.e., skin color, hair texture, and language). Chapter two discusses the qualitative methods employed, as well as a description of the schools and district the students attend and a macro description of the racial/ ethnic composition of Detroit.

Chapter three introduces the students and the ways in which they construct their racial/ethnic self-identification. I draw largely from conversations on what it means to be Mexican and/or Puerto Rican, and how they represent it in their day-to-day activities. More importantly, this chapter demonstrates the students' boundary construction of naming themselves, which includes explanations of markers they consider to mark this boundary.

Chapter four focuses on how the students perceive their identification being constructed by external forces. I draw attention to the ways in which the students' skin color is used by others to construct an identification that for some students is relatively consistent with their self-identification, and while others these external perceptions of identification denote a different racial/ethnic boundary from their own. In this chapter we see how racial/ethnic identification is inextricably linked to multiple internal and external constructs.

Chapter five centers on the students' discussions of how they perceive opportunity, chance, and "making it" operating in defining social outcomes in U.S. society. This chapter examines the students' perceptions of opportunity, chance, and making it as moderated by skin color. I draw attention to subjective renderings of how social outcomes 
are attained, as complicated by the type of racialization these students endure along.

Chapter six draws on my discussions with the students about how they experience the schooling process. I center the conversation in this chapter on the differential experiences of discrimination in school between the students along skin color lines. More importantly, I draw attention to how these differential experiences moderate the ways in which the students perceive the utility of education and arrange their engagement in the schooling process.

In the final chapter, I return to the complexity of racial/ethnic identification as a self-identification and external identification process that moderates perceptions of opportunity and academic orientation. This book underscores several important implications of skin color variation among similarly self-identified individuals. I call attention to the relevant meaning of this relationship among Latino groups, especially in capturing the significant variation in experiences. The theoretical conversation centers on race/ethnicity among Latinos as fluid boundaries that, at times, contain mandatory identifications. As such, the implications of skin color variation in the students' perceptions of opportunity and academic orientation purports that understanding academic variability among ethnic minority groups, like Latinos, must consider inter-group variations. 


\section{Chapter One \\ Mapping Explanations of Academic \\ Variability and Racial/Ethnic \\ Identification}

\section{CULTURAL MODELS: EXPLANATIONS OF ETHNIC MINORITY ACADEMIC VARIABILITY}

For the last forty years researchers have posited competing theories regarding the relative influence of social class background and racialgroup membership on the school experiences, academic performance, behavior, and motivation of ethnic minority students. The general purpose of these competing theories has been to explain why ethnic minority students fail or succeed in schools. Many of these theories consider factors inside the school, and the child's family, culture, racial/ ethnic group affiliation, and responses to school. These theories are commonly situated into three categories of thought: cultural deprivation, cultural difference/discontinuity, and cultural ecology.

Cultural deprivation theory presumes a deficiency in family and cultural practices, while cultural difference/discontinuity attends to the dissimilarity between home and school culture as affecting academic performance. The cultural ecological perspective considers the ecological factors (i.e., history of subjugation, labor market participation, discrimination, immigrant status, housing isolation, socioeconomic status) that surround the ethnic population and how those factors moderate the type of orientation ethnic minority populations have towards school. Although, these three traditions provide compelling explanations for the variability in academic performance among ethnic minorities, the explanations are premised on an incomplete picture of the inter-relatedness of racial/ethnic identification and ecological factors ethnic minorities' experience. In this review I focus on how these theories have been used to explain the limited academic performance of Latina/os in general, and Mexicans and Puerto Ricans in particular, as well as, offer the variation in 
racial/ethnic identification among Latinos as a complexity not fully explored in this literature.

\section{Cultural Deprivation}

Cultural deprivation theory (also known as the culture of poverty argument) maintains that the low academic performance of Latino/as is a consequence of their deficient cultural practices (e.g., Bloom, Davis, \& Hess, 1965; Heller, 1966; Lewis, 1961). The premise of cultural deprivation theory is that familial and community practices suppress the development of low-income minority children's linguistic, cognitive, and affective skills necessary for successful school functioning. According to C.Heller (1966), the cultural practices of Mexican American families focus on values that are not conducive to social mobility in the United States. Heller (1966) asserts that "this type of upbringing creates stumbling blocks to future advancement by stressing values that hinder mobility - family ties, honor, masculinity, and living in the present - and by neglecting the values that are conducive to itachievement, independence, and deferred gratification" (pg. 34-35). Other proponents of this theory assert that this form of cultural socialization is perpetuated from one generation to the next. Oscar Lewis (1961) claims that low-income Mexicans and Puerto Ricans selfperpetuate a culture of poverty that includes violence, an inability to defer gratification, and political apathy. These cultural practices, according to Lewis, are imbedded in the behavior of low-income Mexicans and Puerto Ricans by the time they are 6 or 7 years old and continue even if the economic status of the community improves. The implications are that these behaviors and cultural practices impede academic success.

Although this argument addresses how limited structural opportunities are implicated in the life outcomes of marginalized youth, it fails to examine how schools moderate access to educational opportunity. By not attending to schooling inequities that structure opportunity, this model places the fault of economic immobility on the cultural practices of low-income Latinos/as. In addition by perceiving these practices as non-conducive to academic success, the model reinforces middle-class White cultural practices as the natural pattern for educational attainment. However, such a notion avoids the link between culture and power, especially how it reproduces inequity in the school environment.

According to Pierre Bourdieu (1977), schools are not solely in the business of educating children. They also preserve and transmit specific 
forms of cultural capital in ways that reproduce social and economic inequality.

Cultural capital is defined as the general cultural background, knowledge, disposition, and skills that are passed from one generation to the next. Upper class children, according to Bourdieu, inherit different cultural capital than working-class children. Numerous ethnographies outline the manner in which students of different social class categories come to appropriate distinct representation of cultural capital (e.g., Aggleton \& Whitty, 1985; Hollingshead, 1975; McRobbie, 1978; Willis, 1977). Schools, however, privilege and subsequently reward upper class cultural capital and legitimize the associated practices as being necessary for labor market mobility. Schools simultaneously situate the cultural practices of the poor and working class as non-conducive to academic success. In light of Bourdieu's analysis, cultural deprivation theory does not attend to how the privileging of upper class White culture within schools limits the academic opportunity and performance of ethnic minority students (especially the poor and working class amongst them).

\section{Cultural Difference/Discontinuities}

Instead of focusing on how ethnic minorities differed culturally from middle class Whites, educational researchers began in the 1970 s to examine the "mismatch" between the cultural background of ethnic minorities and the norms of expectations of schools. Within this school of thought, researchers did not presume deficiency on the part of ethnic minority groups. Instead, the model asserted that schools were not providing culturally appropriate educational experiences for ethnic minority youth. As a result, ethnic minority students were failing in schools because school curricula and teacher practices were not responding to nor educating them in consideration of culture and language (Delgado-Gaitan \& Trueba, 1991; Ogbu, 1992; Trueba, 1989). Ogbu (1992) outlined the following ways in which this model indicated that cultural differences impacted the academic performance of minority youth: 1) the content of the curriculum may be foreign to minority children and therefore inhibit school learning from being reinforced in the home and community; 2) the method of teaching in school may be different from that of the home and community; 3) schooling may encourage the children to aspire to goals that are out of their reach; and 4) schools may emphasize values that are in conflict with the values of the children's culture. In accordance with these perspectives, various social scientists have explored the dynamics of language and how 
home-school differences in communication styles and strategies affected the academic performance of minority youth (Cazden, John, \& Hymes, 1972; Gumperz, 1981; Kochman, 1982). Others more specifically documented the language and other discontinuities between Latino/a students and the English-speaking middle class school system as limiting the educational outcomes of Latino/a students (Carter \& Segura, 1979; Trueba, 1987, 1989). Still others concentrate on the conflicts minority children (i.e., Mexican and Indian) have in the classrooms of White teachers (Davidson, 1999; Erickson \& Mohatt, 1982). Overall, these qualitative and ethnographic studies provide insight into the processes and mechanisms by which school failure occurs.

The cultural difference model provided a conceptual framework that assisted in the development of school programs (e.g., bilingual/ESL classrooms and schools) and curricular programs (e.g., culturally sensitive/responsive programs) that are aware of and respond to the cultural and language differences of ethnic minority students. However, this model does not sufficiently explain academic variability among ethnic minority students. Even though cultural differences may exist in classrooms with Latino/a students, recent immigration research notes that the problems particular to Latino/as have more to do with immigration, minority status, and their adaptation process (Portes, 1994; Portes \& MacLeod, 1996b; Suárez-Orozco \& Suárez-Orozco, 1995). Moreover, cultural difference disproportionately concentrates on academically troubled populations of minority students and little attention is given to the culture and dispositions of academically successful students (Ogbu, 1987). Also, because there is limited comparative analysis between high and low performing students, consideration of how ethnic minority students interpret and make meaning of school and home has taken a back seat in cultural difference model. Thus, the limitation of this model lies in the lack of attention to students' subjective interpretations of the relationship between school and social outcomes and the ways in which those interpretations influence engagement in school.

\section{Cultural Ecological Perspective of Academic Variability}

Educational anthropologist John Ogbu $(1978,1987)$ attempts to address the limitations of previous research on academic variability among ethnic minority youth by exploring power differentials and how student subjectivity influences academic performance. Ogbu (1987) argues that 
cultural deprivation and difference models do not account for why some ethnic minority students perform better than other minority and White students. His contention is that ethnic minority students have different histories of entry into and subjugation within the United States, which embody specific experiences of racial discrimination and social mobility. These experiences, Ogbu argues, are reflected in the student's subjective interpretations of the relationship between school and social outcomes, which in turn informs the students' accommodation and/or resistance to school. This argument is referred to as the cultural ecological model.

According to Ogbu's (1987) cultural ecological model, two macro ethnic minority groups are prevalent in the United States: voluntary and involuntary minorities. These categories reflect two migration patterns, voluntary entry into the U.S. (e.g., immigrants) and involuntary entry (e.g., slaves, U.S. commonwealth countries). Immigrant minorities (e.g., Asian, Central and South American, and West Indian) are defined as a population that has voluntarily moved to the United States for better economic opportunity and/or political freedom. Generally in the first generation, immigrants experience adaptation problems due to their minimal language proficiency, lack of knowledge regarding American cultural cues, and gaps in educational background. However, Ogbu (1987) posits that these difficulties in adaptation are reduced after the first generation because immigrant families see the cultural differences as barriers to be overcome in order to have positive academic achievement and/or economic prosperity.

In contrast, "involuntary minorities are people who were originally brought into the United States involuntarily through slavery, conquest, or colonization" (Ogbu, 1987, pg. 315). Such groups (e.g., African Americans, Mexican Americans, Native Americans, and mainland Puerto Ricans) historically been relegated to menial positions, denied assimilation into mainstream society, and experienced difficulties with social adjustment in school. Thus the cultural ecological model asserts that involuntary minorities, recognizing that the opportunity structure has historically not rewarded their ethnic group in comparison to Whites, respond to schooling by engaging in behavior non-conducive to academic success.

According to this model, ethnic minority students' interpretations and responses stem from cultural adaptations that differ between involuntary and voluntary minorities (Ogbu, 1992). The critical differences in cultural adaptations derive from "the type of relationship which develops between the cultures of involuntary minorities and White American mainstream culture, on the one hand, and on the other, in the type of 
relationship which develops between the culture of voluntary minorities and the mainstream culture of White Americans" (Ogbu, 1992, p. 6). Ogbu categorizes these differences as primary and secondary. "Primary cultural difference are differences that existed before two populations came in contact" (Ogbu, 1987, p. 322); this is most applicable to immigrant minorities. These cultural differences include language, religion, and familial values. The significance of these differences is that, even though they comprise ethnic identity, immigrants do not feel as if their engagement in social institutions dominated by Whites challenges their ethnic and cultural identification. Actually, immigrants interpret certain differences (i.e., language) as barriers they need to overcome in order to achieve educational and occupational success. More specifically, "the necessity to participate in the cultural frame of reference of White Americans is perceived as important and not as a threat to [their] own minority culture" (Ogbu, 1992, p. 6). These interpretations and perceptions facilitate the student's ability to cross cultural boundaries in school. For example, an immigrant student is able to distinguish between what they have to learn in order to succeed in school (e.g., English proficiency, accommodating to school behaviors and attitudes) and what conflicts with their own cultural background. These accommodations to school culture have been noted among Punjabi Indians (Gibson, 1987), Japanese Americans (Matute-Bianchi, 1986) and some Central American groups (Suárez-Orozco, 1991).

On the other hand, secondary cultural differences, which are most applicable to involuntary minorities, "are those differences that arise after two populations have come in continuous contact or after members of a given population have begun to participate in an institution controlled by another population, such as schools" (Ogbu, 1987, p. 316). Involuntary minorities appear to interpret these cultural differences as symbols of group identity, and thus construct oppositional identities towards White America. They believe that behaving and/or learning aspects of White American culture in school is detrimental to their own language, culture, and identity (Ogbu, 1991). Moreover, they perceive themselves as unable to reap the benefits of academic success comparable to Whites, and in turn disengage from school.

Recent immigration research, however, complicates this cultural ecological model by asserting that variations in ethnic identification relate to differences in Latino/a immigrant generation's adaptation, which may also explain academic performance (Flores-González, 1999; Matute-Bianchi, 1986; Portes \& MacLeod, 1996a, 1996b; Rumbaut, 1994). For example, in a comparative study of Mexican and White students, Suárez-Orozco and Suárez-Orozco (1995) observed that 
Mexican students identify differently based on generation. First generation students tended to identify as Mexican and perceive the educational and opportunity structure as more promising than their home country. However, some second generation Mexican students experience a discontinuity between Mexican familialism and White American culture in which they become preoccupied with "not making it" and construct "transitional identities" such as Chola/o or Chicana/o. They subsequently align themselves with native minorities (i.e., African Americans and Native Americans) by adopting an adversarial stance towards school. Matute-Bianchi (1986) asserts that the reasoning for this adversarial stance is because second generation Mexican students perceive themselves to have a forced-choice dilemma: do well in school or maintain a Mexican American/Chicana/Chola identity. The dilemma is whether to "participate in both the culture of the dominant group, that is, school culture, and in the Chicano culture" (Matute-Bianchi, 1986, p. 245). For many second-generation Mexican students this adversarial stance includes joining gangs, dropping out of school, and/or increased truancy (Suárez-Orozco \& Suárez-Orozco, 1995).

Limited research exists on the application of this cultural ecological model with Puerto Rican students. However, in a study of highachieving Puerto Rican students, minority status, social class, the sociocultural context of school, and ethnic identity emerged as influencing how these students reconcile academic success and their own ethnic affiliation (Flores-González, 1999). Flores-González (1999) posits that academic success may have more to do with social history, ethnicity, class, school opportunity structure, and role identity than ethnic minority adolescents' ability to "act white." The author posits that regardless of race (i.e., skin color), the academic success or failure of Puerto Rican adolescents in low-income, segregated communities is "a reflection of their status in society, their perceptions of themselves and how schools structure opportunities" (Flores-González, 1999, p. 355). However, though Flores-González uses skin color as a proxy for race, she does not empirically explore it as a variable that may also influence academic performance and engagement. Overall, such immigration and anthropological studies on Puerto Rican and Mexican students introduce the possibility that ethnic minority students construct and interpret their social world in a myriad of ways, which in turn influence their subjective understanding of the relationship between schooling and social outcomes.

These studies expose two limitations of Ogbu's cultural ecological model. First, the model offers a substantive explanation for academic variability among ethnic minority students at a macro-level with little 
attention to its applicability at the micro-level (Foley, 1991). That is, the model is not able to fully explain academic variability within ethnic groups that vary in ethnic identification, involuntary and immigrant generation. Thus, the cultural ecological model may provide categories that could be used to generalize about an entire group, however by doing so the model over-looks micro-level variations that may have major implications as to the influence of subjectivity.

The second limitation exposed is the way in which the model characterizes racial/ethnic identification. The model operates on the implied assumption that racial/ethnic identification can be defined as an "essence" that is reflected in individual and group renderings of opportunity and academic orientation. This assumption defines collective identifications (e.g., Black, African American, White, Hispanic/Latino/a, West Indian) as having some set of core features commonly shared by members and not present in other groups. These features range from experiences of racism and discrimination to similar renderings of slavery, colonization and cultural artifacts and symbols. In addition, this "essence" invokes an implied biological construct by asserting that in the student's identification as Black, African American, Latino/a, or Hispanic, he or she is read similarly by others. Thus, this assumption of an "essence" implies that individuals and groups construct shared patterns of thoughts and beliefs, which define their identification.

This assumption imposes a notion of identification that is static and necessitates careful investigation. At the core, this identification construct promotes the essentializing of ethnic minority groups into "essences" which leads to the conclusion that there is only one way to be Black or Latino/a. Various studies (Fordham, 1998; Fordham \& Ogbu, 1986) support this analytical line of thought through arguments of marginalized students who are academically successful constructing a "racelessness" persona that signifies their disidentification with the racial group of which they are assumed to be a part of. Other research disconnects their identification from the schooling context (Gibson, 1987). However, subsequent research challenges such a framework by illustrating micro-level variations in which students are able to assert a racial/ethnic identification and maintain a strong academic identity without it being perceived as an affront to the collective (FloresGonzález, 1999; O’Connor, 1997, 1999). Such research suggests that Ogbu's essentializing of collective identifications overlooks how identities and identifications are continuously manipulated by the individual student and external forces. More importantly, Ogbu's cultural ecological model and subsequent perspectives minimize the 
significance of, what Craig Calhoun (1995) defines as identity politics. Identity politics involves issues of power relations that complicate how an individual is able to view him or herself. Calhoun writes:

We face problems of recognition because socially sustained discourses about who it is possible or appropriate or valuable to be inevitably shape the way we look at and constitute ourselves, within varying degrees of antagonism and tension. They [identity politics] are struggles, not merely gropings; power partially determines outcomes and power relations are changed by the struggles. They [identity politics] involve seeking recognition, legitimacy (and sometimes power), not only expression or autonomy (p. 20-21).

What is key to extract from Calhoun's definition of identity politics is the significance of power and hierarchy in how identification is formulated. The cultural ecological model overlooks the internal and external processes of identification that are bound to and shaped by power and hierarchy. In other words, there are social and political differences in whether the identification "comes from social groups within the category or if the pressure for boundary keeping and definitions come from without" (Bashi, 1998, p. 960).

In short, what is missing from this cultural ecological perspective is an analytical exploration into marginalized students' racial/ethnic identification process as defined by the identity politics that individuals contend which involves the power relations in how they are identified by others. Such an approach can provide a more robust understanding of how marginalized students come to formulate their perceptions of opportunity and academic orientation. Otherwise, this cultural ecological perspective simply allows identification to be viewed and interpreted as, what Calhoun (1995) calls, "reflections of 'objective' social positions or circumstances" (p. 25). Moreover, it does not "make sense of the dynamic potential implicit in the tension within persons and among the contending cultural discourses that locate persons" (Calhoun, 1995, p. 28).

In the following section, I posit a framework in which to discuss the racial/ethnic identification of Mexican and Puerto Rican students of different phenotypes that captures the politics of identification. This framework posits the process of identification as operating from two axes, a self-identification process and external perceptions of identity (or external identification). Such a framework allows us to explore identification as a process that sustains some form of individual agency. 
This focus on agency highlights the extent to which a person has some control over their identification. The framework also provides room to explore the significance of and power with which external group members can also situate individuals racially and ethnically. In light of these internal and external influences, to which identification do individuals adhere? Is the external group's identification incorporated or not? It is such questions that the following framework asserts are significant.

\section{SITUATIONAL AND CONSTRUCTIONIST EXPLANATIONS OF RACIAL/ETHNIC IDENTIFICATION}

For over fifty years sociologists have discussed the construction of racial and ethnic identification and its persistence as a result of culture, tradition, nation-state imposed ethnic categories, and external perceptions of identity (Barth, 1969; Glazer \& Moynihan, 1970; Gordon, 1961; Nagel, 1986, 1994; Patterson, 1975; Padilla, 1985; Yancey, Erickson, \& Julian, 1976). As such, research on ethnic identification has endured various shifts. However, the most significant changes have been based on the assertion that the fundamental process of ethnic identity formation involves boundary construction (Cornell, 1996). Fredrik Barth (1969) introduced the notion that ethnicity is about boundaries: who is in and who is out. Barth's focus was primarily on the self-ascription and the ascription of others that create an ethnic boundary. In other words, "the cultural stuff [the boundary] encloses" is less significant than the actual boundary itself. This eventually began a discussion as to how external forces are involved in the construction of this ethnic boundary. This discourse also made ethnic identification theory more applicable and responsive to the conditions of racial and ethnic minorities.

Over time, discussions on ethnic boundaries separated into two lines of inquiry: 1) circumstantial or situational factors that construct an arena for ethnic cohesion and affiliation; and 2) the relative agency ethnic groups employ in the shaping and re-shaping of ethnic boundaries (Cornell, 1996). Although, both lines of inquiry advance Barth's notion of boundaries by situating identification as a fluid process that is shaped and reshaped by individuals and/or various external forces, the latter inquiry argues that boundaries also have a mandatory nature. This assertion poses new questions about the boundary-making process that extend beyond how individuals and groups decide who is in and who is out. Instead, the questions focus on the markers used to situate 
individuals and groups within racial hierarchical systems and the power relations it signals. That is, the questions are, how are decisions made as to who is in and who is out? And what role and meaning do markers have in the mandatory process of identification? I will focus on skin color as a key example of a marker that is used as a signifier of race and ethnicity. The role of skin color raises critical questions about the identity politics and power relations of the boundary making process of identification that these lines of inquiry do not fully explore.

More specifically, by observing that skin color has varying cultural meanings depending on context, implies skin color/race is, what Stuart Hall (1998) calls, a "floating signifier." In other words, skin color, as a signifier of race and ethnicity, is acted upon or reacted to based on the meaning it has for the individual and the meaning he or she perceives it has for others while interacting with them (Blumer, 1969). All of these interplays are simultaneously operating within larger societal notions of skin color and what it represents. Thus, the intent of the following discussion is to elucidate the questions these two lines of inquiry raise about boundaries of identification, as well as explore how skin color is implicated in the boundaries of identification.

\section{CIRCUMSTANTIAL AND SITUATIONAL FACTORS IN THE BOUNDARY MAKING OF IDENTIFICATION}

The first line of inquiry considers "the societal conditions and resultant positional interests that have encouraged, compelled, or inhibited organization along ethnic boundaries... and thereby give logic to ethnic group formation and persistence" (Cornell, 1996, p. 266). The implicit assumption of such research is that racial/ethnic identification is intimately bound to and constructed from societal and material conditions. In other words, racial/ethnic groups develop from shared "material interests" (e.g., politics, language, culture), which themselves are constructed from specific historical circumstances or contexts (e.g., migration, community shifts, economic conditions, nation-state policies). Additionally, as circumstances and/or context change, the material interests that comprise the racial/ethnic identification change and eventually alter the racial/ethnic boundary of the identity (Cornell, 1996). The development of pan-ethnic labels serves as a key example of how political, so cial and economic contexts construct and shift the boundaries of identity.

Yen Le Espiritu (1992) operationalizes pan-ethnicity as referring to a politico-cultural collectivity made up of "peoples of several, hitherto 
distinct, tribal or national origin(s)" (p. 2). More specifically, the study of pan-ethnicity considers the continuing interaction between internal and external factors that form and transform ethnic boundaries of identification. Espiritu asserts that the use of pan-ethnic labels grows out of a need to ascribe various groups with an overarching label, treating them as if they represent real cultural and historical groups: Hispanic, Native American, Asian, and Black.

Joan Nagel (1986) argues that nation-states play a decisive role in the construction of these pan-ethnic labels through social policies. This occurs, according to Nagel, through the straightforward treatment of a group of people by using a collective pan-ethnic label as if they represented a real cultural and historical community. For instance, the United States began in the 1980 Census to categorize "persons of Spanish origin or descent" as Hispanic (Fox, 1996). Such pan-ethnic labels not only lump together subgroup boundaries but also "encourages individuals to broaden their identity to conform to the more inclusive ethnic designation" (Espiritu, 1992, p. 6). For instance, in a study of Mexicans and Puerto Ricans in Chicago, Felix Padilla (1985) found that during the 1970s these two groups utilized the term Latino/Hispanic to address the concerns common to Spanish-speaking groups. The civil rights movement, increasing poverty and racial discrimination, and a divided labor market constructed a context in which these urban structural conditions influenced the creation and expression of this Latino/Hispanic identity (Padilla, 1985). Although each group utilized their national identification in daily interactions, Padilla contends that ascribing as Latino/Hispanic was a strategy in acquiring the political and economic needs, and wants of the individual groups under an umbrella term. As a result of such research, Espiritu maintains that individuals begin to view themselves as part of a group that shares critical experiences (i.e., discrimination, political strive). This affiliation appears as a "political history" that, according to Blauner (1972), serves as the core of the pan-ethnic identity and influences behavior, action, and perceptions of dominant groups.

In short, this first line of inquiry situates the boundaries of identification as defined by circumstantial or situational forces (i.e., political, social and economic contexts and circumstances). These forces shape the ways in which people view themselves, their place in the world and the identities they can choose (Cornell, 1996). Ogbu's renderings of racial/ethnic identification as collective operates on a similar presumption of external situational forces shaping individuals and groups' identifications. However, this discourse, by focusing solely on circumstantial or situational forces, minimizes the complex nature of 
agency in constructing and reconstructing identity within the confines of such forces. By centering the discussion on situational forces it assumes a hierarchical relationship of boundary construction. In other words, it conveys that individuals are Black or Latino/a because those identifications are made available by others within the context under study. Instead, the discussion should focus on how boundaries of identity are both optional and mandatory, and how agency is involved in such a process.

\section{AGENCY AND THE BOUNDARY MAKING OF IDENTIFICATION}

The second line of inquiry, on the other hand, attends to individuals' interpretation of and response to circumstantial or situational forces. More specifically, researchers in this area explore the agency individuals and ethnic groups employ in constructing boundaries of identity that satisfy their various needs. Joan Nagel (1994) and Stephen Cornell $(1988,1996)$ assert agency as displayed through the shaping and reshaping of identities with the "raw materials of history, culture, and pre-existing ethnic constructions." In addition, the shaping process is "a composite of the view one has of oneself as well as the views held by others about one's ethnic identity" (Nagel, 1994, p. 154). The resulting effect of this tug and pull is that individuals thus carry a portfolio of identities that they choose to use at their discretion. However, the content of the portfolio is in part shaped by the social context.

This portfolio emerges as, what Nagel calls, a layering of identity. In other words, identities are "constructed by both the individual and group as well as outside agents" (Nagel, 1994, p. 156). For example, Cornell (1988) notes that there are various layers of identity available to Native Americans: subtribal (clan, lineage, traditional), tribal (ethnographic or linguistic, reservation-based, official), regional (Oklahoma, California, Alaska), and supra-tribal or pan-Indian (Native American, Indian, American Indian). Each identification when employed is dependent on where and with whom the interaction occurs, thus making identity a situational construct involving internal choices of how to identify depending on context (Nagel, 1994). Padilla (1985) and Pedraza (1992) also note a similar dynamic amongst Latino/a ethnic groups. Selfidentifying as Mexican, Cuban, Puerto Rican, Dominican, Latino, or Hispanic serves various purposes and functions with different groups. As Nagel (1994) illustrates, 
An individual of Cuban ancestry may be a Latino vis-a-vis non-Spanish-speaking ethnic groups, a Cuban-American vis-a-vis other Spanish-speaking groups, a Marielito vis-a-vis other Cubans, and white vis-a-vis African Americans. The chosen ethnic identity is determined by the individual's perception of its meaning to different audiences, its salience in different social contexts, and its utility in different settings (p. 155).

It is this focus on the individual's subjective ethnic/racial identification in differing contexts that distinguishes this line of inquiry from the previous. In other words, this discourse concerns itself with how individuals select their identity in relation to circumstantial or situational forces versus how such forces define an individual's identity.

However, though this discourse attends to identity as optional, Nagel and other scholars (Bashi, 1998; Cornell, 1988; Portes \& MacLeod, 1996a) assert, that it is also mandatory. In other words, an individual's ethnic identification is constructed by both internal choice and outside agents' perceptions of that identity (Nagel, 1996; Saenz \& Aguirre, 1991). More specifically Nagel (1994) maintains the following:

Ethnic identity is both optional and mandatory, as individual choices are circumscribed by the ethnic categories available at a particular time and place. That is, while an individual can choose from among a set of ethnic identities, that set is generally limited to socially and politically defined ethnic categories with varying degrees of stigma or advantage attached to them (p. 156).

For instance, identity functions differently among White Americans and Americans of African ancestry; "white Americans have considerable latitude in choosing ethnic identities...Americans of African ancestry, on the other hand, are confronted with essentially one ethnic optionBlack" (Nagel, 1994, p. 156). Such differences in the latitude of ethnic options demonstrate the boundary of identity and the significant role outside agents play in restricting the available options for identification. However, Nagel's example of Black and White individuals having distinct ethnic options also points to a more fundamental issue of identification as a positioning of difference with implied power relations. Stuart Hall (1996) argues that identification is "a discursive process of representation" of positions, which includes both the way individuals are situated into certain positions and the process of individuals investing and/or contesting such positions. That is, identification involves internal and external simultaneous renderings of 
"what am I? What am I not? And who makes that decision?" The latter issue of decision-making signals the significance of power relations in the boundary making process. As Bashi (1998) writes:

It matters who does the identifying...it makes a difference who is doing the categorical defining, and who is policing the boundaries of these definitions. It comes down to a question of power: who holds it, where the power-holders see themselves and others in the existing hierarchy, where they think they should be in the racial hierarchy (that is, the meaning or racial positioning), and how they use their power to realize those norms. (p. 965).

In such a process of boundary making, the use of markers as identification represents such power relations. For example, skin color plays the role of a signifier of racial/ethnic identification, but its significance lies in who and in what context its meaning is being invoked. Numerous studies on Latino/a and West Indian groups note individuals change identification based on the context in which they find themselves (e.g., Martin, DeMaio, \& Campanelli, 1990; Massey \& Denton, 1992; Padilla, 1985; Patterson, 1975; Rodriguez, 1992; Rodriguez \& Cordero-Guzman, 1992; Saenz \& Aguirre, 1991). What these studies represent are empirical accounts of how skin color and other signifiers (language and culture) are used by ethnic minorities and Whites to position difference and power relations in the process of identification. For example, Mary Waters (1994) notes that Black Caribbean immigrants acknowledging similarities with African Americans distinguish themselves as Caribbean or West Indian under specific circumstances. More specifically, the Black Caribbean students who resided in middle class areas "reserve[d] their ethnic status for use as an identity device to stress their distance from poor Blacks and to stress their cultural values, which are consistent with American middle class values" (Waters, 1994, p. 194). Meanwhile, those living in segregated neighborhoods were unaware that their ethnic status as Black Caribbean can convey a higher status to Whites. The implicit assumption of Waters' argument is that the youths residing in middle class communities are aware that their skin color operates as a signifier of a Black American/African American identity. In order to defuse the negative meaning Whites derive from brown skin color, they attempt to distance themselves from African Americans by employing their own cultural identification as West Indian.

From this account, we are able to interpret that West Indians and Whites use skin color as a marker of racial/ethnic identification. 
However, what skin color endorses for each group is based on specific power relations. Whites are able to use skin color to define and distance themselves from those who are not White. They subsequently define their level of distance from non-White others by relying on other variations (e.g., class, Caribbean/West Indian roots). On the other hand, West Indian students might opt within specific contexts to emphasize their ethnic over their racial identities because it has a subsequent privileging effect with Whites (i.e., it allows them to be analytically categorized as non-African American, and thus more acceptable to dominant group members).

Studies of Puerto Ricans and Mexicans also note the use of skin color for establishing difference and power relations in the identification process. In a study of Puerto Ricans in New York City, Clara Rodriguez and Hector Cordero-Guzman (1992) noted that among 240 randomly selected Puerto Ricans, $40 \%$ of the sample saw themselves differently from the way in which they perceived that Americans (Whites) viewed them. Additionally, the participant's ethnic/racial identification was strongly influenced by their perceptions of how Americans identify them. For example, participants that believed North Americans viewed them as White, were more inclined to identify themselves as White. Such findings were also apparent in a study of Mexican Americans in which the 546 respondents used various ethnic identities depending on context in order to minimize their social distance from those with whom they interacted (Saenz \& Aguirre, 1991). In these studies, we are able to understand that Mexicans and Puerto Ricans are cognizant of how skin color signifies a racial and ethnic identification. They collapse and/or respond to this knowledge of identity. What this implies is that these groups have limited power in how they can identify themselves.

This phenomenon is also apparent in the school context. Numerous studies note that teachers' and/or peers' racial and ethnic designation of ethnic minority students affect the ways in which these students adapt to classroom and school culture (Connolly, 1998; Davidson, 1996, 1999; Erickson, 1987; Fordham, 1988; Peshkin, 1991). In several studies, ethnic minority students project what is seemingly a "raceless" persona in order to escape the negative stigma associated with the racial/ethnic group signaled by their skin color (Fordham, 1988; Fordham \& Ogbu, 1986). In another study, Mexican students disengaged from classes in which they perceived the teacher's racial/ethnic designation of the student includes negative expectations (Davidson, 1999). Overall, studies like these suggest that skin color and other signifiers (language and culture) can be used to position differences between groups and invoke power relations. In each of these studies, the external group 
maintains the power and privilege to designate racial/ethnic identification via skin color and operate based on the assumptions they attach to that identification. Therefore, what we can come to understand is that identity goes beyond circumstantial or situational forces, or an individual's agency in layering their identification. We need to reconceptualize the boundary making of identification as a complex process of determining "who I am, who I am allowed to be and what am I presumed to be." This process, of course, is couched within a larger societal framework of power relations that depends on the position of the individual, (i.e., internal/external, in-group/out-group, White/nonWhite). These positionings dictate how such questions are answered.

\section{SUMMARY OF LITERATURE}

In sum, the ethnic identification literature offers a framework for looking at identification as a complex process that involves internal and external meaning making of identification. More importantly, how we designate that identification and who makes that decision is a critical component of the identification process. This assessment of identification is absent from the cultural ecological model and the work that substantiates its logic. The model contributes a framework that explains academic variability among ethnic minority students as framed by students' interpretation of the relationship between schooling and social outcomes. However, the model assumes that ethnic minority students from similar ethnic groups identify the same way and are similarly identified by others. More fundamentally, Ogbu's use of collective racial/ethnic identities operates on the assumption that members of the same group share core features and beliefs that are reflected in similar experiences and renderings. However, the inherent problem with such an approach to identity is its inability to explain identity politics that emerge in relation to the external group. The model provides an incomplete picture of who marginalized students are and how they arrive at their identification, which in turn limits our understanding of how marginalized students rationalize the relationship between schooling and social outcomes.

Furthermore, the cultural ecological perspective does not attend to variations in phenotype as shaping the ways in which Latino/a students self-identify and others perceive them. By not accounting for such variations, this cultural model fails to consider the possibility that perceptions of opportunity might also be mediated by the individual's perceptions of how others in their social world might be situating them along racial and ethnic lines. As such, it is critical for this book to attend 
to identity as a variation within ethnic groups that is characterized as both an internal choice (How do I identify?) and a labeling phenomenon which is imposed by others (How do others identify me?). By utilizing such a theoretical frame, I am able to explore the students' perceptions of opportunity and academic orientation as not only grounded in a historical ethnic group experience but also a situational negotiation between how these students' self-identify and how they perceive others identify them. Therefore, the four driving research questions are: 1) How do Mexican and Puerto Rican students of different phenotypes construct their ethnic identification? 2) How do they believe they are identified by others? Do these perceived external-identifications coincide (or not) with the students' self-identification? 3) Are the students' perceptions of opportunity a function of how they self-identify or how they perceive others identify them? and 4) What drives the extent to which they engage (or not) in school?

As noted earlier, qualitative methods were used to explore the above research questions among a group of 17 phenotypically different Mexican and Puerto Rican high school students. In the next chapter, I elaborate not only on these methods but also provide an overview of the schooling and community context. 


\section{Chapter Two Methods}

Over the course of the 1999-2000 school year, I interviewed 26 Mexican and Puerto Rican high school students of various phenotypes to understand how they 1) defined their own ethnic identity; 2) perceived others defined them racially and ethnically; 3 ) assessed the opportunities available for the social group with which they identified and that of those with whom they were identified; and 4) how their academic orientation is related (or not) to the internal and external construction of their ethnic identity and perceptions of opportunity. In the following sections I provide contextual information regarding the research site, the city and community context, the selection of respondents and their background, data collection procedures, and data reduction and analysis.

\section{ADELANTE: A COMMUNITY CENTER}

A stratified purposeful sample of 26 ninth through twelfth grade students ${ }^{1}$ was recruited from a youth center, Adelante, (a pseudonym, as are all other names in this book), that is centrally located in a largely Latino/a populated neighborhood of Detroit. Because I was unable to gain entree to public schools within the neighborhood, this site provided access to a school-going population of youth who are of Latino/a descent (mostly Puerto Ricans and Mexicans) and who range in phenotype. Adelante is a community-based organization that provides various health, legal, and educational services to community members of this neighborhood. Based on formal and informal interviews with the executive director and counselors of Adelante, the bulk of their clientele are from various Latino/a groups (e.g., Mexicans, Puerto Ricans, Cubans, and Central and South Americans), are predominantly lowincome and vary in their immigrant status. Adelante maintains a youth center that provides counseling, after-school tutoring, GED classes, midnight basketball, and other activities for adults, drop-outs, and 
middle and high school students. Over the course of a year, the center services an average of 400-500 youths and adults through their formal GED, computer, guidance counseling, and ESL classes and unstructured drop-in tutorial, computer and open-basketball sessions.

\section{CITY AND COMMUNITY DEMOGRAPHICS}

Adelante operates within the confines of a city and community that has a significant Latino/a population. The U.S. Bureau of the Census (2000) regards Detroit as the largest Black City in the nation. According to 2000 census data, African Americans constitute 81.6\% of the 951,270 people living in Detroit. The next largest groups are Whites $(12.3 \%)$ followed by Hispanics/Latino/as (5\%). However, similar to national figures, Latino/as are the fastest growing population in Detroit (Cardenas, 2000). The 1990 Census calculated the Latino/a population in Detroit at 28,500, and a decade later the Census captured the population at 47,167 , a $60 \%$ increase. Of that population, $62 \%$ are Mexican, 10\% Puerto Rican, 3\% Cuban, and 15\% from various Central and South American countries (Census, 2000). As Table 1 illustrates, the Latino/a population in Detroit is comparable to national population counts.

The various Latino/a groups that populate Detroit have unique migration patterns which provide further understanding of the context. Over the last 10 years, many of the newly arrived Mexicans living in Detroit have come from the cities of San Ignacio, Jesus Maria and Arandas, which are cities in the middle of Mexico, east of Guadalajara and north of Mexico City (Cardenas, 2000). However Latino/a groups have been a part of the Detroit landscape since the beginning of the 20th century. From 1900 to 1930, Detroit experienced a large influx of Mexicans, Puerto Ricans and Central and South Americans. Many came because of the growing industries in Detroit (sugar beet and automobile), the decent wages and the lower cost of living compared to Chicago, Florida and California. Each group, focusing specifically on Mexicans and Puerto Ricans, migrated to Detroit.

Although Mexicans have generally been the largest population of Latino/as, during the 1930s the United States repatriation program deported an estimated 12,500 of the 15,000 Mexicans living in Detroit. It was not until WWII that a second wave of immigrants arrived from Mexico looking for work in agriculture fields and assembly lines. This wave was considered part of the Braceros program that focused on using immigrant labor to fill labor positions left by Americans who went to fight in WWII (Cardenas, 2000). 
Table 1 Percentage of National and Detroit Latino/a Groups

\begin{tabular}{lclc}
\hline National Groups & Percentage & Detroit Groups & Percentage \\
\hline Mexicans & $65 \%$ & Mexicans & $62 \%$ \\
Puerto Ricans & $10 \%$ & Puerto Ricans & $10 \%$ \\
Cubans & $4 \%$ & Cubans & $3 \%$ \\
Central \& South & $14 \%$ & Central \& South & $15 \%$ \\
American & & American & \\
Other & $7 \%$ & & \\
\hline
\end{tabular}

Note: From United States Bureau of the Census, U.S. and Detroit Census Data 1999.

During the 1950s a second wave of Puerto Ricans migrated to Michigan. This wave of Puerto Ricans was responding to the employment conditions on the island in which the United States, via Operation Bootstrap changed the physical landscape and industry of Puerto Rico by encouraging the opening of U.S. factories on the island. Within a ten-year time span (1945-1955), Puerto Rico's urban population changed from $40 \%$ to $70 \%$. Unfortunately, the operation did nothing to diminish the rising unemployment rates. Consequently, Puerto Ricans living in rural areas migrated to cities like Springfield, Massachusetts, Camden and Trenton, New Jersey and Detroit, Michigan to follow employment opportunities that could be found in these cities (Nieto, 1998). These groups have not only been a part of the labor industry in Detroit, but they have also infused Mexican and Puerto Rican culture into their surrounding community. The community that encompasses these two groups maintains cultural festivals, such as Cinco de Mayo, Diego Rivera murals, the "Africa in Mexico" exhibit, open fruit markets, etc., that are representative of Mexican culture; however, the festivals and showcases the larger Latino/a presence in Detroit.

Within the contemporary context, numerous social services agencies have played important roles in the social and economic establishment of Latino/as in Detroit. Adelante and three other non-profit agencies are considered key partners in the transitioning of new immigrants and the adaptation of subsequent generations. These agencies provide faithbased educational programs for "at-risk" youth, legal services for recent immigrants, healthcare resources, job training programs for drop-outs and recently paroled youth, tattoo removal for former gang members, etc. In addition, a Hispanic business organization operates within this neighborhood to provide employment opportunities and referrals for its 
community members. The significant role these agencies have within this predominantly Mexican and Puerto Rican community points to their importance in the social and economic adaptation of Latino/as entering and leaving this community.

\section{RESPONDENT SELECTION AND PARENTS' SOCIAL AND ECONOMIC BACKGROUND}

Due to the book's emphasis on skin color as a moderating factor in perceptions of opportunity and academic orientations, it was imperative that the selection of students ensure a cross-section of students of different phenotypes. As the primary investigator, I spent approximately three days a week for six months visiting Adelante's youth center. During this time I interacted mainly with one of the three counselors, Roberto, who worked with students from neighboring high schools: Crestwood, Westwood, and Smith. Roberto and I talked extensively about the services Adelante provides and the types of students that come in and out of the site. Over time Roberto asked me to participate at the center by helping students in the computer lab with either writing or editing papers. It was during these moments that I got a chance to meet and interact with a variety of students. These interactions provided the opportunity for me to ask students of different phenotypes, gender, ${ }^{2}$ grades, and immigrant generations if they wanted to participate in a study about Latino/a students' experiences in school. Roberto and the executive director of Adelante also gave me permission to post flyers in the center asking Latino/a students currently enrolled in school to participate in the study [See Appendix I]. In addition, Roberto called students who had previously participated in his academic planning workshops to participate in the study. Finally, I offered each participant a $\$ 15$ gift certificate to a music store as compensation for his or her participation. Through these modes of recruitment, I was able to interview 26 students.

As alluded to above, part of the recruitment process involved identifying students who ranged in phenotype. As the primary investigator, I selected students based on my impression of their skin color. That is, with the knowledge that they were Latino I sought to identify students within three general categories of skin color: 1) white or fair skin tone; 2) reddish brown to olive skin tone; and 3) light brown to dark brown skin tone. Such categorization also included noting how I would identify them racially and ethnically and what markers I used to situate the students (i.e., skin color, language, slang). In every instance I situated them into ethnic and racial categories such as Mexican, Puerto 
Rican, Black/Afro Puerto Rican, or White Mexican. However, though I knew that these students were most likely either Mexican or Puerto Rican, in the absence of that information I still would have categorized them racially and ethnically based on those same markers (i.e., skin color, language, and slang). The assumptions that I made about their identities provided a first indication of how they might have been identified by others.

The 26 students that I interviewed are not all discussed in this book. In the hope of controlling for immigrant generation, I concentrate on the second and third generation of students, which was the largest group represented. My reasoning is based on immigration research that has established the adaptation process of first generation immigrants as distinct from that of second and above generations (Portes, 1994; Rumbaut, 1996; Waters, 1990; Zhou, 1997). Such data reduction resulted in the pool of 17 students who are the focus of this book. This group of 17 contained both gender groups and reflected the following three phenotype groupings: White-looking, Mexican/Hispanic-looking, and Black/Biracial-looking. These groupings represent the categories the students described, as well as my own interpretations of the students' phenotype. That is, the categories reflect how each student perceived others racially and ethnically situated them. Furthermore, the categories usually coincided with the impressions I would have had of these students in the absence of additional information. Table 2 shows the distribution of student's ethnic identification, gender, how others racially and ethnically identified them, along with how I racially and ethnically situated these students. From this pool of 17, three students defined themselves as Mexican or Chicano, another three identified themselves as having multiple ethnic identities that include Mexican, and the remaining 11 students identified themselves as Puerto Rican.

Although an equal number of Mexican and Puerto Rican students are not represented in this pool, it is not the intention of this book to make comparisons between the two groups. Instead the recruitment procedure focused on identifying students who ranged in phenotype. The racial/ ethnic identifications of the students are, however, related in part to their phenotype and will necessarily be implicated in how Mexican and Puerto Rican students of different phenotypes navigate in and out of the school environment.

The other dynamic that is important to understand is the educational and economic background of the students' parents. Table 3 provides an overview of each participant's familial employment and educational status. The students reside in single and two-parent households. They are the children of professionals, white and blue collar workers. Their 


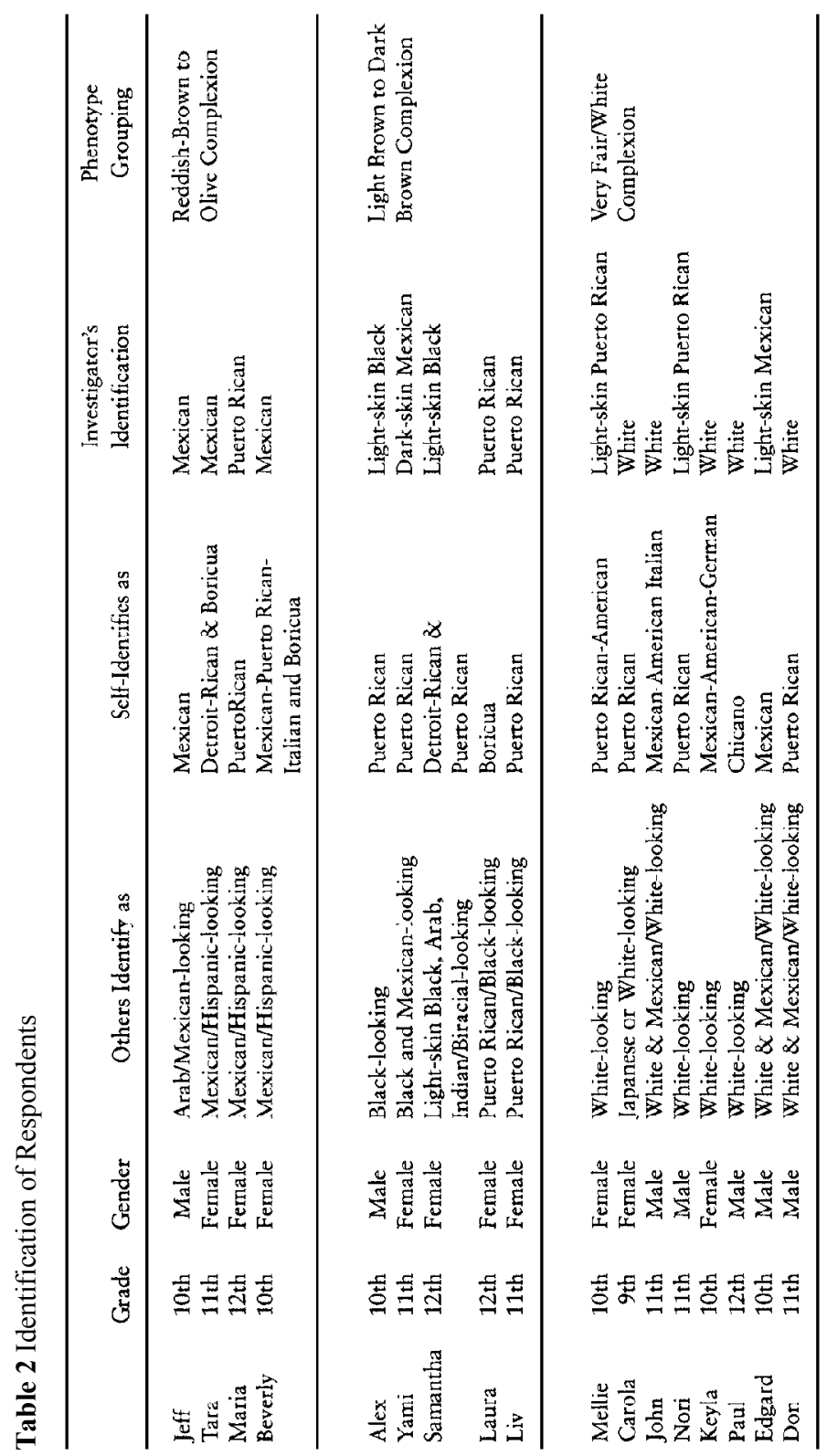


Table 3 Participant Background

\begin{tabular}{|c|c|c|c|c|c|c|}
\hline & Grade & $\begin{array}{l}\text { Primary } \\
\text { caretaker }\end{array}$ & Generation & $\begin{array}{l}\text { Age of } \\
\text { Arrival }^{3}\end{array}$ & $\begin{array}{l}\text { Caregiver's } \\
\text { highest level } \\
\text { of education }\end{array}$ & $\begin{array}{c}\text { Caregiver's } \\
\text { employment } \\
\text { status }\end{array}$ \\
\hline Mellie & 10 th & Mother & 3rd generation & N/A & $\mathrm{M}=$ College & $M=$ Teacher \\
\hline Carola & 9th & $\begin{array}{l}\text { Mother } \\
\text { Father }\end{array}$ & 2nd generation & 6 & $\begin{array}{l}M=\text { High school } \\
F=\text { High school }\end{array}$ & $\begin{array}{l}M=\text { Homemaker } \\
\mathrm{F}=\text { Lead inspector }\end{array}$ \\
\hline John & $11 \mathrm{th}$ & Mother & 3 rd generation & N/A & $M=9$ th grade & $\begin{array}{l}M=\text { Disabled; } \\
\text { unemployed }\end{array}$ \\
\hline Nori & 11th & $\begin{array}{l}\text { Mother } \\
\text { Father }\end{array}$ & 2nd generation & N/A & $\begin{array}{c}\text { M=High school } \\
F=\text { High school }\end{array}$ & $\begin{array}{c}\mathrm{M}=\text { Homemaker } \\
\mathrm{F}=\text { Store owner }\end{array}$ \\
\hline Keyla & 10th & Mother & 3 rd generation & N/A & $\mathrm{M}=$ High school & $\mathrm{M}=$ Waitress \\
\hline Paul & $12 \mathrm{th}$ & $\begin{array}{l}\text { Mother } \\
\text { Father }\end{array}$ & 2nd generation & N/A & $\begin{array}{c}\mathrm{M}=\text { College } \\
\mathrm{F}=\text { High school }\end{array}$ & $\begin{array}{c}\mathrm{M}=\text { Teacher } \\
\mathrm{F}=\mathrm{Maintenance} \\
\text { Supervisor }\end{array}$ \\
\hline Edgard & 10th & $\begin{array}{l}\text { Mother } \\
\text { Father }\end{array}$ & 2nd generation & N/A & $\begin{array}{l}M=6 \text { th grade } \\
F=3 \text { rd grade }\end{array}$ & $\begin{array}{c}\mathrm{M}=\text { Unemployed } \\
\mathrm{F}=\text { Grinder }\end{array}$ \\
\hline Don & 11 th & $\begin{array}{l}\text { Mother } \\
\text { Father }\end{array}$ & 2nd generation & 8 & $\begin{array}{c}M=6 \text { th grade } \\
F=6 \text { th grade }\end{array}$ & $\begin{array}{c}\mathbf{M}=\text { Homemaker } \\
\mathbf{F}=\text { Factory worker }\end{array}$ \\
\hline Jeff & 10 th & Mother & 2 nd generation & $N / A$ & $\begin{array}{c}M=6 \text { th grade } \\
F=5 \text { th grade }\end{array}$ & $\begin{array}{c}\mathrm{M}=\text { Factory worker } \\
\mathrm{F}=\text { Welder }\end{array}$ \\
\hline Alex & 10 th & $\begin{array}{l}\text { Mother } \\
\text { Father }\end{array}$ & 2nd generation & N/A & $\begin{array}{l}M=11 \text { th grade } \\
F=11 \text { th grade }\end{array}$ & $\begin{array}{c}\mathrm{M}=\text { Homemaker } \\
\mathrm{F}=\text { Factory } \text { worker }\end{array}$ \\
\hline Yami & 11 th & Mother & 2nd generation & 6 & $\begin{array}{c}M=5 \text { th grade } \\
F=9 \text { th grade }\end{array}$ & $\mathrm{M}=$ Factory worker \\
\hline Samantha & $12 \mathrm{th}$ & $\begin{array}{l}\text { Mother } \\
\text { Farher }\end{array}$ & 3rd generation & N/A & $\begin{array}{l}M=\text { College } \\
F=9 \text { th grade }\end{array}$ & $\begin{array}{l}\mathrm{M}=\text { Administrative } \\
\text { Assistant } \\
\mathrm{F}=\text { Train operator }\end{array}$ \\
\hline Tara & $10 \mathrm{th}$ & $\begin{array}{l}\text { Mother } \\
\text { Father }\end{array}$ & 3rd generation & $N / A$ & $\begin{array}{l}M=6 \text { th } \text { grade } \\
F=10 \text { th } \text { grade }\end{array}$ & $\begin{array}{c}\mathrm{M}=\text { Laundromat } \\
\text { attendant } \\
\mathrm{F}=\text { Carpenter }\end{array}$ \\
\hline Maria & 12 th & Mother & 2nd generation & 5 & $\begin{array}{c}M=\text { High school } \\
F=\text { High school }\end{array}$ & $\begin{array}{c}\mathrm{M}=\mathrm{Nursing} \text { home } \\
\text { attendant }\end{array}$ \\
\hline Beverly & $10 \mathrm{th}$ & Mother & 3rd generation & N/A & $\mathbf{M}=$ College & M=Social worker \\
\hline Liv & 11 th & Mother & 2nd generation & 8 & M=High school & $\mathrm{M}=$ Teacher's aide \\
\hline Laura & $12 \mathrm{th}$ & $\begin{array}{l}\text { Mother } \\
\text { Father }\end{array}$ & 2nd generation & 9 & $\begin{array}{c}M=\text { High school } \\
F=\text { High school }\end{array}$ & $\begin{array}{l}M=\text { Factory worker } \\
\mathrm{F}=\text { Factory worker }\end{array}$ \\
\hline
\end{tabular}

parents also range substantively in educational background. Nearly half (9) of the students' parents are college and high school graduates, while the remaining parents (8) have some high school or middle/elementary school education.

Single and two-parent household families are equally represented in this book, 8 and 9 respectively. The mean parental education level is 10 th grade, and $41 \%$ of the households represented did not complete high school. Such a percentage parallels national figures in which $44 \%$ of Latino/as 25 or older have not completed high school (U.S. Department of Education, 2001). The majority of the parents are 
blue-collar workers and, according to the students, work long shifts. Several students reported parents having to leave a job because of health conditions that emerged at the job site. For example, Tara's mother quit her job at the laundromat because she began to have problems with circulation in her hands, and John's mother has been disabled since 1993 because of an accident at the factory in which she used to work. Other parents work in the service and labor industry and a small percentage hold white-collar jobs that range in status, such as teaching aide, social worker, and administrative assistant.

As stated previously, Mexicans and Puerto Ricans have had a presence in Detroit since the beginning of the 20th century. Although various generations of Mexicans and Puerto Ricans live in Detroit, the majority of the students represented in this book are either second ${ }^{4}$ or third generation immigrants. Many of the third generation Puerto Rican students and/or their parents were born in east-coast cities, such as Reading, Pennsylvania; Trenton, New Jersey; and the Bronx, New York. Some of the students born in Puerto Rico did not come directly from the island; several came via the Virgin Islands, New York City, New Jersey and another from Chicago. The second and third generation Mexican students were either born in Detroit, California or Houston, Texas. This sample of students does not include students born in Mexico, however several students discussed that they had lived in Mexico for extended periods of time (i.e., 1-6 years).

In sum, the sample of students in this book represents a range in phenotype, gender, grade, and immigrant generation. In addition, the students' distinct histories of migration and parents' educational and economic background allows us to focus on phenotype as operating regardless of all these factors. As I will report on below, the participants attended three high schools in the Detroit Public School System. I begin by providing background on the district, especially highlighting, when applicable, information relevant to the experience of Latino/as students. I then discuss the background of each of the high schools.

\section{DISTRICT AND SCHOOL DEMOGRAPHICS}

The public school district of Detroit contains 268 elementary, middle and secondary schools, along with special education, alternative middle/ high school programs, and career and technical centers. As of 2000, these schools service over 160,000 school-age children in Detroit. Similar to Detroit, the school district is also primarily African American. As Table 4 shows, African American students are the largest ethnic minority group represented. The figure also shows that demographic 
Table 4 District Student Population by Ethnic Group

\begin{tabular}{lrrrrr}
\hline Ethnic Groups & 1996 & 1997 & 1998 & 1999 & 2000 \\
\hline African American & 160,461 & 161,151 & 158,591 & 152,498 & 147,740 \\
Asian or Pacific Islander & 1,760 & 1,752 & 1,649 & 1,578 & 1,485 \\
Hispanic & 4,997 & 5,251 & 5,605 & 6,008 & 6,550 \\
American Indian & 451 & 423 & 394 & 362 & 353 \\
White & 9,256 & 8,480 & 7,424 & 6,740 & 6,074 \\
\hline Total & 176,925 & 177,057 & 173,663 & 167,186 & 162,202 \\
\hline
\end{tabular}

Note: From www.detroit.k12.mi.us, the Detroit Public Schools official district profile Website.

shifts have occurred in the last five years that point to Latino/as having a growing presence in Detroit public schools. In 2000, Latino/as represented $4 \%$ of the school-going population. However, they have had a $31 \%$ increase in enrollment rates over the course of five years. Such gains are consistent with national and state wide demographic shifts that point to Latino/as as the fastest growing school-going population (U.S. Department of Education, 2001). Immigration has contributed greatly to this shift.

Aside from shifting demographics, the district faces a high concentration of low-income families and low academic performance. The Detroit Public School District has the largest percentage of students eligible for free or reduced lunch programs in Michigan (Standards \& Poor's, 2000). During the 1997-1998 school year, 70\% of students who attended Detroit Public Schools participated in free or reduced lunch programs. This figure dropped during the following school year to $67.6 \%$. However, such numbers suggest that a large percentage of students attending public school come from low-income households. In fact, city figures note that $50 \%$ of children under five live in poverty and $33 \%$ of the population above 18 are living at or below the poverty line (U.S. Census Bureau, 2000). In comparison to state figures of $26.7 \%$, Detroit has a high concentration of poverty and low-income families.

Although the district maintains a high concentration of low-income students, the overall academic performance of the high school students in the district has risen during the 1998-1999 and 1999-2000 school years. As Table 5 shows, student proficiency on the Metropolitan Achievement Test (MAT) exams has risen from 1999 to 2000. The MAT tests grade level proficiency in reading, math and science. The figures show that in the 1999-2000 school year compared to the 
Table 5 Metropolitan Achievement Test Scores (MAT) Percent of Students at Grade level

\begin{tabular}{rcccccc}
\hline Grade & Reading & $\begin{array}{c}1999 \\
\text { Math }\end{array}$ & Science & Reading & $\begin{array}{c}2000 \\
\text { Math }\end{array}$ & Science \\
\hline 9 & 21 & 29 & 25 & 22 & 33 & 28 \\
10 & 10 & 19 & 23 & 19 & 26 & 18 \\
\hline
\end{tabular}

Note: From www.detroit.k12.mi.us, the Detroit Public Schools official district profile Website.

Table 6 School's Student Ethnic Composition

\begin{tabular}{lrrr}
\hline & Crestwood & Westwood & Smith \\
\hline African American & $95 \%$ & $25 \%$ & $55 \%$ \\
White & $2 \%$ & $15 \%$ & $21 \%$ \\
Native American & $0 \%$ & $1 \%$ & $2 \%$ \\
Asian & $1 \%$ & $1 \%$ & $1 \%$ \\
Latino/a & $1 \%$ & $58 \%$ & $21 \%$ \\
\hline
\end{tabular}

Note: From www.detroit.k12.mi.us, the Detroit Public Schools official district profile Website.

1998-1999 school year, a larger number of students are testing proficient or at their appropriate grade level.

While district data provides us with a broad view of the Detroit public schools, specific school data enables us to contextualize the school environment. The students in this book attended three different high schools: Crestwood, Westwood and Smith. Each school maintained similar ethnic group composition although they were distributed slightly differently at each school. Table 6 shows the 1999-2000 ethnic composition of each school.

The table shows that Crestwood and Smith are primarily populated by African Americans. Westwood, however, has a mainly Latino/a student body. Such numbers contradict Westwood students' impression that African Americans represent the predominant ethnic category. The students' perception may be due to the high percentage of African American faculty and staff that work at each school. Table 7 shows the 1999-2000 ethnic composition of the faculty and staff. These numbers include the school principals, all of whom are African American.

Each school maintains distinct curricular structures. Additionally, student performance on standardized exams varies considerably from one school to the next. Crestwood is an alternative high school with a 
Table 7 Schools' Faculty and Staff Ethnic Composition

\begin{tabular}{lccc}
\hline & Crestwood & Westwood & Smith \\
\hline African American & $75 \%$ & $55 \%$ & $61 \%$ \\
White & $22 \%$ & $27 \%$ & $29 \%$ \\
Native American & $0 \%$ & $1 \%$ & $2 \%$ \\
Asian & $2 \%$ & $1 \%$ & $1 \%$ \\
Latino/a & $0 \%$ & $17 \%$ & $8 \%$ \\
\hline
\end{tabular}

Note: From www.detroit.k12.mi.us, the Detroit Public Schools official district profile Website.

curricular program primarily geared towards students identified as gifted and talented. Students admitted into the school must apply for and test into one of the 20 college preparatory programs. These programs include architecture design, aeronautics, business administration, robotics technology, and a vocational music. Advanced placement and honors classes are offered along with mentoring/tutoring programs in which National Honor Society (NHS) students tutor peers and even parents in various subject areas.

In contrast to Crestwood, Westwood has a curricular focus on multiculturalism and international affairs. The school boasts an international abroad program in which students that are learning Spanish are able to travel to Spain and Costa Rica. In addition the school houses a community-based organization that offers SAT and college prep program for students with 3.0 GPAs and above.

Smith differs from the other two schools in its curricular focus on career/technical education. In other words, the curricular emphasis is on vocational activities. The school maintains a cooperative work program in which students are placed at various vocational sites (e.g., dental offices, recreation centers, hospitals). Smith maintains the standard offerings that are necessary for students to pass proficiency exams, but this school does not contain the large number of AP and Honors classes that are found at Crestwood and Westwood.

These differences in curricular focus were made evident in academic test scores and grade point averages. As Table 8 shows, academic achievement in terms of standardized test scores differs greatly between schools. Crestwood has the largest percentage of students at or above grade level on both the MAT and HST (High School Test) standardized exams. Additionally it has the highest GPA and ACT averages among all three schools. This suggests that between the three schools, 
Table 8 Schools' average test scores 1999-2000

\begin{tabular}{lcccc}
\hline & & Crestwood & Westwood & Smith \\
\hline Percent at or above & Math & 78.0 & 28.0 & 17.0 \\
grade level on MAT & Reading & 75.0 & 14.0 & 16.0 \\
exam & Science & 59.0 & 22.0 & 19.0 \\
\hline ACT Average Score & & 19.3 & 16.6 & 16.0 \\
\hline Percent meeting & Math & 79.0 & 20.7 & 23.5 \\
standards on & Reading & 78.5 & 32.5 & 37.9 \\
HST exam & Science & 36.9 & 8.7 & 7.4 \\
\hline Average GPA & & 2.8 & 2.0 & 2.1 \\
\hline
\end{tabular}

Note: From www.detroit.k12.mi.us, the Detroit Public Schools official district profile Website.

Crestwood students have a higher likelihood of advancing to postsecondary schooling.

In sum, the district and school data establishes and contextualizes the ethnic demographics and academic profiles of the schooling environments these students must navigate.

\section{DATA COLLECTION}

The primary data for this project was collected through tape-recorded interviews. ${ }^{5}$ Prior to each interview, students were required to have parental consent via a consent form approved by the University of Michigan Human Subjects Board [See Appendix D]. These consent forms were taken home to parents by students seeking participation in the study and were accompanied by a letter of introduction to parents [See Appendix B]. The letter and consent forms were in English and Spanish [See Appendix C]. Students additionally signed assent forms in which they affirmed their voluntary participation in the study and their knowledge of their rights and my obligations as a researcher.

The interview protocol featured structured open-ended questions and closed-ended questions as well as a one-page survey [See Appendix A], The one page survey captured students' rankings of various factors related to getting ahead in life (e.g. education, luck and skin color). The closed-ended questions were followed by open-ended probes so that the participant could qualify and elaborate upon his/her responses. Taken in total, the open-ended and closed-ended questions were designed to 
capture 1) students' discussion of their ethnic identity, culture, and external perceptions of identity; 2) how they discuss the opportunities available for the social group with which they identify as well as the social group with which they believe others situate them; and 3) academic orientation, which includes students' educational aspirations, views on school, academic performance, and engagement in school related activities. These questions were designed for students to respond in their own words and thoughts regarding each question, thus introducing concepts not considered by the researcher (Patton, 1990). Each student was asked the same series of questions in order to capture the same information across respondents (Patton, 1990). Additionally, in order to increase the internal reliability, more than one question within each section of the interview measure spoke to a specific construct. This tactic enabled the researcher to observe any inconsistencies in responses (Weis, 1994).

The interview protocol consisted of four main sections. ${ }^{6}$ The first section was focused on capturing some of the familial, socioeconomic and migratory background of each student for contextualizing student responses to the aforementioned issues. The second section explored the student's ethnic identification. This section included questions that allowed students to articulate how they self-identify along ethnic and racial lines as well as how they perceived that others identify them ethnically and racially.

The next section of the interview protocol consisted of questions on academic orientation. Academic orientation was gauged by student selfreports of occupational aspirations (e.g., What do you want to be when you get older?). How they viewed the utility of school also provided another dynamic of this orientation (e.g., How important is school to your life right now? What are your parent's attitude(s) towards school?). Engagement in school related activities (e.g., Are you a member of any clubs, teams, or social organizations at school? Have you ever been an office aid or teacher's assistant?) and accommodation to school norms illustrated how they might have enacted their orientation (e.g., How often do you go to school? What do you like and dislike about school? Do you participate in classroom discussions? Describe last Tuesday at school—what did you do?). Data collection also involved gathering copies of students' most recent report cards. This form of data collection was necessary in verifying the students' self-reported grade point average and types of courses.

The last section of the interview protocol focused on the students' perceptions of opportunity. These questions illuminated students' assessment of whether and how they interpret and explain social equity 
and inequity, the process of status attainment and mobility, and their perceptions of advantages and disadvantages for the group with which they affiliate, and other ethnic groups. While questions that illuminated the aforementioned signaled students' perceptions of opportunity in society at the macro-level, other questions captured how students made sense of the opportunity made available to them as individuals in school. Some questions additionally explored the opportunity they felt was available to the social groups with which they identified, as well as others in the school (e.g. African Americans, White).

\section{DATA REDUCTION AND ANALYSIS}

The data for this book was reduced through various levels of analysis. First, the data was coded in accordance with coding categories which reflect a priori "concepts" that were articulated in the framing and design of the study. The following coding categories signal those concepts:

- Ethnic identification

- External perceptions of identity

- Whether and how students interpret and explain social inequity

- Interpretations of how one "makes it"

- Perceptions of equality in society

- Perceptions of self-opportunity, ethnic group opportunity, and other ethnic groups' opportunity

- Educational aspirations and expectations

- Engagement in school related activities

- Accommodation to schooling norms

- Perception of racialization within school

- Socioeconomic class

- School context

- Gender

- Immigrant generation

These categories were used to conduct deductive analysis within a data matrix that allowed for within-case and across-case analysis (Miles \& Huberman, 1984) [See Appendix F and G]. The initial deductive analysis was conducted by categorizing the data by student and examining the data from that vantage point. The data was then examined by the phenotype groups the students perceived others situated them into (i.e., White-looking, Mexican/Hispanic-looking, and Black/Biracial-looking). In addition, within each phenotype grouping, I further divided the students by gender and immigrant generation. 
Within-case analysis were conducted in order to compare the responses of students of similar phenotype. Also across-case analysis were conducted to compare responses of one phenotype grouping to another.

The inductive analysis process followed a similar pattern of examining the data. The data matrix divided by phenotype groupings generated additional categories that were not considered before and became the basis for further examination of the phenotype groups. In order to understand whether these additional categories were specific to a phenotype or occurred across the phenotype groupings, I analyzed these new categories within-cases and across-cases. Toward this end, I relied on a conceptually clustered matrix to analyze relationships that emerged between categories and clustered them as conceptually related themes across phenotype lines (Miles \& Huberman, 1984) [See Appendix H]. For example, during the students' discussion of their ethnic identification they referenced moments in which they shifted their identification dependent on context. Their decision to shift was conceptually clustered with their accounts of others' interpretation of their skin color in order to explore whether the shift was in response to external identifications. The development of such a matrix became important in understanding how skin color moderated perceptions of opportunity and academic orientation.

By conducting various forms of deductive and inductive analysis, I was able to compare and contrast the differences in how students of similar and differing phenotype discuss their ethnic identification, external interpretation of identity, perceptions of opportunity, and academic orientation. Moreover, the intent of this coding was to allow the data to speak for itself and perhaps illustrate categories and relationships that were not previously considered. Analytical memos were also used throughout the coding process in order to re-inspect the data, modify predetermined codes, and construct new codes (Miles \& Huberman, 1984). Thus, the result of these coding patterns was to encourage deductive as well as inductive coding and interpretation throughout the analysis.

In sum, the methods employed for this book focused on ensuring that the participants could speak as candidly as possible about their experiences as Latino/a students. In addition, as the sole investigator, I took measures to ensure that the anonymity of the students was maintained, while reporting on their subjective renderings. Although I provide the name of the city the students reside in because of its relevance to the book, I deemed it not necessary for the students' school or community center to be identified. The general descriptions provided about each school are sufficient to understand the general academic 
environment of the participants. Thus, the methods employed in this book evidence and extrapolate the complex nature of skin color in the lived experiences of these students.

In order to begin this journey of understanding the influence of skin color on how these Mexican and Puerto Rican students came to perceive opportunity and the making it process, and translated such perceptions into their academic orientation, we must first make sense of how they construct their ethnic identification. To this end, the next chapter centers on the meaning they attached to their identification and culture. 


\section{Chapter Three Portraits of Self-Identification}

In this chapter I discuss how these 17 second and third generation Mexican and Puerto Rican students construct their ethnicity (i.e., what it means to be Mexican or Puerto Rican) through identification and culture. The focus of this chapter is on the meaning the students assert when they invoke their identification and culture, and what it signifies of who they are and who they are not. The term "culture" is intended to capture the definition and attributes of culture the students assign to their identification as Puerto Rican, Boricua, Chicano, or MexicanAmerican; it does not convey a finiteness to Puerto Rican or Mexican culture. What emerges in this chapter is a dynamic discussion of ethnicity that centers on the students' use of identification and culture to describe themselves. However, this does not mean that their report of their ethnicity is solely a subjective construction. In fact, in chapter four I will discuss how the students perceived others interpreted their skin color as a signifier of race and what that meant for the construction of their own understanding of their ethnicity. With that said, the focus of this chapter is on the meaning of the identification the students use and what attributes of their group's culture do they use to account for who they are, what they look like and how they think and act.

This chapter is divided into two sections. The first section attends to the students' definitions of their chosen identification. The next section presents the ways they define Mexican and Puerto Rican culture, and its relevance to their identification. What emerges from the discussion is that these students use self-identification as a boundary of how and why they are a part of the Mexican or Puerto Rican community. Meanwhile, culture is treated as "the stuff inside the boundary," which provides further context to why they construct specific boundaries. 


\section{ETHNIC IDENTIFICATION}

Although the students invoked ethnic categories in asserting who they are, they also situated why they do not use racial categories. Such action posits that they intuitively consider there to be a difference between ethnicity and race. In light of such differences, it is important to map the distinction the students make in relation to traditional definitions and discussions of race and ethnicity. Research on race and ethnicity divides into two distinct camps of thought: 1) race and ethnicity are separate constructs; and 2) race and ethnicity are similar constructs. Some scholars argue that, although ethnicity conveys similar social constructs embedded in notions of race, ethnicity does not necessarily testify to the discrimination aligned with race, which is based on biological features like skin color (Rodriguez, 2000). For example, census forms and other official bodies define race and ethnicity as separate constructs; this can be evidenced in the recent Census 2000 categorization of Latino/as into an ethnic category while simultaneously requiring a racial identification (i.e., Black, White, Asian, Native American) [See Appendix E], The implication of such a separation is that a Latino/a identification is not necessarily a racial category. Meanwhile, other scholars argue that race and ethnicity are defined based on social criteria, such as common ancestral ties and sense of identity, and share similar cultural, political and economic interests, thus making them similar constructs. While there is confusion as to whether race or ethnicity are similar or independent constructs, the students in this book simultaneously invoke race and ethnicity as separate and similar constructs. In other words, they use ethnicity and race as interchangeable terms, and at other times race is a dichotomous construct of Black and White that does not include ethnic categories. Thus the students' narratives provide an empirical account of how these theoretical struggles occur on a day-today basis.

Each student was asked a number of questions regarding how they described themselves (e.g., How would you describe yourself in terms of race or ethnicity? Do you describe yourself as Black or White? How about Hispanic or Latino/a?). There was consensus among the students that Black and White were not terms they used to identify themselves because of perceived cultural group identification. To them, Black means African/Black American and White means Caucasian/White American. However, it is uncertain whether the categories Black and White referenced a biological construct: as Alex, who is of brown complexion, stated, "I'm not Black," when asked if he identified himself as Black or White. In other words, his designation seems to refer to not being a member of a particular group versus not looking like a 
member of that particular group. The latter statement may not be something that can be expected from a student with his complexion. However, this rendering of not being Black or White was something that others with a lighter complexion also articulated. How they described themselves set a model in which their use of categories like Black and White implied a reference to a group identification rather than a reference to a biological construct, as we will see others (i.e., African American students and teachers) do in the next chapter. More importantly, it represents part of the distinction these students make between race and ethnicity, as well as an illustration of the interplay between these students' definitions of race and ethnicity and the definitions of their external context (which includes, African American peers, teachers, and other Latino/a ethnic group members).

Instead, students opted to use ethnic terms, like Mexican, Chicano or Puerto Rican, Boricua, Detroit-Rican, and in some instances Hispanic. Although their use of ethnic terms provided a concrete idea of what groups they identified with, it offered no insight into the meaning they attached to these ethnic designations. Therefore, the students were additionally asked to discuss what it meant to be a member of the ethnic categories with which they affiliated. From this discussion, three main typologies of identification emerged: 1) a hyphenated identification, 2) an ancestral/national identification, and 3) a cultural identification. A hyphenated identification was a means of "representing" the multiple locales that comprise who the students considered themselves to be. ${ }^{1}$ Ancestral/national identification reflected a birth in Mexico or Puerto Rico, or ancestral ties to Mexico or Puerto Rico. Both terms are connected because what is implicit in the students' definition involved a direct connection to Mexico or Puerto Rico, either through family or actual birth in the country. Cultural identification reflected the students' actual use of the term "culture" in defining who they are. Even though the students may have articulated the meaning they attach to the term they use most often, these typologies were not mutually exclusive. Some students used two different typologies to describe themselves, thus implying that the students' maintained multiple points of reference regarding their identification.

These typologies not only had specific meaning that defined — at least for these students-who they are, but also emerged as related to the students' immigrant generation. ${ }^{2}$ As Table 9 shows, third generation students mainly used a hyphenated identification, and the second generation used cultural and/or ancestral/national identification. Such relationships are consistent with immigration literature, which argues that certain identifications are more prevalent in some generation versus 
Table 9 Student Origin and Identification

\begin{tabular}{|c|c|c|c|c|c|}
\hline & $\begin{array}{l}\text { Place of } \\
\text { Birth }\end{array}$ & Generation & $\begin{array}{l}\text { Age of } \\
\text { arrival }\end{array}$ & $\begin{array}{c}\text { Type of } \\
\text { Identification }\end{array}$ & Self-Identifies \\
\hline Jeff & California & 2nd generation & N/A & Ancestral Identity & Mexican \\
\hline Alex & Connecticut & 2nd generation & N/A & Cultural Identity & Puerto Rican \\
\hline Yami & Puerto Rico & 2nd generation & 6 & Ancestral Identity & Puerto Rican \\
\hline Samantha & Detroit & 3rd generation & N/A & $\begin{array}{l}\text { Hyphenated and } \\
\text { Ancestral Identity }\end{array}$ & $\begin{array}{l}\text { Detroit-Rican \& } \\
\text { Puerto Rican }\end{array}$ \\
\hline Tara & Detroit & 3rd generation & N/A & $\begin{array}{l}\text { Hyphenated and } \\
\text { Cultural Identity }\end{array}$ & $\begin{array}{c}\text { Detroit-Rican \& } \\
\text { Boricua }\end{array}$ \\
\hline Maria & Puerto Rico & 2nd generation & 5 & Ancestral Identity & Puerto Rican \\
\hline Beverly & Detroit & 3rd generation & N/A & $\begin{array}{l}\text { Hyphenated and } \\
\text { Cultural Identity }\end{array}$ & $\begin{array}{c}\text { Mexican- } \\
\text { Puerto Rican- } \\
\text { Italian/Mexican- } \\
\text { American and } \\
\text { Boricua }\end{array}$ \\
\hline Laura & Pucrto Rico & 2nd generation & 8 & Cultural Identity & Boricua \\
\hline Liv & Puerto Rico & 2nd generation & 9 & Ancestral Identity & Puerto Rican \\
\hline Mellie & Detruit & 3rd generation & $\mathrm{N} / \mathrm{A}$ & $\begin{array}{l}\text { Hyphenated } \\
\text { Identity }\end{array}$ & $\begin{array}{l}\text { Puerto Rican- } \\
\text { American }\end{array}$ \\
\hline Carola & Puerto Rico & 2nd generation & 6 & Ancestral Idenrity & Puerto Rican \\
\hline John & Detroit & $3 \mathbf{r d}$ generation & N/A & $\begin{array}{l}\text { Hyphenated } \\
\text { Identity }\end{array}$ & $\begin{array}{c}\text { Mexican- } \\
\text { American- } \\
\text { Italian/American }\end{array}$ \\
\hline Nori & Reading, PA & 2nd generation & $\mathrm{N} / \mathrm{A}$ & Ancestral Identity & Puerto Rican \\
\hline Keyla & Detroit & 3 rd generation & N/A & $\begin{array}{l}\text { Hyphenated and } \\
\text { Ancestral Identity }\end{array}$ & $\begin{array}{c}\text { Mexican- } \\
\text { American- } \\
\text { German }\end{array}$ \\
\hline Paul & California & 2nd generation & N/A & Cultural Identity & $\begin{array}{l}\text { Chicano \& } \\
\text { Mexican- } \\
\text { American }\end{array}$ \\
\hline Edgard & Texas & 2nd gencration & $\mathrm{N} / \mathrm{A}$ & Ancestral Idcntity & Mexican \\
\hline Don & Puerto Rico & 2nd generation & 8 & Ancestral Identity & Pucrto Rican \\
\hline
\end{tabular}

others (Portes, 1994; Rumbaut, 1994; Suárez-Orozco \& Suárez-Orozco, 1995).

In the following subsections, I offer more elaborate indications of the distinctions between a hyphenated, ancestral/national, and cultural identification, and how these typologies relate to their generation. In addition, the discussions within each typology focus on the common pattern(s) that emerged in the students' narratives but also the 
complexities that besiege each typology. I present the complexities of each typology through illustrative cases of students.

\section{HYPHENATED IDENTIFICATION}

Immigration research asserts that immigrants who identify with or hyphenate American into their identification are second generation and above immigrants because over time individuals begin to incorporate their U.S. native status with their ethnic identification (Hein, 1994; Matute-Bianchi, 1986; Portes, 1994; Portes \& MacLeod, 1996a; Portes \& Rumbaut, 1996; Rumbaut, 1994). These students were no different. All of the students that hyphenated their identification with American were third generation [See Table 9]. However, the hyphen connected more than just a U.S. native status. Hyphenated identifications referenced for some a native status as U.S. citizens (e.g., Mexican-American, Puerto Rican-American), for others the significance of the place they were born (e.g., Detroit-Rican), and yet others hyphenated as a way of acknowledging their multiple ethnic lineages (e.g., Mexican-Puerto Rican/Boricua-Italian). However, the thread that connected why all these students used a hyphenated identification involved a need to incorporate the multiple locales they believe comprise their identification. The hyphen represented a border crossing mechanism in which they merged identifications that operate in some instances on opposite sides of the border. I consider these moments of hyphenation as synonymous with Gloria Anzaldúa's (1987) notion of borderlands: "a vague and undetermined place created by the emotional residue of an unnatural boundary. It is in a constant state of transition. The prohibited and forbidden are its inhabitants... in short, those who cross over, pass over, or go through the confines of the "normal" (1987, p. 3). The border, as Anzaldúa suggests, involves the moments or places in which friction, transition, and negotiation occurs between the oppressors and oppressed. In the case of the hyphenating students, their identifications symbolized what they considered themselves even though, at times, it was in opposition to what their ethnic group peers expected them to be. In fact, although these students traversed the border between Mexican/ Puerto Rican and American/Detroit, they found themselves challenged by their ethnic peers for crossing such borders.

For Mellie, identifying herself as Puerto Rican-American centered on a specific locale. She did not reference citizenship as the reason for her use of "American": because Puerto Rico has been a U.S. commonwealth since 1917, thus Puerto Ricans automatically have citizenship status. Her use of "American," instead, was about recognizing and asserting 
her U.S. birthplace; regardless of how it may seem to others that she is accepting an American identity, Mellie was going to assert her American identification alongside her Puerto Rican-ness.

Interviewer: There are a number of ethnic terms which are associated with people of Puerto Rican descent, e.g., Puerto Rican, Nuyorican, and Boricua. What comes to mind when you think about each of these terms?

Mellie:Well, people are more like, they say "I'm Puerto Rican," they're proud of their race and those people who are saying no [to being Puerto Rican] and they don't give a tip about their race. But I say you know I'm Puerto Rican American. You know, I don't have any shame that I'm born here, because I'm proud of what I am, so.

Although she centered much of her description of Puerto RicanAmerican on what it represented to her, what seemed to also underlie this identification of herself was what others thought. The shame Mellie talked about refers to a common belief held among Latino/a students in the school that it is assumed and expected that Latino/as should not identify as American. As several students stated, American is synonymous with White, and Mellie's use of the term was something that went against the grain of what was a popularly held belief and expectation among her ethnic peers. However, it should also be stated that the same students who defined American as White, also described themselves as "Americanized," but their use of the term implied an acculturation to "American ways," (e.g., eating hot dogs and hamburgers instead of arroz con habichuelas/porotos [rice and beans] and cerdo asado [grilled pork]). On the other hand, Mellie's use of the term American invoked an acceptance of her birthplace, which may be interpreted by others to mean she identifies with Whites. Being situated by others as White is explored in the next chapter. However, what we can extract from Mellie's subjective rendering is that by asserting an American identification Mellie, from the perspective of others, presents herself as wanting to be White.

Mellie not only constructed an identification that operated against the grain but she also distanced herself from other Puerto Ricans by pointing out the distinction between herself and how other Puerto Ricans celebrate their identification. For Mellie, her identification appeared to be very functional versus other Puerto Ricans whose invoked their identification as a celebration. 
Interviewer:Do you ever describe yourself as Hispanic or Latina?

Mellie: Well, yeah. I know if they tell me nationality, I say Puerto Rican, but I'm not like proud of it like others are like, yeah, living la vida loca Puerto Rican. Since I was born here, I'm like Puerto Rican American mixed.

Mellie's self-separation from how other Puerto Ricans invoke their identification also included behavior. She designated that, although she identifies as Puerto Rican American because of where she was born, this does not mean that her identification as Puerto Rican is central to who she is in comparison to others. Mellie outlined behavior as key to what her identification symbolizes.

Interviewer: Would you say that being Puerto Rican American is important to you?

Mellie: Well, you know it's not really important because that's not really what matters. You know, what kind of nationality you are. I could be Black, I could be Mexican, it doesn't matter. But you know as Puerto Rican I kind of represent. You know you have to have be well mannered to show people you're Puerto Rican. So they say, you see that girl, she's Puerto Rican, she's well mannered. There are some people who, believe me, they are not mannered at all.

This distinction she made between how she identifies and behaves from other Puerto Ricans suggests how she operates with other Puerto Ricans and thinks of Puerto Ricans. Mellie felt connected to her identification. However, she also thought of her Puerto Rican community as misrepresenting itself. And it is in reference to this misrepresentation that she tried to distinguish her self. In response to a question about stereotypes Americans hold about Puerto Ricans, Mellie further outlined this distinction, "Now that's Puerto Ricans who cause that. They're [Americans] like, look at those Puerto Ricans and look how they, you know do murders and crimes and stuff like that." Mellie's separation of her identification and behavior from other Puerto Ricans involved presenting a Puerto Rican-American identification that does not perpetuate the stereotypes she believes other Puerto Ricans reinforce with their behavior and "living la vida loca" attitude. Thus, Mellie has constructed a boundary between what it means for her to hyphenate as a Puerto Rican-American and how other Puerto Ricans choose to display their identification as "living la vida loca" or committing crimes.

Mellie was not the only student whose hyphenated identification underscored a need to establish a boundary that defined her distinction 
from other Latino/as. John invoked the U.S.-Mexican border as the boundary that symbolizes his identification as Mexican-American. Unlike Mellie who appears to assert her identification, John's identification process was more of what he calls "going with the flow." This flow involved him going along with whatever the popular identification is at the time. However, he did assert one rule regarding the figurative location of his identification: it must be located on the U.S. side of the border.

Interviewer: What do you think about Mexican?

John: I know I'm half Mexican. I'm not Cholo or Chola. I go with what the ladies tell me. (Laughter)

Interviewer: You're half Mexican?

John: Yeah I'm also Italian...My mom is Italian and German.

Interviewer: What do you think about Chicano?

John: That's for the ladies. (Laughter)

Interviewer: What about Mexican-American?

John: That's what I am. I'm Mexican and I'm in America. It doesn't really matter as long as I'm on this side of the border.

John's use of the border as the point that decides where his identification lies is significant politically and symbolically. Since the Treaty of Guadalupe Hidalgo of 1848, the Rio Grande border has become a geo-political border of immigration policy in relation to Mexico and Mexicans. In 1848, this constructed border made between 75,000 to 100,000 Mexicans living north of the border American citizens, relegated them to over 150 years of an inferior castelike status ${ }^{3}$ and laid the foundation for the emergence of a new community and solidarity among Mexican Americans in the Southwest (Guiterrez, 1995). Such a history embodied John's use of the border as his point of departure. However, this border also has symbolic significance in that it is, as Gloria Anzaldúa (1987) states, "set up to define the places that are safe and unsafe, to distinguish us from them" (p. 3, italics in original text). And for John, this American space is safe not because he may define Mexico unsafe or safe, but rather because his lived experience as a Mexican in America is what is most familiar to this third generation Mexican.

In addition, this Mexican-American space is more significant than his Italian roots. John described himself as half Mexican, and half Italian based on his parental lineage. However, his Italian identification was not something central to how he defined himself. As he stated, "Being Mexican is more important to me. I don't speak Italian. I've talked to Italians before and they are concerned about things that I'm not. They 
were talking about Italy and stuff and that was nice. But living here in Mexicantown, it's all in my face." What John referred to as being "in his face" is the familiarity of everyday experiences in Mexicantown, not Italy, which for him is a place that he has only heard about from other Italians. What was in his face included a lived experience as a Mexican on this side of the border.

This lived experience also involved the inconsistent meaning the U.S. projects onto Mexicans on this side of the border. According to John, the border advertises an inconsistent message as a geo-political fence that is focused on keeping Mexicans out of the U.S. on the one hand, and simultaneously desiring the "border culture" on the other. ${ }^{4}$ In other words, Americans push Mexicans out yet want them to fill the "undesirable" jobs in America.

Interviewer: Do you think Americans have stereotypes of MexicanAmericans?

John: Yeah, because we jump. I know it's about the border. Would you pick up shit after an animal? We would because we'll do anything it takes to make money and survive. That's a job for us. We don't take things for granted, like an American would do.

In short, John's hyphenated identification defined the border as the location that he viewed as defining his identification, his lived experience as a Mexican in America, and the place that made his presence undesirable yet desired for his labor.

What was unique about these hyphenated identifications involved their usage as a means of bridging the multiple worlds these students traverse, and for some the hyphen (re)constituted a new world for them. Samantha's discussion of her Detroit-Rican identification represents how such a new world emerged. Samantha's identification as DetroitRican defined an ethnic affiliation that adapts to place. Her construction of Detroit-Rican was reminiscent of Nuyorican, an ethnic identification that emerged as a disparaging term for mainland Puerto Ricans that mixed English and Spanish, but was later appropriated by poet Miguel Algarín (founder of Nuyorican Poet's Café) as a symbol of pride for New York Puerto Ricans (Fox, 1996). However, New York is not the only context that has been incorporated into a Puerto Rican identification. Cities like Chicago, Los Angeles, and even Detroit contain populations of Puerto Ricans that are (re)constituting a new Puerto Rican identification in these cities. Samantha's usage of Detroit-Rican is simply one example. 
Interviewer: Numerous terms are used by people of Puerto Rican descent to describe themselves, like Puerto Rican, Boricua, Nuyorican, etc. What comes to mind when you hear these terms?

Samantha: Puerto Rican is like my grandmother, I'll say she's Puerto Rican because she is from the island. Boricua is something that you represent, like if you say African pride, Boricua is like Puerto Rican pride. And Nuyorican is what my mother is; she's from New York and she is a Puerto Rican raised in New York.

Interviewer: And why did you describe yourself as Puerto Rican?

Samantha: I say I'm Puerto Rican because that is what they got on the paper and everything, but I'm like a Detroit-Rican or something like. [laughter] The Rican is always there but it's just wherever you live that's what you get adapted to.

Samantha's identification as Detroit-Rican invoked a recognition of her Puerto Rican roots as always present wherever she goes, and in this case she adapted her grandmother's and mother's "Rican-ness" to the Detroit context. Samantha's use of Detroit-Rican involved a layered understanding that along with her identification to the Puerto Rican community she also signaled the chameleon nature of her "Rican-ness." That is, Puerto Ricans can transport to any locale but they will always embody their "Rican-ness" even if they incorporate the new locale into their identification. Such a construct disrupts essentialized notions of an ethnic group as only embodying the cultural memories of their homeland. Instead, Samantha offers a shift in which, as a third generation Puerto Rican, she not only embodied Puerto Rico but also incorporated Detroit into her identification and (re)constituted a new Rican-ness.

Hyphenated identifications were also used as a mechanism of acknowledging a multiple ethnic lineage. Beverly, as a third generation immigrant, identified herself as a Hispanic-Mexican-American-Puerto Rican/Boricua-Italian. Although these are the different categories that Beverly believed construct who she is, she also understood that to others she may not always be allowed to be all these identities. Beverly recognized that within the U.S. context she could only use one word categories, such as Hispanic.

Interviewer: How do you describe yourself in terms of race or ethnicity? Beverly: I'm Mexican-American but my dad is Puerto Rican. Even though he hasn't played a real part in my life, I do embrace that part of my culture. So when people ask me if I'm Hispanic, if they want more specifics I'm Mexican-Puerto Rican, they want to be more 
specific I'm Mexican-Puerto Rican-Italian because my father is half Italian, half Puerto Rican.

Interviewer: When do you find yourself having to describe yourself as Hispanic versus Mexican-Puerto Rican-Italian?

Beverly: When people want to stereotype you, even in the classroom when they want to say something about a story, they'll be like how many people are Mexican, Puerto Rican. Or even like on tests lately - we been filling out them standardized tests like their gender and your ethnicity. I don't really like to go say I'm Hispanic. I'm American I live in America, I was born and raised here and as much as I am Mexican and I am Puerto Rican. Everything is joined together to create who I am.

Nicola Evans (1998) in a review of Stuart Hall's Questions of Cultural Identity (1990) poses a poignant question about identification to which Beverly's account and that of the other students points. Evans asks: "When we identify someone as Black, or when we self-identify that way, what is it that we think we know or do not need to ask about the feelings, cognitions, cultural preferences and political agendas of that person? What, if anything, are we entitled to presume?" In other words, what is the substance that exists in these discrete racial/ethnic categories? According to Beverly, when she is asked to select Hispanic or when others want to know whether an individual is Mexican or Puerto Rican, there is a presumption attached to these categories - $\mathrm{a}$ presumption that she challenged and considered as not including the complexity of identification. Beverly was conscious of such presumptions when she was asked to identify. For example, when I asked Beverly which identification she used most often, she stated Mexican, simply because she socialized more with Mexicans and that is how others viewed her. The latter rationale suggests that in her selection of a Mexican identification over a multiple identification she took into consideration others' perceptions of her as Mexican. Thus, Beverly's hyphenation provides a view of where she locates herself based on lineage; however, the meaning behind using one identification versus all her identifications was bound to rules that were external to her. These external rules are further explored in chapter four. What Beverly and the other students illustrate was that within the self-ascriptive process of identification they were making choices and decisions based on their external world's rules and regulations of identification.

These hyphenated identifications additionally expand the significance of identification in the adaptation process of immigrants. Hyphenated identifications have traditionally been interpreted by immigration research as the result of generational adaptation to the U.S. context. That 
is, over the course of several generations immigrants tend to adopt an American identification. However, these students provide a complex picture of what that adaptation process looks like and what exactly about this American identity or lived experience in America they are incorporating. The voices of these third generation Mexican and Puerto Rican students convey that within the construction of their identification they contend with their own definitions of ethnic affiliation and what it means from the perspective of others to adopt an American identity. Thus the thread that comes through these hyphenated identifications is that these students are trying to incorporate everything that is available and influential to whom they believe they are into a hyphenated identification. Some of what they incorporate is "out there" and some of it is internal (i.e., What do I represent?).

The incorporation of the external and internal, as it will be shown, is present in the other typologies. As is illustrated in the following discussion of ancestral/national and cultural identification, the fact that context (i.e., the external) is also invoked in these identifications points to context as significant in how these students define themselves.

\section{ANCESTRAL/NATIONAL IDENTIFICATION:}

Not surprisingly the second generation students used an ancestral/ national identification. Current research on post-1965 second-generation immigrants has established their identification process as similar to first generation immigrants (Portes, 1994). The second generation is more prone to continue using the same ethnic terms their parents used because, similar to their parents, these students' rationalize its usage based on an ancestral or direct national birthplace connection.

The second generation students used terms like Mexican and Puerto Rican in order to demonstrate an ancestral and/or national connection to Puerto Rico or Mexico. An ancestral identification was defined as a connection to a Mexican or Puerto Rican homeland via familial kinship. A national identification was defined by a birthplace connection to a Mexican or Puerto Rican homeland. In both forms of identifications, the presence of a homeland, or sometimes its replication in the home, was the connecting thread to these identification labels. However, the most salient pattern involved the notion of the homeland connection as inescapable. The inescapability involved this quasi-biological sense of who they are, i.e., "I am Mexican or Puerto Rican because either I or my parents were born there." Further, the complexities of lived experiences and skin color determined, in part, why these identifications were interpreted as inescapable. 
Edgard is a perfect example of a student whose definition of his identification is couched in where he was born. For Edgard he is Mexican because he was raised in Mexico for the first six years of his life. Even though as a sixteen year old he has spent most of his life in the United States and was even born in Texas, Edgard still considered himself Mexican because he's lived in Mexico and has lived a Mexican life in the United States.

Interviewer: There are number of terms which are associated with people of Mexican descent, e.g., Mexican, Mexican-American, Chola/o, and Chicana/o. What comes to mind when you think about each of these terms?

Edgard: I think I'm Mexican because most of my mom and dad's family were all born down there in Mexico. And I was raised down there for six years.

Interviewer:So, what comes to mind when you say "I'm Mexican?"

Edgard: That I'm from Mexico.

And what matters to Edgard about his Mexican identification is his ability to get along with various people and the opportunity to visit Mexico and see his family.

Interviewer: Would you say that being Mexican is important to you?

Edgard: I never thought about that whether it's important to me. Well, I like being Mexican.

Interviewer: What do you like about it?

Edgard: I get along with people well. They don't say nothing. They don't call me names or nothing. I get along with Black, Whites, mixed, no matter what kind of people they are. And I don't know, it's just fun, and I like being Mexican 'cause I can go to Mexico. It's fun down there too. Instead of just staying here all the time, I go visit in the summer. Mostly every summer I go to Mexico to visit to grandfather, my family down there.

Throughout Edgard's interview his homeland of Mexico defined what it meant for him to be Mexican. The land along with the people embodied what it meant to be Mexican. In response to questions about how he would describe himself in front of others, he stated, "I'll tell them I'm Mexican and where I was born. I'll tell them how like life is in Mexico or tell them about my family." This life in Mexico, which he parallels to his family, differed from the "American" cultural life, which he defined as White culture, "hot dogs, baseball, football, track, and stuff like that." On the other hand, he defined Mexicans as interacting in a particular 
way. According to him, "the people [i.e. Mexicans] down there they like where we live they always say good morning or like good night." This way of life was also embodied in his family. At home he only spoke Spanish and in the outside world he was the translator for his family, which is how others knew Edgard and his family were Mexican.

Interviewer: You said that by looking at your family teachers know that you are Mexican. How is that they [teachers] know that you are Mexican?

Edgard: Well, one, they [parents] don't know English, so that's probably how they [teachers] can tell. It's like every time I'm with my mom and dad, I got to translate what they say.

However, this perception that Edgard has about others knowing he is Mexican can also be attributable, in part, to the presumption made in Detroit that every Latino is Mexican. ${ }^{5}$ These lived experiences and definitions of Mexico, Mexican ways of interacting, and his role in the family were central to his identification as Mexican. Even when asked whether he considered himself American, especially since he was born in the United States, he asserted a Mexican identification: "In some ways I do because I was born here in the USA and I was mostly raised here too, but I'm still Mexican." Once again his identification as Mexican was something inescapable.

This assertion of an inescapable identification seemed to underline the identification of many of the students. For Alex, his definition of Puerto Rican centers on an ancestral connection to Taino Indian and African roots. These "races," as Alex called them, are what he physically embodies.

Interviewer: There are a number of ethnic terms which are associated with people of Puerto Rican descent, e.g., Puerto Rican, Nuyorican, and Boricua. What comes to mind when you think about each of these terms?

Alex: Like I have friends who call me Boricua. I mostly prefer Puerto Rican.

Interviewer: Do you see any difference in people using one term over another?

Alex: No.

Interviewer: Do you see them as the same?

Alex: Yeah.

Interviewer: Would you say that being Puerto Rican is important to you? 
Alex: Yeah, because like for me being Puerto Rican is like being mixed with two other races. Like me, I'm mixed with Indian and Black. That's what makes me Puerto Rican.

Alex discussed his ancestral identification as an unavoidable part of who he is because he physically embodied this identification. His focus on "races," i.e., Taino Indian and Black, suggests that his identification is bound to a race/ethnicity that he embodies. And that is what makes his identification as Puerto Rican inescapable, because his definition of Puerto Rican was bound to the mixing of specific "races." Further, his focus on his ancestral identification, as bound to his construction of race, raised the question as to whether his defining Puerto Rican identification in that way is consistent with or different from how others may define it (this issue is further explored in the next chapter).

Alex's defining of himself based on his ancestral heritage was not devoid of an affiliation to an American identity. However, it was not an affiliation that was central to his identification as Puerto Rican. This American affiliation only resonated as $2 \%$ of who he defined himself to be:

Interviewer: Would you consider yourself American?

Alex: A little bit. Like 1\%.

Interviewer: So you have citizenship but do you consider yourself an American?

Alex: A little bit because I was born here since I think I have inherited a little of the American. So I consider myself as $2 \%$ American.

Interviewer: The rest of you is...

Alex: Pure Puerto Rican.

For Alex, who he is involved a specific physical and cultural heritage that encompasses $98 \%$ of who he is and an "Americanized" way of being that is only $2 \%$. And it is that $98 \%$ which he can't necessarily escape but rather is central to his identification.

Maria presented a different inescapable reality. Maria, born in San Juan, Puerto Rico, always made sure that she reminded herself that she was Puerto Rican; especially when she was around White people and felt herself changing her way of interacting. Maria did not want to forget that she was Puerto Rican because of concern that she may be classified as an "oreo."

Interviewer: Are there times when being Puerto Rican is more or less important to you? 
Maria: I mean it's important to me but you know I don't go around saying that's real important to me. It's just that at certain times when a certain situation comes up concerning my identity I have to reflect who I am.

Interviewer: Can you describe a situation?

Maria: Not to be wrong or anything but when I'm around a whole bunch of White people and I'm doing all that "you know" and everybody is talking all intellectual and I do that too but yet I still have to remember that, I'm Puerto Rican you know-I can't just fall into the thing of I don't know who I am. Cause they call Black people who act White as 'oreo,' so I'm not trying to let people think that I'm a White person or anything. I'm me.

Maria raised a dynamic that many students of color are concerned with in some way or another. That is maintaining a sense of authenticity or what these students call "representing" one's identification at all times. This representing for Maria involved being conscious that every time she says "whatever" or "you know," she must remind herself or assert her Puerto Rican identification in order to prevent others from perceiving her as minimizing her Puerto Rican identification. Ann Phoenix (1998) and Stuart Hall (1992) conceptualize this dilemma, which is particular to students of color, to be a consequence of the "politics of difference." Students, like the ones Maria referenced, mark differences between themselves and Whites through categories like "oreo," which imply a specific interactional style that is characteristic of Whites and not others. In essence these students are policing what it means to be Black, White and Puerto Rican by constructing static differences between each group. For a student like Maria who interacts with Whites and takes on an interactional style that is defined by her peers as White, this causes a great deal of anxiety in making sure that she "represents" her identification, especially in front of other students of color.

Maria's world was anything but simple. Maintaining an awareness of her identification, especially around Whites who may not interact similarly to her, speaks to the numerous realities or worlds of which she needs to keep track. When asked about the importance of being Puerto Rican, Maria stated, "Being Puerto Rican means I was not born on American soil, but I'm an American citizen and yet I still have culture. I see the side of two worlds." These two worlds are very complex and represent different things about herself and the U.S. context. One world involved her identification as a Puerto Rican with American citizenship, which Maria does not deny as part of her nor does she deny its influence in making her an "Americanized" Puerto Rican. 
Interviewer: Would you consider yourself American?

Maria: I consider myself...that's a good one. I consider myself Puerto Rican, but I still think of myself of American. I still consider myself as American, because as my background, I was born in Puerto Rico, you can check. But it's like you know, I'm Americanized. Once I came here, I'm Americanized and I usually live the American way, but I still hold my Puerto Rican background. Because if I go back to Puerto Rico, people look at me different, because I talk different, I act different. I might forget how to say a lot of things. It's not that I consider myself American; it's just that I've been Americanized.

The other world that embodied her identification involved her image of an American culture defined by Whites because they are the ones, according to Maria, that are at the top of the social stratification system and designate the acceptable cultural, interactional style.

Interviewer: Do you see your culture similar to or differ from American culture?

Maria: That's a hard question, because when you say American culture, you still got to say they are White people or Black people, because even American culture, white and black people are different.

Interviewer: Well how would you describe American culture?

Maria: I'd say American culture is White, because everybody, you know who's always on top? The white people and everybody expects us to speak a certain way.

Interviewer: OK, so thinking that American culture is "White" would you say that Puerto Rican culture is different or similar to it?

Maria: Different.

Interviewer: Now, how is it different?

Maria: American Caucasian people, they expect everybody to speak a certain way. If you're poor they look at you, like whatever. Even if you're white and poor they look at you as trash and whatever. You have to present yourself, and the way of living the clothes and whatever, like a high class society.

These were the worlds that Maria vacillates between on a daily basis and that defined her ancestral identification: a Puerto Rican living an Americanized life in which White culture dominates and designates the perimeters of how to present yourself and interact with others. At the same time, she has an anxiety over being ex-communicated from her community for donning what is perceived as a White style of interacting. 
In short, the ways in which Edgard, Alex, and Maria defined their identification as ancestral/national demonstrate a commonality in the use of lineage. That is, they each referenced their identification as something that was an inescapable lineage. However, Edgard, Alex and Maria touched on different dynamics of why it was inescapable. For Edgard, his embodiment of a Mexican identity centered on the Mexican life that surrounds his daily interactions of speaking Spanish at home, the ways in which Mexicans interact differently than Americans, and his summer trips to Mexico to see his grandfather. Alex's ancestral identification was defined by his Taino Indian and African roots, which reference his lived experience as a Puerto Rican with brown skin. Finally Maria could not escape her Puerto Rican identification because the multiple worlds she was traversing between expected her to identify in certain ways and maintain specific mannerisms in the hope of achieving some type of mobility. The differences in what their ancestral identification means demonstrates the myriad of issues that are unique to each student and are folded into their identification as members of an racial/ethnic group.

\section{CULTURAL IDENTIFICATION}

Identity and culture are two significant strands that individuals utilize on a day-to-day basis to define themselves, but most often these concepts are discussed as two separate entities showing two sides of the same coin. However, for several of the students interviewed, they defined their identification as representative of their culture. Thus how they invoked their identification referenced culture not as a place or a national affiliation. Instead, the cultural identifications they invoked characterized their feelings of cultural pride and for some a cultural point of view. What is important to understand about their definitions of these cultural identities is that it describes the student and not necessarily references a specific cultural content.

Beverly's use of Boricua registered for her a feeling of cultural pride, which differed from the terms' original derivation from the Taino Indians' name for the island, "Borinquen" and the 1960-1970s political meaning of "Boricua First" (Fox, 1996). ${ }^{6}$ Beverly did not discuss the political significance of Boricua, but rather the feeling of pride and affiliation that it projected. This orientation is consistent with how the usage of the term has been popularized through the hip-hop music culture. The commercialization of the term has not only mainstreamed its usage but has also simplified its meaning. ${ }^{7}$ Consequently, in the case 
of students like Beverly, Boricua is reduced to the "feeling" they get when they say it.

Interviewer: How about Puerto Rican and Boricua: what are the differences that you see?

Beverly: I don't see any difference; I mean the most common term that I use is Boricua.

Interviewer: Why do you prefer that one over the other?

Beverly: I, cause it's like the feeling of the word you know, the culture, the things you know about it, you feel it.

Boricua only represented one dynamic of Beverly's hyphenated identification-Mexican-American-Italian-Boricua. However it was the only identification which Beverly attached a cultural connotation. This suggests that the students' usage of certain terms symbolized, as in the case with Beverly, a specific layer of who she is.

The idea of having multiple identifications also has political significance for some students. Students like Paul suggest that multiplicity comes in the form of multiple identifications and also in the form of one term that symbolizes multiple locales and has political meaning. Paul, like Beverly, employed two identifications, Chicano and Mexican-American. He used both to demonstrate that he is both " $100 \%$ Mexican-blooded" and an American citizen. However, Paul only invoked Chicano as a cultural identification that referenced his perspective on the world. He defined his Chicano identification as a cultural perspective that guides who he is. (I begin with the exchange I had with Paul regarding him being 100\% Mexican-blooded.)

Interviewer: There are a number of ethnic terms which are associated with people of Mexican descent, e.g., Mexican, Mexican-American, Chola/o, and Chicana/o. What comes to mind when you think about each of these terms?

Paul: Well, I describe myself as Chicano. I'm Mexican-American, Chicano, I go with any one of them 'cause I'm 100\% Mexican blooded, but yet I was born in the United States. Like, I was born in California. So I'm not from there-I'm an American citizen, I'm from here, but I am full-blooded Mexican. I grew up with the identity like here what shaped my identity was this culture not Mexican I mean my Mexican tradition and culture through my parents but not like the outside world.

As a second generation Mexican, Paul was not born in Mexico, and the majority of his life has been spent in the United States. And how he 
conceptualizes his $100 \%$ Mexican-bloodedness is based on the "Mexican tradition and culture" that his parents imparted to him.

Literature on Mexican identity articulates that "Chicano" is a term primarily used by Mexicans born and raised in the Southwest (Guiterrez, 1995). Chicano began in the 1940s as a pejorative term used to refer to low-income Mexicans. During the 1960s, it was appropriated as a term of cultural pride and symbolized solidarity against the United States' history of racial discrimination and oppression (Gutierrez, 1995). Paul's definition appeared not only to parallel such a perspective but also situated how he viewed the world. Paul emphasized his "Chicanoness" as easily defined by a point of view signified how culture frames his identification.

Interviewer: Would you say that being Chicano is important to you?

Paul: Yeah I think it's really important to me. Like the way I have grown up and like the way I understand things from Chicano point of view has helped me greatly in terms of family, in terms of education, in terms of chances that I get. There is just a million things that it helps you. I know about certain things that other Latinos wouldn't know about and lot more than a person who is not Mexican. I think being Chicano is a big part of who I am and what I learn everyday because I take things from my point of view.

When asked if he considered himself American, Paul offered a sample of his Chicano point of view that focused on the geo-political significance of America and the use of the term American. Paul's world view of the American identification was steeped in an historical and global context of who gets to become American and who really is American. Paul stated that he would describe himself as American because,

Paul: I think that I would consider any Mexican, Mexican-American, I would consider any Canadian, South American, American just because I believe that these are the Americas and we are American. There are Mexicans in Mexico, Canadians in Canada, Guatemaltecos in Guatemala, Nicarguenses in Nicargua, Puerto Riqueños in Puerto Rico, Colombianos in Colombia, but the United States, there is no person to describe the United States, why is that? Because it's made up of Colombianos, Mexicanos, Canadians, Nicarguenses, it's just a mix of people. Am I a US? Yes. Am I an American? Yes, I'm an American. 
Paul's rendering of American as a continental identification illustrated his Chicano point of view. He points out that the United States as part of the American Continent does not have more of a right to describe its people as Americans, than do other countries in the continent, like Canada, Panama and Chile. He reminds us that it is the Americas that are comprised of people who live in these different countries. Thus the American identification, to which Paul pledges allegiance and which is captured by his Chicano point of view signals a more global identification. In addition, what Paul offers by his identification is that the countries in the Americas have a national term to identify their people, in contrast to the United States that uses the continents' name to identify its people. Paul interprets this as the United States representing the merging arena of all these national identifications. In sum, Paul's construction of his cultural identification as Mexican-American and Chicano defines his multiplicity as also involving a point of view that operates from a global context perspective. That is, he does not define himself as having multiple locales but rather his world view incorporates the influence of multiple locales and he interprets his surrounding in such a way.

Overall, these three typologies - hyphenated, ancestral/national, and cultural-designate the meaning these students place on their selfidentifications. In addition within each typology exists various layers of how that meaning is used to define the boundary of their identification. It is important to point out that across these hyphenating, ancestral/ national and cultural identifications is a desire for recognition of their identification and the significance of their multiple worlds and identifications. However, these ethnic identifications do not provide complete renderings of how these students defined themselves. As noted earlier, identity and culture are the basic building blocks of ethnicity and these two concepts assist in the boundary making process of identification, which includes who we are, what we do, and what we think. The following discussion on the interpretations of culture focuses on the "stuff inside the boundary" of the students' Mexican-American, Detroit-Rican, Chicano, and Puerto Rican identifications.

\section{INTERPRETATIONS OF CULTURE}

Culture supplies, as Joane Nagel (1994) argues, "the content and meaning of ethnicity." Culture constitutes a history, ideology and system of meaning from which, "individuals and groups are able to reinvent the past and invent the present" (Nagel, 1994). That involves individuals and groups using culture to account in a meaningful way for what they 
do, who they are, what they look like and what they think (Baumann, 1996). Culture does not differ greatly from identification, and that is because culture and identification operate in tandem. They represent two sides of the same coin. Although it can be argued that culture and identification are similar and/or distinct constructs, my reasoning for parceling out these students' notions of culture is to illustrate the content of what they focus on. In other words, the shopping cart analogy that Nagel (1994) presents: culture is the various things that are put in and taken out of the shopping cart. That is, what are the cultural artifacts and even cultural memories that these students maintain about Puerto Rican and Mexican culture? In addition to describing the content, I also analyze why Puerto Ricans and Mexicans differentially rely on certain indices of culture.

As is to be expected, both ethnic groups described their culture differently. In order to capture what they included in the content of their culture, the students were asked to pretend that they were standing in front of a classroom and had to describe their culture. Unfortunately, not every student was able to describe their culture in concrete terms; however, those that could offered interpretations of culture that centered on content and how the content defines them.

\section{Ancestry in Puerto Rican Culture}

When asked to describe their culture, the Puerto Rican students focused on their varying ancestry, material artifacts, and patterns of social relations, as accounting for Puerto Rican culture. Ancestry and artifacts articulated what made them special and why they looked a particular way. The selected artifacts operated as representations of Puerto Rican culture, while the students' discussions of their ancestry focused on physical appearance. Many of the students explained that such ancestry resulted in the variation in physical appearance that exists among Puerto Ricans (i.e., skin color, hair texture, and eye color). Also material artifacts like fruits and instruments, and styles of interacting account for who they are. In his description of Puerto Rican culture, Alex focused on the interactional style and goods that are owned by Puerto Rican and Spanish culture.

Interviewer: If you were asked to stand in front of a classroom, how would you describe yourself and culture?

Alex: I would say that Puerto Ricans are fun to be around with; they'll teach you things you've never known before like um, I'll teach you to play any Puerto Rican music like salsa, meringue, and parandas. I 
would bring in some Puerto Rican instruments like maracas and congas. Or I'll bring in like one of my Spanish fruits, like once I brought a Puerto Rican fruit (describes the fruit-tamarindos) my favorite is the mangos, I like mangos.

Although his neighborhood is predominantly comprised of Mexicans, Alex did feel like there were things and events in his neighborhood that also celebrated his Puerto Rican heritage. More importantly there were festivals and food markets that provided examples of Puerto Rican culture and artifacts that he sees on his annual trips to Puerto Rico.

While some Puerto Rican students pointed to cultural artifacts as exemplary of their culture, others viewed family interaction styles as symbols of Puerto Rican culture. Samantha, who talked about her family of four being very close, considered Puerto Rican families (which included extended family) as having particular ways of interacting with each other that differs from other groups.

Interviewer: Do you see your culture similar to or different from American culture?

Samantha: Sometimes they're similar because they like to join the family together. They like to eat a lot of food and listen to music and have their get-togethers. But Puerto Ricans are more loud, they like to party more, they like dancing more. They feel what they think. They don't hold anything back. Unfortunately, Puerto Ricans love to gossip.

These differing ways of interacting, for Samantha, defined what it meant to be part of a Puerto Rican family. The ways of being in a Puerto Rican family that differed from the interactions in an American family also defined what it meant to "be" Puerto Rican.

Interviewer: Are there any aspects of 'American' you like?

Samantha: I like that no matter what happens in the family, the family should still stick together not matter what. Sometimes, Puerto Rican families they get into an argument and we never see them again. They just disappear. You don't know you have an uncle anymore.

Interviewer: Are there any aspects of 'American' you dislike?

Samantha: They always so proper. You can be proper when you're at work, or with people you don't know, but when you're with your family, don't act proper to your family. I wonder if they're just trying to make their family feel dumb. Most of the time when I went to White gatherings, they'd be like 'I went to this college and that college,' talking about education and stuff. That's the time we talk 
stuff to get to know each other, not about they're better than most. Not who's better than who.

Samantha's interpretation of how Puerto Rican families interact with each other and its difference from American (i.e. White) families elucidates the ways in which these students interpreted interactions as representations of culture. Being part of a Puerto Rican family did not involve some of the pretense or demeaning interaction that Samantha perceived exists among White families. Instead her conceptualization of Puerto Rican culture as centered on family, suggests that how she interacts with others may derive from the rules of interaction she learned within her family.

The Puerto Rican students' descriptions of their culture at times seemed to be in response to the context, or to whom they would be describing their culture. In a specific instance with Maria, her description of Puerto Rican culture contained the same reference to hair and eye color, but her use of White and Black introduced her awareness of her audience. Although Maria would not identify herself as White or Black because of its reference to White and Black Americans, she would in front of a classroom of students use the terms White and Black to describe the skin color spectrum of Puerto Ricans versus other terms (e.g., blanquito, guerito, trigueño, negrito). ${ }^{8}$

Interviewer: If you were asked to stand in front of a classroom, how would you describe yourself and culture?

Maria: I be like, well, we are a multicolored race, because we come from White to all types of shades to Black. Our hair is straight, curly, kinky, different colored eyes. We descendents from Africans and Spaniards and Taino Indians and stuff like that. I'd describe our music, what we listen to and how we are similar to Mexicans and stuff like that but yet I'd put the boundaries on what makes us so different.

Maria's use of White and Black to describe skin color variations among Puerto Ricans points to a dual application in meaning that is based on context. When asked whether she would identify herself as White or Black, Maria said, "that doesn't describe me." However, in discussing culture, White and Black reference skin tones rather than a cultural group definition. What this suggests regarding her description of culture is that though some Puerto Ricans have skin color that looks like White Americans and Black Americans, Puerto Ricans do not embody an affiliation with either group. 
The distinctions that Maria offers and that other Puerto Ricans make between identification and culture reveal several significant issues. First, these students are aware that their skin color within the American context categorizes them as White or Black. Thus the students use of White and Black may have been invoked to assist others in understanding the spectrum of skin color, despite their association of it with their lineage. What Maria also offered in her description of Puerto Rican culture was a sense that the variation in skin color is what makes Puerto Ricans unique. Yami affirmed that sense of uniqueness by stating,

Yami: We're different. Some people are White and they're Puerto Rican, green eyes and they're Puerto Rican, blue eyes, dark, light. Puerto Rican is a lot of culture[s] mixed together.

Yami indicated that her Puerto Rican heritage is in part articulated by a variation in skin color and eye color that is unlike other groups that may have an essentialized "general look." And according to Samantha, who asserted a strong identification with her Puerto Rican culture, this cultural mixture was something which all Puerto Ricans are proud of: "Puerto Ricans aren't 100\% anything. Puerto Ricans have got a lot of different nationalities inside of them. Puerto Ricans are real proud of their race." Samantha described her family's different skin color tones as representative of this mixture: "My father looks Arab but my mother looks Black, so it's a mixture. And my sister looks White."

In short, from the perspective of these students Puerto Rican culture involves specific material artifacts as a way of interacting among Puerto Rican families that differs from White families and a cultural heritage of Taino Indian, Spanish and African roots that construct different looks among Puerto Ricans. These descriptions provided an idea of how they imagine and (re)produce their culture to themselves and others. In other words, the "stuff" they describe animates what it means to define oneself as Puerto Rican, Detroit-Rican or Boricua.

\section{Family and spirituality in Mexican culture}

The Mexican students defined their culture differently. When asked to describe Mexican culture they focused on historical content, familial involvement and the significance of religion and family. In the case of one student he imagined how such cultural attributes would transgress the U.S. demographic and political spheres. To elaborate upon these 
interpretations of culture, I will begin with Jeff who emphasized the historical content of Mexican culture.

Interviewer: If you were asked to stand in front of a classroom, how would you describe yourself and culture?

Jeff: It's a great culture.

Interviewer: What would you tell them?

Jeff: I'd tell them about the Aztecs and all that stuff.

Jeff reported that each time he visits Mexico he comes back with a greater appreciation for being Mexican. Part of that appreciation derived from his knowledge of the history of Mexico. He explained, "[I] know where I'm from." Jeff also described as unique to Mexican culture how parents are involved in their child's life, especially friendship networks. In response to a question of whether he viewed Mexican culture as similar to or different from American culture, he stated:

Jeff: Different. Its like, how can I say this? Like my Ma, she won't let me hang out with just any old guy friends. Like, American people would be like OK, even though they don't know them. It's like discipline.

Jeff was not the only student that pointed to a specific way of being that is characteristic of Mexicans. Beverly, when asked about her MexicanPuerto Rican/Boricua-Italian cultures, focused on spirituality and family as significant markers of her combination of cultures. ${ }^{9}$ However, these markers have special symbolism because, as Beverly states below, this way of being that is characteristic of Latino/as is something which will impact the United States context.

Interviewer: If you were asked to stand in front of a classroom, how would you describe yourself and culture?

Beverly: It's a beautiful thing. It's a rich people, rich in blood, rich in spiritual beliefs and they don't take things lightly, they're strong people, strong voice. People need to learn that we're coming and they have to be ready for us.

Beverly points to the strength of her Mexican-Puerto Rican/BoricuaItalian cultures and people as something "to be ready for." According to Beverly what others have "to be ready for" is "Latino/as taking over everything." So what Beverly introduced was that from the perspective of a third generation Latina, the cultures that she embodies and the 
increasing numbers of Latino/as will have significant impact on United States demography and political scene.

In short, what emerged in this discussion of culture is the difference in content between both ethnic groups. The differences in content provide an opportunity to understand how students interpret the fragments composing their identification. For instance, the history of Taino Indians, African slaves, and Spanish conquistadors in Puerto Rico is central to the cultural memory of Puerto Rican students. The significance of spirituality, the centrality of family and religion, and culture as defining day-to-day interactions are important components of both Mexican and Puerto Rican culture. In both descriptions of content, the aim of the students was to further define the boundary of their chosen identification. Therefore, the combination of their chosen identification and interpretation of culture "animates and authenticates ethnic boundaries" (Barth, 1969). In other words, for these students, being Mexican and Puerto Rican takes shape and is defined by the identifications the students choose and their descriptions of who they are, what they look like and specific orientations they attach to it through "culture."

\section{SUMMARY}

The construction of ethnicity is a complicated process. The findings of this chapter support previous assertions that the construction of ethnicity is a self-ascription process in which the two basic building blocks, identification and culture, provide the boundary and content. However what these students also assert is that the boundary making process of identification and their interpretations of culture respond to a myriad of external and internal forces. Consequently, through these students' voices we gain insight into the layers of their identification and how this reconstitutes and molds new boundaries of who they think they are as members of ethnic groups, and how these definitions of group membership are reflected in their daily lived experiences as Mexican, Mexican-American, Chicano, Boricua, Puerto Rican-American, and Detroit-Rican.

The typologies discussed earlier in this chapter show that the definitions attached to specific identifications come from numerous places. For instance, students who hyphenated their identifications generally focused on adding a place or a locale to their ethnic affiliation. For some this augmenting of an American identification was part of who they are. That is, who they were as Puerto Ricans or Mexicans involved where they were born and raised. The location 
became as symbolic as their ethnic affiliation and possibly represented the type of Puerto Rican or Mexican they were. For example, some students defined their identifications as Detroit Puerto Rican or as Mexican from this side of the border. For others, hyphenating was more of a process of acknowledging their multiple cultures and understanding the significance of hyphenating within a context that expects singular identifications. Ancestral/national identifications signaled the importance of a Mexican or Puerto Rican birthplace lineage. These students defined themselves by their lineage. However, this lineage was inescapable because of how they looked, and the worlds they moved in and out which reminded them that they were not White. Finally cultural identifications defined for these students a specific way of being that is unique to them and a cultural perspective of the world that challenges what identifications they represent.

Several students cued that culture featured in how they understood themselves and evolved their identity. Culture actually became a tool for further defining themselves. More specifically, culture situated what was special about their group. The Puerto Rican students focused on artifacts, ways of being, and their cultural heritage to account for who they are and what they look like. The Mexican students articulated the significance of family and spirituality, and the group's political strength as what defines who they are. These different accounts of culture rally around a common purpose of illustrating how their group is unique and the stuff that animates the boundary of their identification.

Although the students' discussion of their identification and culture highlights the degree of agency individuals employ in this process, simply discussing the construction of ethnicity as such "runs the risk of emphasizing agency at the expense of structure" (i.e., external perceptions of that identity and culture) (Nagel, 1994). Especially, since even within the confines of how these students self-ascribe to specific identities they made references to external dynamics that play a role in this seemingly subjective process. We must simultaneously explore ethnicity as a fluid construct that is either dependent on or takes context into consideration. In the following chapter I more precisely situate how external forces operate to impose identifications upon these students. 


\section{Chapter Four \\ Negotiating Identification with Other Students and Teachers}

Over the course of interviewing these 17 students, two competing narratives continued to appear. In the first narrative, the students described and defined themselves and subsequently their social world from a self-assertive perspective. In this instance, the emphasis was on how they defined their social locations. However, their self-definitions also operated, in part, based on perceptions of external interpretations of racial/ethnic identification. The focus of this chapter is on those external identifications which comprise the second narrative. This narrative involved the students being conscious of how they perceived external forces and/or individuals define them and subsequently frame their social world. In essence, this second narrative elucidated those factors that constrained how these students could identify and who they could be. Therefore, the central question of this chapter is, how do these students perceive others situating them racially and ethnically?

As I will elaborate upon in this chapter, these dynamics were based, in part, on external interpretations of their skin color. I focus on how African American students and teachers used skin color as a proxy or "floating signifier" of the Latino/a students racial/ethnic affiliation. As noted in the methods chapter, the three high schools these Latino/a students attended were primarily comprised of African American students and/or teachers. ${ }^{1}$ Students who thought of and defined themselves as Detroit-Rican, Mexican-American, Boricua, and Puerto Rican simultaneously faced their African American peers and teachers situating them into three discrete categories; White-looking, Mexican/ Hispanic-looking, and Black/Biracial-looking. These students reported experiencing racial/ethnic designation based primarily on skin color. Their accounts raise substantive questions that not only challenge race/ethnicity as more than discrete categories but more importantly challenge the meanings attached to skin color and race/ ethnicity. What did the skin color-based identifications signal about these students? How did they respond to the impressions of these 
imposed identifications? More importantly, how did their renderings of those external interpretations of skin color affect the students' selfidentification?

These accounts provide us with one vantage point of assessing the racializing process that occurs for individuals operating within and across specific contexts. Consistent with research that explores racializing as a positioning process (e.g., Bashi, 1998; Winant, 1994; Omi \& Winant, 1996), the discussion in this chapter centers on what it means for individuals inserting themselves and being inserted into existing racial hierarchies, especially the Black/White binary hierarchy (for scholarly examples of this concept, see Espiritu, 1992; Portes \& MacLeod, 1996; Rodriguez, 2000; Rodriguez \& Cordero-Guzman, 1992; Waters, 1994). In accordance with the concept of racialization, the students reported that in addition to being situated within the traditional binary (i.e., Black vs. White) they were also situated as Mexican/Hispanic. In light of this triad of racial/ethnic categories we must reconsider the racialization process as not only who is in and out, but also, what does that process look like from the perspective of the individual being positioned within the triad.

In this chapter I will report on the students' perceptions in accordance with how they are divided into three phenotype groups. The group labels derive from the students' perceptions of how others situated them racially. ${ }^{2}$ They, however, coincided with how I would have situated the students were I only to rely on visual cues. These groupings are as follows:

- White-looking: This grouping includes students who were identified as White and/or half White and half Hispanic. They generally had dark brown hair with green or brown eyes and a fair skin color.

- Mexican/Hispanic-looking: This grouping includes students who were simultaneously identified as Arab or Indian and Mexican/ Hispanic. They generally had dark hair, brown eyes and an olive to reddish brown skin color.

- Black/Biracial-looking: This grouping includes students who were identified as Black and/or perceived as Biracial or having "some Black in them" (i.e., Black \& White; Black \& Hispanic; Black \& Filipino). These students had what I consider a trigueño skin color, which ranges from olive to a brown skin color, along with brown eyes and curly black/brown hair. ${ }^{3}$

The analysis of the students' narratives follows along these phenotype lines. However, in reporting the data I collapse them into two categories: 
White-looking, and Mexican/Hispanic and/or Black/Biracial-looking. I collapse these categories in my discussion because the latter two phenotype groups discussed what it meant to be situated as Hispanic and Black in similar ways. In addition, in chapters five and six these similarly reported experiences result in parallel interpretations of opportunity and academic orientation. Finally, these collapsed categories allow for us to dissect the differences in privilege that emerge from being situated as White-looking versus non-White-looking. As I will report on, the understanding of privilege is, however, nuanced by the fact that the students were situated in a predominantly African American setting.

We established in chapter three that the identifications that the students chose and their subsequent definition related to their immigrant generation. However, as is indicated by Table 10, immigrant generation did not appear to be related to how they perceived others situated them. By only attending to the self-selection process of identification, the generational literature on immigrants masks the possibility (as suggested by these findings) that external identifications are less likely to exhibit generational shifts. Further, the findings in this chapter beg for more micro-level inquiry into why identification within and across immigrant generation shifts.

In the following section, I focus on how these students make sense of how others situate them racially/ethnically. More importantly, I explore how these external identifications related to how they viewed themselves.

\section{EXTERNAL INTERPRETATIONS OF SKIN COLOR}

\section{White-looking Students}

Craig Calhoun (1995) argues for us to observe identity as more than simply a self-discovery process that is held solely by the individual and matters only to the individual. "Rather, it is much harder for us to establish who we are and maintain this own identity satisfactorily in our lives and in the recognition of others" (Calhoun, 1995, p. 10). The chore of the self-discovery process for these students was to learn how to maintain their identification even though others identified differently. In addition, the process that I point to here focuses on the following questions: first, what do these students perceive the external voices are stating about their identification? And more importantly, what do they 
Table 10 Ethnic Self-Identification and Others Identification

\begin{tabular}{|c|c|c|c|c|}
\hline Birth & $\begin{array}{l}\text { Place of } \\
\text { Generation }\end{array}$ & Other's Identify as & Identification & Self- \\
\hline Jeff & California & 2nd generation & Arab/Mexican-looking & Mexican \\
\hline Alex & Connecticut & 2nd generation & Black-looking & Puerto Rican \\
\hline Yami & Puerto Rico & 2nd generation & Black and Mexican-looking & Puerto Rican \\
\hline Samantha & Detroit & 3rd generation & $\begin{array}{l}\text { Light-skin Black, Arab, } \\
\text { Indian/Biracial-looking }\end{array}$ & $\begin{array}{l}\text { Detroit-Rican \& } \\
\text { Puerto Rican }\end{array}$ \\
\hline Tara & Detroit & 3rd generation & Mexican/Hispanic-looking & $\begin{array}{c}\text { Detroit-Rican \& } \\
\text { Boricua }\end{array}$ \\
\hline Maria & Puerto Rico & 2nd generation & Mexican/Hispanic-looking & Puerto Rican \\
\hline Beverly & Detroit & 3rd generation & Mexican/Hispanic-looking & $\begin{array}{c}\text { Mexican-Puerto } \\
\text { Rican-Italian and } \\
\text { Boricua }\end{array}$ \\
\hline Laura & Puerto Rico & 2nd generation & Puerto Rican/Black-looking & Boricua \\
\hline Liv & Puerto Rico & 2nd generation & Puerto Rican/Black-looking & Puerto Rican \\
\hline Mellie & Detroit & 3rd generation & White-looking & $\begin{array}{l}\text { Puerto Rican- } \\
\text { American }\end{array}$ \\
\hline Carola & Puerto Rico & 2nd generation & Japanese or White-looking & Puerto Rican \\
\hline John & Detroit & 3rd generation & $\begin{array}{l}\text { White \& Mexican } \\
\text { White-looking }\end{array}$ & $\begin{array}{c}\text { Mexican- } \\
\text { American-Italian }\end{array}$ \\
\hline Nori & Reading, PA & 2nd generation & White-looking & Puerto Rican \\
\hline Keyla & Detroit & 3rd generation & White-looking & $\begin{array}{l}\text { Mexican-American } \\
\text { \& German }\end{array}$ \\
\hline Paul & California & 2nd generation & White-looking & $\begin{array}{c}\text { Chicano \& } \\
\text { Mexican-American }\end{array}$ \\
\hline Edgard & Texas & 2nd generation & $\begin{array}{l}\text { White \& Mexican/ } \\
\text { White-looking }\end{array}$ & Mexican \\
\hline Don & Puerto Rico & 2nd generation & $\begin{array}{l}\text { White \& Mexican' } \\
\text { White-looking }\end{array}$ & Puerto Rican \\
\hline
\end{tabular}

believe are the markers used to situate them into these racial/ethnic categories of identification?

The students answered various questions about how others viewed them (e.g., Do your teachers see you as Mexican/Puerto Rican? Do your friends see you as Mexican/Puerto Rican? Has someone ever assumed you were part of another ethnic or racial group?). The White-looking students responded to the latter question by discussing their experiences of others, mainly African Americans, situating them as White based on their skin color. They were identified as White, Italian or, in some instances, a racial mixture that included White (e.g., White and Mexican, and White and Japanese). Regardless of how they were situated, these students perceived themselves as being primarily viewed as White. Even during moments when they were "performing" their 
ethnic identification (I elaborate on this notion later in the chapter), they continued to be seen as White. The students reported that this association with Whiteness sometimes signified to these external others only a physical congruence with Whites. Other times, however, the students registered that this Whiteness signified to external others a racial affiliation with Whites. From the perspective of these others, congruence involved the students having similar physical features as Whites, while affiliation signaled identification with Whites. Such differentiation suggests that the students perceived African Americans making distinctions between Mexican and Puerto Rican students based on various markers including, but not limited to, skin color. It is important to point out the process of racialization done by others involved situating the students into already established racial categories, whether the categories were White and Biracial (i.e., White and Mexican/Japanese). And part of the external identification process, the students suggest, involved an assignment to Whites and may be even Whiteness. In other words, their skin color raised questions with their peers as to their level of affiliation with Whites and others.

Edgard was situated as White-looking by his peers but such an identification referenced a racial congruence not affiliation to Whites. As a Mexican student in a predominantly African American high school, Edgard generally felt that his teachers and friends viewed him as Mexican. However, he was also conscious that some people outside of his social circle situated him as White-looking. According to Edgard, he was perceived as having a racial congruence to Whites but not necessarily an affiliation. In other words, Edgard considered his external identification as White-looking was a function of his skin color and not because he interacted or behaved in ways that African Americans may read as an affiliation to Whites.

Interviewer: Has someone ever assumed you were part of another ethnic or racial group?

Edgard: Yeah, some people think that I'm half White and half Mexican.

Interviewer: Can you describe that situation or what happened?

Edgard: I think they thought I was half and half 'cause my skin wasn't that dark and I don't know, they just thought I was White, like half White, half Mexican.

Interviewer: Did they tell you that or how did you find out that?

Edgard: They told me, they were like, 'Are you Mexican or what?' I was like, 'Yeah I'm Mexican,' they were like, 'I thought you were, like, White and Mexican.' I was like, 'no.' 
Edgard explained his external identification as marked by his light skin color. Such an identification was not in concert with how Edgard viewed himself, which was as "a Mexican with slicked black hair" that talked Spanglish (Spanish and English mixture) with other Mexican students. As far as Edgard was concerned, by invoking the attributes that he considered indicative of a Mexican identification, he was embodying a Mexican identification. ${ }^{4}$ That is, his construct of identification operates around the idea of inescapability or a discreteness to the Mexican category. He is Mexican because he dresses, talks, and combs his hair like a Mexican, what else could he be and how else could he be seen? However, to his African American peers he was White-looking, based not on those attributes but rather on his skin color. Thus, Edgard and his African American peers operated under the same premise that identification is discrete. However, their use of different signifiers of that identification points to a fundamental disconnect that marked Edgard's experience and is possibly representative of experiences between in and out group members.

Like racial congruency, affiliation was also marked by skin color, but only in part. For example, Keyla, who identified herself as MexicanGerman, reported that African American students blamed her for what White Americans have done to African Americans based on her White skin color and German roots. Her public identification as part German signaled to her African American peers that she held a racial affiliation to Whites.

Interviewer: Are there students who treat you differently because of your racial/ethnic background?

Keyla: They bring up that my ancestors treated them wrong and they say that I probably don't speak to Blacks and they say "we are probably niggers to you." I just look at them like whatever; just because of something my ancestors did and my white skin that's not my fault.

Keyla equated her German ancestry with Whiteness and accepted that Whites treated African Americans poorly. However, she did not consider this maltreatment her fault. Her experience differed from the other White-looking students in that she acknowledged "White" (i.e., German) as part of her identification. This acknowledgment placed her in a precarious situation of being marked as responsible for discrimination. Thus students who identify themselves as multi-racial (i.e., White ethnic and Mexican/Puerto Rican) or affiliate themselves with Whites are sometimes accorded blame for the racism and other transgressions that are enacted by Whites. 
Although the majority of the experiences the students described referred to African American students and teachers, they were not the only group using skin color to make such racial/ethnic identifications. Paul also faced a White-looking identification from other Mexicans making assertions about race based on skin color. Paul was displaced outside of a Mexican ethnic boundary by other Mexicans, which additionally meant that they possibly questioned his authenticity and ability to understand what it means to be Mexican.

Interviewer: Has someone ever assumed you were part of another ethnic or racial group?

Paul: Yeah I've always been confused as a White kid because I have a real light complexion and my eyes are light. Most Mexicans are darker than me "cause they tan or that they are just naturally darker. You know I'm really light-skinned so and of course my eyes are blue. I mean I walk up to Mexican girls and they automatically think that I am White. Well, here's an example, like last month I walked into Ethnic studies program, and it was high school night, and people go there to hear people talk about college, and I enter the room and right away people are like what are you, what are you doing. They didn't think I was part of the group. I always get from everybody that I am White, you know I get that until they hear me talk or they hear my name. Yeah so I get that a lot.

Paul's experiences around his identification have always maintained this gain and loss dynamism. Identification, as Hall and du Gray (1996) argue, is a process of gain and loss in which the individual and external forces make decisions about who can own an identification and how that is done. I borrow from this concept the idea of power that lies behind an individual gaining or losing their identification. Paul's narrative and other White-looking students' narratives point to identification as a process that they endure in which others assign racial/ ethnic affiliation or congruence based on skin color. However, this only illustrates one dynamic of the gain and loss process of identification: power is also integrated into that process. In other words, there is a certain degree of power implicit in being able to gain or lose your identification with or without challenge from outsiders. In the following exchange with Paul, I came to understand some of the power that lies in gaining and losing identification.

Interviewer: Have there been times when being Chicano has been more or less important to you? 
Paul: Oh yeah, when I was in middle school me and my sister we were the only Latinos in the whole school. You know, all my friends were White just because I assimilated myself with White folks because I had just moved out of my neighborhood and into a White neighborhood. You know I wanted to be like them. I started to lose my Spanish. I started to not like my name; I wanted to change it. I really wanted to change my name. I just didn't wanted to be Mexican. You know, so my middle school years I really had a hard time because I wanted to assimilate my whole life to like, White culture. But then as soon as I hit high school that changed cause there were so many Latinos, and so then I wanted to be more Chicano than ever. I lost my self-identity during my middle school.

Paul's account of being able to gain and lose his identification illustrated the unique power of being able to move in and out of identifications. In other words, Paul was able to be White and possibly be accepted as a White person because of his skin color, but he could also acquire a Chicano identification because having White skin color and a Latino/a identification does not require hyphenation unlike those who are Afro-Latino or Black Latino (Rodriguez, 2000). Basically, he can "disown" his White skin and be Chicano or vice versa. Either way, such identification movement symbolizes the power and, to some degree, privilege that comes with White skin color. Thus, the Whitelooking students, as Paul's narrative above indicated, retain more flexibility in their identification process.

Another example of the relative power these White-looking students retain involved their performance of identification. In fact, these students consciously participated in positioning themselves. Five of the eight White-looking students discussed various moments in which, while "performing" their identification, they were situated or at least asked if they were Mexican or Puerto Rican. These performances I defined as moments in which the students "represented" their identification to others, via using or "sporting" a Boricua jacket (the word Boricua and the Puerto Rican flag were on the back of the jacket), speaking Spanish in public spaces, and participating in cultural pride events. These performances, in some ways, were based on using what they considered authentic markers of a Mexican or Puerto Rican identification, which resulted in offsetting their light/fair skin color. The indirect result of these "performances" was that each student could control how he/she was perceived, or at least (re)construct a context in which they could be viewed or even asked if they were Mexican or Puerto Rican. However, the absence of such a discussion among the other phenotype groups also suggests that these performances were 
purposeful in the hopes of warding off others identifying them as White. It is significant to include these narratives in the discussion of how others interpret them because these "performances" were not always sufficient in getting others to define them in ways consistent with their own identifications.

Language, like skin color, functioned as a signifier of identification. However, unlike skin color, language was not externally captured but rather was employed by the individual for the purposes of communication and as a marker of affiliation. Several students described moments in which they were situated as Mexican or Puerto Rican because others overheard them talking in Spanish. Don, a Puerto Rican student, articulated that only when he spoke Spanish in the classroom and/or hung out with students that "look Puerto Rican" did others identify him as Puerto Rican. Don was born in Puerto Rico and moved to Detroit when he was 5 or 6 years old, thus Spanish was not only his first language and the language spoken at home, but it was also the language in which he felt most comfortable communicating. In a school where Spanish language is a signifier of Latino/a affiliation, Don's constant use of the language, conscious or not, became a performance of his identification.

Carola, on the other hand, is identified as Puerto Rican because of the bomber jacket she wears all the time that says Boricua with the Puerto Rican flag below it. The jacket appeared to hang off her frame, but it was something she liked wearing all the time. This was Carola's indirect way of ensuring that she was not identified as White, Japanese or "some type of Latin, maybe Spanish." Carola described herself as the type of individual who does not profess her identification to everyone. As she stated, "[I'm] a shy person, I get along with basically everyone." However, the jacket allowed for her to perform her Puerto Rican identification to others or, as she rationalized, to "represent" her identification. Although I discuss this notion of "representing" in relation to these students' experiences of being identified as Whitelooking, "representing" is also part of the general adolescent experience of wanting to define oneself by something. However, in a context like these three schools with three ethnic minority groups and the presence of racial tension, their adolescent experience involved "representing" their racial/ethnic identification. This need to "represent," as the students discuss in chapter six, involved claiming the racial/ethnic group they belonged to, which was important in schools marked by racial/ethnic tension. My interpretation here is similar to James Vigil's (1988) discussion of individuals participating in gangs, in part, to affiliate with a group that "had [their] your back" or connected with [their] your 
experience and/or belief systems. These students wanted to "represent" an identification with something, and there were instances when the need to represent something was heightened. For example, during the weeks leading up to and following the boxing match between Trinidad (Puerto Rican) and Oscar de la Hoya (Mexican) in 1999, the students became preoccupied with representing their identification. They discussed the fights that occurred in school over establishing which fighter deserved to win.

Representing identification for these students also involved participating in cultural events. Mellie recalled an instance in which, while participating in a Puerto Rican festival, others mentioned that they were surprised that she was Puerto Rican. Such a venue for performance provided her an opportunity to be situated, if only momentarily, as Puerto Rican. The signifier in this performance became the festival.

Interviewer: Has someone ever assumed you were part of another ethnic or racial group?

Mellie: [W]e had a Puerto Rican festival and they, you know I had a Puerto Rican flag and they look at me and say, "Are you Puerto Rican?" and I say "yeah," and they say, "you don't look like it, you look American." I'm like "No." So they think of me as something else.

Mellie's account further illustrates the nature of racialization that is happening to these students. In the eyes of others, Mellie was American. That is, she was situated as White American. In addition, the assertion by her peers that she "don't look like she is Puerto Rican" projects another code of racialization in which a Puerto Rican identification is devoid of White skin.

In sum, these illustrative cases of performance constitute a unique occurrence that only the White-looking students raised as relevant. As was made apparent, the performances may not have always been purposeful. However, these students were aware that others racialized specific artifacts or performances. That is, these performance signifiers were part of how their peers and African American teachers constructed/ defined racial congruence and affiliation. Skin color, language, clothing, and festivals may have functioned as signifiers of racial affiliation. However, skin color ultimately appeared to supercede these performance signifiers. In other words, though these students could be viewed as affiliated with a Mexican or Puerto Rican community, within a context in which skin color has specific meaning of who you are and how you get treated, the ultimate signifier of racial affiliation or congruence is skin color. 


\section{MEXICAN/HISPANIC AND BLACK/ BIRACIAL-LOOKING STUDENTS}

Skin color was also used to define the Mexican/Hispanic-looking and Black/Biracial-looking students. As in the case of the White-looking students, the Mexican/Hispanic-looking and Black/Biracial-looking students reported that external others made a distinction between those who affiliated with Mexicans or Blacks and those who solely had a physical congruence with Mexicans or Blacks. Each grouping signaled the general notion that non-White skin color symbolizes an affiliation or congruence to either Hispanics or Blacks. The Mexican/Hispanic grouping was based on African Americans using these terms interchangeably and simultaneously implying a particular look. Several students described their African American peers and teachers identifying them as Hispanic, but they interpreted that to mean that African Americans have limited knowledge of other ethnic Latino groups. In other words, Mexicans became the representative group of Hispanics. On the other hand, the Black/Biracial grouping was comprised mainly of Puerto Rican students which implied that Puerto Ricans were viewed as having African features and/or looking Black.

The racializing process with these students appeared slightly different from the White-looking students. The Mexican/Hispanic-looking students were positioned into a category that disrupts the historical racial binary of Black/White-Hispanic/Latino. More importantly, these students reported African Americans racializing the Hispanic label as synonymous with Mexican. In other words, Hispanics looked like Mexicans and vice versa. Meanwhile Puerto Ricans were racialized as looking like "they have some Black in them" which involved them having a racial congruence and at times identified as having a racial affiliation with Blacks. Such movement in the racialization process points to, what Bashi (1998) considers a reconstituting of the existing racial hierarchy. The Black/White is transformed into a triad in which some are Black (i.e., "Black in you"), others White (i.e., look White or "have some White in you"), and yet others Hispanic (i.e., look Mexican). However, much of this reconstitution was guided by the students' skin color (i.e., what do you look like). Thus, the following narratives tell the story of how external interpretations of skin color situated students with a Hispanic or Black racial affiliation/congruence.

The students were asked various questions regarding how they perceived the ways in which others viewed them and whether they have ever been identified as part of another ethnic or racial group. The accounts they provided involved them being situated as Hispanic, Mexican, Arab, and Black. Once again, these identifications were not 
always interpreted as racial affiliations but sometimes conveyed a racial congruence.

Alex, a dark brown student with hazel eyes, is an example of how racial congruence operated with the darker skinned students versus the lighter skinned students. Alex, like the other darker skinned students, was conscious of his brown skin color. He pointed out that his interactions with African Americans were positive because he looked like them.

Interviewer: You indicated that you see yourself as a Puerto Rican, do your friends see you in this way or do they identify you in other ways?

Alex: Sometimes, they mostly see me as Black. Some Blacks have my skin color so they get confused.

Interviewer: Can you think of a time in your life when someone has assumed you were of another race or ethnic group?

Alex: Just when my friends think of me as Black.

With Alex, skin color was not the only signifier used to identify him as Black, he also participated in this identification by talking like African Americans: "Its just when I am around full blown Blacks I start talking like them." Alex could not explain why he tended to talk like "full blown Blacks" but such behavior suggests that on some level Alex tried to develop a Black identification. In addition, his reference to African Americans as "full-blown Blacks" simultaneously suggests that he views himself as distinct from African Americans but interprets himself as Black (i.e., it seem as if he is saying that he is a less than full-blown Black). It is such an interpretation that implies a connection between his self-identification and the external identification others have of him. That is, Alex's definition of his ancestral/national identification as connected to an ancestral (i.e., Taino Indian and African) history suggests that the content of his self-identification parallels the external factors others use to identify him. This of course begs the question, does his self-identification respond to or take into consideration his lived experiences of others using skin color to identify him? It is difficult to predict any type of causality with identification, but in the case of Alex and other Black/Biracial-looking students there appears to be consistency in the content of their self-identification and the relevance of external factors in how others situate them racially/ethnically.

Laura, like Alex, also defined her cultural identification as Boricua because of her Taino Indian and African heritage. Her self-identification as well as her external interpretations of skin color similarly focused on her racial/ethnic content. According to Laura, her African American 
peers identified her Black/Biracial-looking because she had some "Black in her" based on the way she acts and looks.

Interviewer: Has someone ever assumed you were part of another ethnic or racial group?

Laura: Yeah. People always ask me if I have Black in me and stuff. I'm like, nah, I'm Puerto Rican, you know. They think, 'cause the way I act and look that I'm a different race. But I'm not.

With Laura and Alex, skin color along with the "Black" persona that they took on signified a racial affiliation with Black Americans that extended beyond the racial congruence others had with them. Although students like Laura and Alex did not necessarily mind that they were being situated as Black, they still desired to be viewed as Puerto Rican. Samantha, a light-brown student with brownish curly hair, desired to represent her Puerto Rican identification and not simply be a student with "some Black in them."

Interviewer: Has someone ever assumed you were part of another ethnic or racial group?

Samantha: One of my teachers, my first hour computer teacher she says I could pass for anything except White. I could pass for, most people think I am either mixed with White and Black, Hispanic and Black, or Filipino and Black, or Indian, Arab sometimes. They always say, sometimes they say I'm everything but what I really am.

Interviewer: How does that make you feel?

Samantha: Well most of the time it don't bother me because you know I was raised, you know, my father, we were raised in a community of not only Hispanics but also Whites, Blacks, and all different minorities so I learned that it don't bother me. But then there is times when you want to be known as Puerto Rican-you want people to know who you are 'cause you want to be proud of where you came from.

Although these students appeared to talk about these occurrences as not affecting them, it is apparent with Samantha that sometimes they want to be situated as part of their self-identified ethnic group. This not only occurred with students that looked Black but also with those that were perceived as looking Mexican/Hispanic.

Similar to the students who were identified as Black/Biraciallooking, the Mexican/Hispanic-looking students made accommodations to how others perceived them. They were willing to be identified as Hispanic because at least they were being affiliated with the Latino/a 
collective. However, such compromising also involved knowing that African Americans coded Hispanic to mean Mexican and/or the image of a Mexican symbolized a Hispanic. For the Puerto Rican students, that was not something they desired. This was especially the case since feeling "recognized" is important for all of these students. Even a student like Beverly, who identified herself as a Mexican-Puerto Rican/ Boricua-Italian, wanted to be recognized as all these identifications and not by a collective Hispanic or national identification (i.e., Mexican). However, it was difficult for someone like Beverly whose straight black hair and olive skin color were often viewed as signifiers of a Mexican identification. $^{5}$

Interviewer: You indicated that you see yourself as Mexican and Puerto Rican, do your teachers see you in this way or do they see you differently?

Beverly: No I think most of them see me as Mexican.

Interviewer: Why do you think they see you as Mexican and not Mexican and Puerto Rican?

Beverly: I think because of my features they are not as strongly, I guess they are more strongly Mexican than Puerto Rican. And since I live with my mom and they see mom, and my mom is Mexican. They see me with her and see me as Mexican. They don't categorize me as Mexican and Puerto Rican.

Interviewer: Do you find that pretty hard them thinking of you as just Mexican and not both?

Beverly: Their opinion to me does not really matter but if its going to interfere with what they are going to teach me we're going to have a situation.

Students like Beverly who embodied distinct identifications operated within this racializing process in which they were positioned based on skin color and sometimes the people with whom they were seen. With Beverly, because she lived with her mother and had little contact with her father, when others saw her with her mother it further solidified their perspective that she was Mexican. When Puerto Rican students did not "look" like they had "some Black in them" but rather more indigenous features, they were identified as Mexican. Maria, a Puerto Rican with straight black hair and a reddish brown skin tone, was situated by her teachers as Hispanic, which was code for Mexican.

Maria: [T]he majority of my teachers they be like, okay, you are Hispanic, so you're Spanish or Mexican, they always think I'm Mexican because all there is around here is Mexican. 
Interviewer: How do you feel about that?

Maria: As long as they know that I am Hispanic I don't have no problem but when they start just 'cause they see my appearance, they be like, 'oh you're Mexican,' 'No.' But I correct them all.

Even though these students were not seemingly frustrated by the fact that they were situated as Hispanic or Black, they ultimately wanted to be seen as belonging to their Mexican or Puerto Rican community. The racializing experiences of these students took on a distinctly different tone from the White-looking students. The positioning process involved being affiliated with Mexicans or Blacks. Some students were even identified based in part on a perceived performance of a Black identification, while others became Hispanic (aka Mexican) based on indigenous features and with whom they were seen. Such a racializing process purports that there are aspects of these students' identification that are constantly being interpreted based on the definitions of others.

\section{SUMMARY}

The construction of ethnicity is a process that simultaneously involves self-defined notions of what ethnicity and race are and a process engendered by external notions of what ethnicity and race are. That is, how these students thought of themselves and what identification they could use sometimes took into consideration how they were being read by others. In chapter three, we saw that external interpretations were involved in how these students constructed their identification and interpreted their culture. However in chapter four, we were able to understand how it was these Mexican and Puerto Rican students perceived that African American students and teachers used a combination of signifiers like skin color, language, behavior, etc., as a way of externally marking identification. These students could not simply be Mexican, Chicano, Boricua, or Puerto Rican. They were simultaneously White-looking, Black/Biracial-looking, or Mexican/ Hispanic-looking.

The White-looking students were positioned according to their skin color and behavior. They were situated into a White-looking identification either through congruence or affiliation. Being affiliated with or having features that were congruent with that of Whites placed these students in situation in which they were either treated as White or at times made to feel as if they did not readily belong to a Mexican or Puerto Rican community. In order to offset their light skin color, many of the students performed a Mexican or Puerto Rican identification. 
These performances represented the students' way of positioning themselves within the racializing process. However, this selfpositioning did not supercede the external interpretations of skin color. Thus, what emerged was a story of racializing that involved others positioning these students as either affiliated with or congruent with Whites, and these White-looking students challenging such racializing by positioning themselves into a Mexican or Puerto Rican category through artifacts and cultural events.

On the other hand, the Mexican/Hispanic-looking and Black/Biraciallooking students were situated into racial and ethnic groups that were somewhat connected to their ethnic identification. The Mexican/ Hispanic-looking students were situated as racially affiliated with Mexicans. The Black/Biracial students were racially congruent with Blacks but not necessarily deemed as affiliated with Blacks. The Mexican/Hispanic-looking students contended with being situated as part of a collective term that others used as code for Mexican. Such coding not only implied that African American students and teachers have little knowledge as to the geographic, social and political differences between Mexicans and Puerto Ricans but also that this coding reflects the historical experience that African Americans have had with Latino/a groups in Detroit. The Latino/a group that has had a significant presence in Detroit are Mexicans, thus they probably became the image of Hispanic.

The Black/Biracial-looking students experienced a similar kind of racializing. The students identified as such were Puerto Rican. Thus it was plausible for these students to stretch their Puerto Rican identification to include Black because, as many of them stated, part of Puerto Rico's cultural history includes a significant African presence. However by being positioned as Black/Biracial-looking in predominantly African American high schools, these students either donned a Black persona or were perceived as having a Black persona. This impression of a Black persona solidified their affiliation with Blacks. Overall, neither category allowed for the students to be Mexican or Puerto Rican. Many of the students incorporated these labels into their repertoire of identities, but they could not be absent of such identities.

In short, the narratives of these students illustrate that the lived experiences of these students are complicated by how others situate them. More importantly, the construction of ethnicity is not only a selfascriptive process but also bound to how others engage in this process through the racializing of individuals. These students were not only conscious that their identification could change depending on context, 
but they also understood that skin color would be the primary factor that would initiate that change. As the foregoing discussion demonstrates, these students operate from the standpoint that who they are and how they are viewed by others is significant in how they navigate in their day-to-day lived experiences. This suggests that their experiences as students and how they perceive and orient themselves to their social world operates from and/or takes into consideration these myriad encounters as White-looking, Black/Biracial-looking or Mexican/ Hispanic-looking Mexicans or Puerto Ricans. The significance of such an identification process has an impact on how these students perceived their opportunity, which is the subject of the next chapter. 
80 SKIN COLOR AND IDENTITY FORMATION 


\section{Chapter Five \\ Perceptions of Life Chances}

Ain't No Making It (1995), Learning To Labor (1977) and other such texts on the working poor and ethnic minority youth (e.g., Hollingshead, 1975; Solomon, 1992) present compelling arguments for the significance of students' subjective understanding of mobility in explaining their social outcomes. These subjective interpretations of mobility, which I refer to as perceptions of opportunity, define students' assessment of the availability of chance, definitions of the 'making it' process, and overall belief in the achievement ideology (e.g., MatuteBianchi, 1991; Ogbu, 1978, 1987; Solomon, 1992; Suárez-Orozco, 1991). Within this area of research, students' perceptions of opportunity inform how they engage in school. That is, students' reasoning of how opportunity operates for people like them shapes the ways in which they participate and, in part, perform in school. Although research in this area differs as to the relative impact of and whether or not social factors, like race and/or class, have a more or less predictive role in social outcomes, they do lay an analytical approach for exploring the various perceptions of opportunity that working poor, low-income and ethnic minority youth maintain. This approach involves exploring students' understanding of how opportunity is made available, what opportunity provides, what kind of opportunity are available to them, what it means to make it, and so forth. Of course, what underlies this analytical approach to understanding students' social and educational outcomes is that such outcomes are informed by students' rendering of opportunity and the making it process. Thus, for the purposes of this investigation, exploring perceptions of opportunity is a useful analytical approach in understanding the students' outlook on how they perceive their social world as well as how society operates and what it may indicate about their academic orientation.

However, exploring these students' perceptions of opportunity involves another analytical purpose. This purpose is to understand how their experiences of racialization inform how they interpret the societal 
structure of mobility (i.e., opportunity and the making it process). This chapter seeks to answer two questions: 1) Are the students' perceptions of opportunity a function of self-identification or external interpretations of skin color? And 2) What is likely to determine whether it is self rather than external interpretations that drive perceptions of opportunity?

The discussion in this chapter focuses on whether the students maintain (or not) the achievement ideology along with other notions regarding making it. According to MacLeod (1995), achievement ideology is a social perspective that outlines American society as open, fair and full of opportunity. The achievement ideology, MacLeod argues, involves a belief that success is acquired via a meritocratic educational system (i.e., hard work in school results in positive academic performance). Additionally, lack of ambition and ability explains why some people are unable to be successful. In other words, students who maintain an achievement ideology belief that everyone can make it because the educational system is structured in such a way that if an individual puts forth effort and works hard in school he/she will be able to reap benefits that result in success. Thus, by focusing on whether and the extent to which the students maintain (or not) the achievement ideology allows us to understand how the students envision the process of making it occurs, how schooling operates within such a process, and who (i.e., individual or structure) dictates the impact or level of success that an individual can achieve.

The chapter is divided into two sections. The first section attends to two constructs of perceptions of opportunity and the achievement ideology_"making it" and "chance." More specifically, I discuss "making it" as an end product of the achievement ideology. That is, the process of "making it" presumes, as traditionally articulated in the achievement ideology, that all those who work hard and demonstrate effort will make it. While on the other hand, "chance" represents opportunity that in some ways is controlled either by a system or individual versus it being an arbitrary action that is not controlled (i.e., luck). Additionally, "chance" focuses on the availability of opportunity which allows everyone to make it. As such, the "making it" process and "chance" represent substantive portions of the achievement ideology and in turn offer a glimpse of these students' perceptions of opportunity. Consistent with previous research, the students in this book substantiate the significance of the "making it" process and "chance" in achieving positive social outcomes. In addition, the students express a commitment to the achievement ideology. 
However, as the second section of this chapter illustrates, the students also express complications of these two concepts of opportunity that follow along phenotype and gender lines. More specifically, skin color and gender emerge as moderating the story of the availability of opportunity and its impact on social mobility. Thus, what this chapter offers is a complex discussion of Latino/a students' perceptions of opportunity and commitment to the achievement ideology, which includes interpretations of certain social factors (i.e., race/ethnicity, language, skin color, and gender) that alter their perceptions of opportunity. But more importantly, those interpretations of social factors operate from their social experiences of racialization based on their skin color and gender.

\section{DEFINING MAKING IT AND CHANCE}

In order to understand how these students' envisioned the making it process and the availability of chance, I asked multiple questions that focused on the meaning of making it, attributes of opportunity and chance, and the availability of opportunity (e.g., What does it mean to make it? What does it take to make it? Who has the best/worst chance of making it? ${ }^{1}$ ). The students, regardless of skin color, described making it as symbolized by markers such as wealth, education, having children, and getting married. The descriptions of these markers were consistent with Jennifer Hochschild's (1995) concept of absolute success. In other words, the markers symbolized an absolute or ultimate goal in life. Another form of success that students described was relative success. That is, relative success, as Hochschild (1995) defines it, consists in being "better off than some comparison point, whether one's childhood, people in the old country, one's neighbors, a character from a book, another race or gender-anything or anyone that one measures oneself against" (p. 16). The comparison point for these students involved defining making it as being able to leave behind their low-income neighborhood and/or low-income status. Thus, for these students making it was about them achieving a level of success that was significant and differed from their current status.

The students' discussion of making it not only involved what it meant for them to make it but also embedded within their definitions were their interpretations of how one makes it. This interpretation involved a rendering of the achievement ideology. That is, they interpreted education as a critical tool in the social mobility process that in various ways education defined making it and not making it. This finding is consistent with previous research which outlines ethnic 
minority students' maintaining a strong belief in education because of the potential they believe it holds for lifting them from poverty and oppression (e.g., Flores-González, 1999; Mickelson, 1990; O’Connor, 1997, 1999; Ogbu, 1978; Patchen, 1982; Suárez-Orozco \& SuárezOrozco, 1995). This is reflected in their relative and absolute perspective on success, which was defined by education. Additionally, the students offered specific orientations needed to succeed. They explained making it as requiring an ambition for acquiring knowledge, a setting and achieving academic goals like getting a Ph.D. or a "good degree," and working hard (i.e., individual effort). Their explanations centered on the individual shaping their absolute or relative success. In turn, they attributed a lack of individual effort, ambition, and ability in the schooling process as why some people did not make it. Although the majority of students expressed the individual as holding sole responsibility for making it or not, some students also perceived the making it process and the distribution of chance as complicated by other factors, such as, race/ethnicity, skin color, gender, and language. These complex explanations, as will be discussed in the next section, are moderated by gender and skin color. The following illustrative cases demonstrate the students' focus on education as how they defined making it. The intent of these cases is to provide a general landscape of the various explanations of making it and chance.

Carola's parents shared her belief that education defines the making it process. As a 9th grade student, Carola stated that her parents outlined school as the most important endeavor, and she in turn believed it was essential in the making process. Thus, in her rendering of making it, employing academic behavior that is conducive to positive academic performance (i.e., studying, working hard, and staying in school) defined making it.

Interviewer: What does it mean to make it?

Carola: It means to study hard and don't drop out of school, go to college and be what you want to be.

Interviewer: What does it take to make it?

Carola: A lot of hard work and focus in school.

The same characteristics of studying hard and not dropping out of school not only explained the making it process but also defined for Carola the persistence of social inequality. In other words, for Carola poverty is the result of disengaging from school. 
Interviewer: Why are some people rich and others poor?

Carola: The rich people end up being rich because they went to school and had good grades, and they became someone in life and they, like, wanted something more and got it, and they made it, and now they are rich. The poor people, basically, they are, probably they didn't go to school, they dropped out and they started doing drugs.

These characteristics, such as going to school and showing effort and ambition for "something more," strikes at the core of the achievement ideology. That is, within Carola's explanation she was situating a straight-line association of engagement in the educational process leads to success and social mobility, while a lack of engagement leads to no mobility. However, more importantly, Carola outlined that individual actions determine social inequality. Accordingly, social inequality is due to individual differences in ability and ambition (MacLeod, 1995). In other words, while many of the students, like Carola, perceived society as structured unequally because "some people are rich and some are poor," they did not imagine that the structures that determine social inequality as unfair. Rather, they imagined it was the function of individuals' ambitions to be rich or stay poor. These characteristics of ambition, ability, and effort also defined how she interpreted chance being distributed. According to Carola, individual effort and ambition defined the distribution of chance.

Interviewer: Who has the best chance of making it?

Carola: People who study a lot.

Interviewer: Who has the worst chance of making it?

Carola: People who don't care and don't want to go to school and quit.

And they do nothing but expect to get a job that they can get a lot of money.

Chance, Carola argued, is something that everyone can attain if they exercise specific attributes, such as studying a lot. Alternatively, chance is reduced by not assuming those attributes. Placing the emphasis on individual effort and ambition as defining the making it process and the distribution of chance suggests that students like Carola perceive opportunity as individually dictated. In the following passage, Carola offered a compelling scenario as to how she believes making it and chance are defined by the individual.

Interviewer: Are people equal in American society?

Carola: Yeah they do. Its up to them; everybody is smart in the world. If you're not, its because you don't want to, 'cause what they teach in 
one class, everybody hears it, and one kid gets good grades and another doesn't - that's because they didn't try.

Such an assertion illustrated that students like Carola perceive education as a system that equally provides opportunity. However, it is the individual's responsibility to capitalize on that opportunity. And it was this belief in the individual and what they do within the educational system which personified Carola's commitment to the dominant achievement ideology. In other words, how she outlined the process of social mobility rested on the assumption that mechanisms like education are equally distributed and that it rests on the individual to engage in the process of education. This argument was common among the students. However, other students also focused on the individual as pertinent in the social mobility process and simultaneously offered more complicated explanations of making it and chance.

Keyla, like Carola, also came from a family that supported her ambition and focus on education. The youngest child of four ( 2 sisters and 1 brother) in a female-headed household (mother and aunt), Keyla indicated that she is expected to go to college and make it. Her older brother and sisters dropped out of school and were parents by the time Keyla was in 10th grade, thus Keyla's mother desire was for her to attend college.

Interviewer: What does your mom want or hope for you to be?

Keyla: She wants me to be whatever I want to be. She supports me in whatever I want. She's the one that really wants me to go to college because my sisters and brothers have dropped out or gotten pregnant.

Such expectations from her mother explained in part why making it was so important to Keyla. She aspired going to college not only to interrupt the pattern of limited educational achievement in her family, but also to have some mobility for herself and possibly to help her mother. Thus, for Keyla education had a purpose: mobility.

Interviewer: What does it mean to make it?

Keyla: To be able to finish school and get a good job and get out of this society, this ain't happening to my life.

Interviewer: Do you mean this area of Detroit?

Keyla: Yeah. I'm not staying here.

Keyla's notion of making it involved attaining a success relative to her low-income status. She desired a different class status, which I am sure 
many low-income students hope for. However, Carola viewed herself as having a better chance to make it than other Mexican girls because she did not have other factors holding her back.

Interviewer: Do you believe that you have a better, worse, or same chance at making it as other Mexican girls?

Keyla: I think I have a better chance because some of my friends around here are Mexican that come from Mexico are married and have kids. They are not even trying to go to school. I'm going to make it, I will graduate.

Interviewer: How do you plan to do it?

Keyla: By going to college. I'm not going to be on the street selling anything, my body [i.e., prostitution]. I'm doing it the honest way.

Although various arguments assert that low-income students are circumscribed to low-income job options as adults based on numerous factors (e.g., poverty, social policy options, schooling opportunities and differential curriculum, differential accumulation of wealth among ethnic groups, employment opportunities and race) (Anyon, 1981; Danziger, Sandefur, \& Wienberg, 1994; Oliver \& Shapiro, 1997; Willis, 1977; Wilson, 1980, 1987, 1996), this does not necessarily mean that such students desire those positions. Keyla expected not to "sell her body" or anything else or even become a waitress at a Mexican restaurant like her mother. She wanted to have a good job, "somewhere where you are sitting behind a desk." Keyla aspired for more out of her life, such as becoming a lawyer. And how she envisioned herself becoming a lawyer — not on the street doing something illegal—and by studying hard and getting good grades. In Keyla's words, "that's the only way you can make it out of high school is through your grades. That's the only way you can get into college, and the only way you can pass that is with your grades."

Although Kelya placed a great deal of significance on the educational process as facilitating making it, she also recognized that sometimes it is not the only means individuals have available to them. Sometimes individuals resort to illegal activity in order to make it.

Interviewer: Why do you think some people are rich and others are poor? Keyla: Some try but they can't succeed. But some, they'll do whatever it takes to make it. Prostitution sometimes people do to make money. You gotta do what you can.

Keyla's explanation of social inequality introduced that within her conceptualization of making it, she recognized that some people are 
unable to take the "honest path." Keyla, unlike Carola, does not place fault on the individual but rather understands that "honest" effort does not always result in success. Individuals can make a resolve to make it but also achieve some form of economic success through nontraditional means; in other words, Keyla's resolve of "you gotta do what you can" implies that making it also involves taking the less traveled and sometimes illegal path. However, she additionally believed that even if you make it, there are further obstacles that emerge.

Interviewer: Do you agree or disagree that America is a land of opportunity where everybody can get ahead, and that everybody gets what they deserve out of life?

Keyla: No, most of the time, if you make it, you still don't get what you want.

Interviewer: Why do you think you still don't get what you want?

Keyla: If you try hard enough you'll get mixed up they won't let you get your job, your diploma and all that.

Although, when asked, Keyla could not articulate who the "they" is she was referring to, her discussion suggests that she believes in external factors limiting the 'making it' process. That is, constraints operate in the 'making it' process that can not be circumvented by individual effort. Thus we begin to see with students like Keyla, that the individual along with external factors play a role in situating the making it process and chance.

Paul concurred with Keyla that external factors such as class privilege some individuals over others, which results in a better opportunity to make it. However, Paul's resolution for contending with such privilege was to exert individual effort, and it is this individual effort in education that he considered defines the making it process. This belief in education Paul described as something that is important to him and his family. Paul was from a Mexican family with four siblings ( 2 brothers and 2 sisters) in which each child is expected to achieve some form of success. In his family, education was a top priority. While discussing his father's background, he noted that his father continues to enroll in vocational trade programs because he believes in improving oneself. However, this desire to improve does not come overnight, as Paul argued.

Interviewer: What does it mean to make it?

Paul: In my belief, to accomplish what you want to do, to accomplish your goals. You set certain goals, certain dreams to become successful you have to have accomplish your goals. 
Interviewer: What does it take to make it?

Paul: I think it takes a lot patience and a lot of hard work because a lot of things don't pay right away. And it takes time for things to pay off but gradually things will pay off.

Paul's description of making it as taking time to pay off and a lot of hard work was something he was familiar with from not only his father's experience but also his own schooling experience. During the first 2 1/2 years of high school, Paul admitted to not caring about school and failing classes, but after getting suspended and almost expelled, he reconciled that he needed to do something with his life. He refocused his energies on getting better grades. It was not until his senior year that he achieved his goal of earning straight A's. Achieving that goal he stated, "took me a long time" and required a great deal of effort on his part. So, his definition of making it involves this recognition of things taking a long time to come to fruition and involving a great deal of hard work. He maintained a similar assertion when explaining social inequality. That is, wealth is the result of hard work and effort, while poverty can be escaped through hard work as well as having a strong supportive network.

Interviewer: Why do you think some people are rich and others poor?

Paul: I think some people are rich because they inherit it, you know their parents are rich so they get the richness too. Other people are rich because I really believe that some people really work real hard for their money, they might have been like a middle class person like myself. I'm not poor, but I have to work for every penny. I think some people are rich because they work their butts off to be rich. They are the ones with the doctoral degrees and all that stuff. And some people are poor because they were born in a poor community like nobody...I seriously think that every poor person can become successful they just have to have the right support system, family structure, you know, that is important. Maybe the people who are have good family structure and you know the minority who come up to be rich people, you know they come from good family system. I know people that are rich just because they are, and they don't have to go to school because they are rich, so they don't have to work for their money.

Although Paul argued that making it does not occur overnight and requires hard work, embedded within this assertion is what the other students' also professed. That is, the individual dictates this process. However, when explaining poverty Paul did point to other circumstances 
in addition to individual choices. From Paul's perspective, people are poor because of the circumstances they are in as well as the decisions they make not to be educated.

Interviewer: Why are people poor?

Paul: Because people don't want to get educated and they could care less about being educated and they could just live on welfare and be cool with that. And other people are poor because they come into this poor thing and nobody wants to give them a chance; you have to have the right circumstances, the right family structure and right belief in yourself to be successful. To me, rich could be being successful but not rich-wise. I think that too many people associate richness with money and poor with not having money. The richest person could be poor because they don't have nobody, they are just there with their money. People need to understand that some people can't make it because they are discriminated against because of the color of their skin.

Paul's conceptualization of the 'making it' process involved various layers of explanations. These layers incorporated the numerous explanations offered by many of the students: the individual effort perspective that Carola offered, Keyla's "you gotta do what you can" ideology of making it, and a combination of the two. His definition, like Carola's and Keyla's, exemplified some of the common threads found in many of the students who assert a commitment to the achievement ideology. These assertions outlined their commitment to the ideas embedded in achievement ideology — such as, through individual effort and hard work in school success can be attained. However, when asked to explain social inequality, students like Keyla and Paul, who are both White-looking, suggested that sometimes the opportunity or chance to make it is not offered in the same manner to everyone. Some people have more wealth or a better family support system that allows them to make it. Thus, making it, chance, and its explanation of social inequality involve various layers of dynamics that center around the individual and surrounding circumstances that cut across the phenotype groups.

It became apparent through the analysis of the students' definitions and explanations of making it and chance that they perceive a myriad of factors were involved. More importantly, their explanations of making it and chances as outlined by the educational process are reminiscent of Roslyn Mickelson's (1990) model of abstract and concrete attitudes towards education. Mickelson argues that ethnic minority students' attitudes toward education are multidimensional. Students maintain abstract and concrete attitudes towards education that inform their 
academic performance. The students in my study expressed such abstract attitudes within their notions of the achievement ideology and perceptions of opportunity. Additionally, they expressed concrete attitudes or interpretations of education and the making it process that involve social factors, such as race/ethnicity, gender, language, nativity status, and skin color. However, Mickelson operates from the assumption that ethnic minority groups' identification constructs sustain similar meaning across group members, and in turn maintain parallel interpretations of discrimination. In other words, Mickelson assumes ethnic minority groups derive their concrete attitudes about education from parallel meaning making of their identification and interpretations of discrimination. And it is the meaning making of selfidentification and external interpretations of skin color discussed in chapters 3 and 4 that become of salient concern in this chapter and raise substantive questions about previous assumptions and constructs of identification. The question that becomes of concern is, how do the experiences of identification of these Mexican and Puerto Rican students inform their perceptions of opportunity?

Although Mickelson offers a substantive approach to exploring the attitudes ethnic minority students maintain about schooling, there is not sufficient attention to the multiple social positionings of ethnic minority students and how it informs opportunity and academic orientation. Carla O'Connor $(1997,1999)$ points to such an interaction as critical to how we can understand students' perceptions of opportunity and engagement in school. More importantly, O'Connor (2001) argues for a more complex rendering of social identification and its implications to perceptions of opportunity and academic achievement. In O'Connor's (1997) exploration of high and low performing African American students she identifies students' articulating co-narratives of opportunity in relation to their multiple social positionings. That is, co-narratives reflect the ways in which students complicate the achievement ideology by maintaining "an ideological commitment to many of the fundamental elements of the dominant theory of making it, but... modif[y] the character and structure of the story by incorporating mitigating factors and circumstances that mediate the efficacy of the individual and affect his or her probability of realizing particular social and educational outcomes" (O'Connor, 1999, p. 141). I borrow this analytical approach as a way of explaining that, along with maintaining a commitment to the achievement ideology, these students argue various social factors as mitigating the making it process. However what I offer in the following section is that these students' co-narratives operate, in part, based on the social experiences they have around skin 
color and gender. More specifically, different co-narratives emerge cutting across the phenotype groups but also varying within phenotype groups. In addition, gender differences emerge in explanations and relevance of social factors. The next section provides a substantive contribution in understanding how Latino/a students' perceptions of opportunity operate in relation to their social experiences of skin color and gender, as well as the usefulness in the concept of co-narratives.

\section{GENDER, SKIN COLOR, AND RACE/ ETHNICITY-BASED CO-NARRATIVES}

\section{White-Looking Students}

As mentioned above, co-narratives postulate social experiences around race/ethnicity, gender and class as informing the ways in which students of color explain social outcomes in relation to their perceptions of opportunity. We have already established that all the students maintained perceptions of opportunity as dictated by the ways in which they engaged in the schooling process. However, when asked to explain different levels of social inequality, the White-looking boys articulated an explanation that differed from other phenotype and gender groups. The White-looking boys maintained a co-narrative of social inequality in which Whites have more opportunities than minorities because of a privileged educational background and native status, not because of their racial/ethnic status. In addition, they stress that despite minorities' immigrant status and low-income individuals' minimal education, individual effort can supercede such obstacles; thus they place the onus of making it on the individual.

Such an explanation suggests that these students are able to understand that certain markers enhance mobility. However, their explanations focused on why Whites and minorities are in specific social class stratums, not why class differences exist. By dichotomizing social class along racial/ethnic lines, these students suggest they do not perceive racial/ethnic stratification as an explanation for social inequality. It further suggests that these White-looking boys are erasing race/ethnicity from how social inequality operates. What is further intriguing about this erasure of race/ethnicity is that the White-looking girls and White-looking boys who were situated as biracial (i.e., White and Mexican/Japanese) did not assert such a co-narrative of opportunity. These two groups did not mention race/ethnicity as a factor in the making it process. Instead they focused on everyone having the same opportunity, regardless of race/ethnicity, to making it through 
education and individual effort. However, such a discussion could be interpreted to mean that the White-looking girls and the White-looking students who were situated as biracial were erasing the significance of race/ethnicity by not accounting for it, but that differs from what the White-looking boys were doing. The White-looking boys argued that there are conditions among Whites and Hispanics/Latinos that privilege and prevent their success/failure and opportunity, respectively. Thus, my rendering of erasing or erasure of race/ethnicity is focused on how it symbolically disavows race/ethnicity as structuring such privileges and limitations.

The White-looking boys ability to erase race/ethnicity as operating in the distribution of chance-which differs from the Mexican/Hispaniclooking and Black/Biracial-looking acknowledgement of racial/ethnic stratification-suggests a skin color and gender privilege that parallels discussions of how and why White men deny race (hooks, 1995). In other words, they are able to erase race/ethnicity because as Whitelooking boys they have not socially experienced race/ethnicity-and possibly gender stratification-as mechanism by which they are judged. ${ }^{2}$ In addition, by erasing racial/ethnic stratification and asserting that differences in social inequality are due to their father's educational background and immigrant status, they imply objectivity to structures of opportunity and the achievement ideology. In other words, for them making it is not structurally defined by race/ethnicity and class or other social factors, but rather defined by an individual's action and "lot" in life (i.e., father's educational background, immigrant status). Thus, the co-narratives these White-looking boys assert suggest a privileging effect of having White skin and thus being able to deny or erase race/ ethnicity and possibly gender. The following narratives exemplify how these students' discussed issues of racial/ethnic stratification as not limiting the making it process and opportunity/chance.

Don argued that making it is something "you have to do in order to be somebody." What it takes to become that somebody is work hard and have "good ideas." However, Don also argued that the distribution of chances follows along race/ethnic lines. In other words, though he defined making it as something an individual takes control of, the distribution of the chance to make it operates according to other criteria.

Interviewer: Who has the best chances of making it?

Don: I think White people. I mean because their fathers do good so they do good.

Interviewer: Who has the worst chance of making it?

Don: Maybe Hispanics.

Interviewer: Why do you think that? 
Don: Because their fathers come from another country and they do well there but not here. They want to be able to succeed here too...they can do it through working up the ladder.

Don offered a traditional social mobility argument in which the father's educational background is perceived as having sole impact on social outcomes. Although he mentioned race/ethnicity, his argument centered on how the structural circumstances of Whites ensure that they have the best chances of making it. He continued with such a structural argument by maintaining that Hispanics have the worst chance of making it because of differences in transferable skills and education. However, he undermines this belief with the notion that hard work does lead to success, and therefore suggests that the problems Hispanics face can be overcome through hard work. Simultaneously, he interpreted the structural circumstances of Whites and Hispanics dictate whether they can make it. For instance, in the passage below, he discusses some of the obstacles facing Hispanics.

Interviewer: So do you think there are things that make it harder for Hispanics to make it?

Don: Yeah.

Interviewer: Like what kind of things?

Don: Like in their house there is a lot of problems they have to take care of their kids can hold them back.

Although it is pertinent to note that Don constructs a structural argument for the distribution of chance, such an argument did not consider how race/ethnicity is utilized as a barrier for Hispanics and a tool of privilege for Whites. According to Don, race/ethnicity does not affect making it; instead, education and effort determine success and mobility. Even though Don recognized that everyone comes from different backgrounds, in his conceptualization of Americans being equal, "if you want to succeed in life it doesn't matter one way or the other what you're background is." What mattered to Don was the conviction of the individual to want to make it, which is why he expressed he has a better chance of making it than other Puerto Ricans, "because people encourage me. Because I've decided to make it." In short, Don perceived opportunity as stratified due to native status and educational background; however, such stratification had not occurred because of race/ethnicity but rather because of individual effort.

Paul also presented a structural argument for how chance is distributed. Like Don, Paul underlined his dismissal of race/ethnicity as impacting the making it process with the belief that hard work can 
improve mobility, especially in school. Even though he perceived minorities as having minimal chances of making it because of discrimination, Paul held on to the belief that if you work hard you can make it.

Interviewer: Who has the best chance of making it?

Paul: Educated people. If you're not educated, you not going to get anywhere. You might be capable but you don't have the capability to be something.

Interviewer: Who has the worst chance of making it?

Paul: Minorities I guess, but also the people who are in the lower class. I think that minority people who are uneducated, but if you work hard you can make it.

Paul's interpretation of chance centered on education as a tool for mobility. In other words, the availability of opportunity is determined by educational achievement. In spite of the racial discrimination which he perceived exists, making it and having the chance is dictated by education, not by external factors like skin color.

Interviewer: You circled here that skin color is somewhat important in making it, why do you think so?

Paul: I think that in this day and age that we are getting more towards, it's still an issue. I'm not saying that it's a little issue, it's a big issue, but yet you can still overcome obstacles these days. You always have a right.

Paul's reference to rights suggests that unlike 50 years ago, minorities have the law on their side and thus their inability to make it can not be readily attributed to structural barriers that involve skin color/racial discrimination. The responsibility of making it and having the chance to make it rests on the individual.

In sum, it is difficult to argue definitively that Don and Paul's interpretation of race/ethnicity as not playing a major role in the distribution of opportunity is due to their social experiences of being situated as White-looking males. However, the fact that the Whitelooking girls, White-looking biracial boys, Mexican/Hispanic-looking and Black/Biracial-looking students did not share the same interpretation of race/ethnicity as these White-looking boys suggests that their experiences around skin color and gender moderate the ways in which these students perceive opportunity. In other words, within their expressed commitment to the achievement ideology, they have constructed a co-narrative that explains social inequality among 
different racial/ethnic groups as due to individual abilities and a commitment to making it. What makes their discussion gendered is the absence of White-looking girls arguing that race/ethnicity does not matter. Furthermore their "erasure" of race/ethnicity as having an impact on opportunity raises various questions regarding the intersection of skin color and gender. For instance, if perceptions of opportunity emerge, in part, from various social experiences and perspectives, could it be argued that having White skin color as a Mexican or Puerto Rican male privileges experiences and perspectives that moderate perceptions of opportunity? How do these privileged experiences and perspectives construct the significance (or not) they place on race/ethnicity? Within the confines of this book and data it is difficult to answer such questions, but the accounts of the Mexican/Hispanic-looking and Black/ Biracial-looking girls described in the following section begin answering these questions through a comparison of these groups.

\section{Mexican/Hispanic-Looking and Black/Biracial- Looking Students}

The Mexican/Hispanic-looking and Black/Biracial-looking girls provide an explanation of the making it process that involves their experiences of and perspectives on gender, skin color, and race/ethnicity. However, these girls were the only ones from their phenotype groups that provided accounts in which gender, skin color, and/or race/ethnicity were raised as pertinent factors in the making it process. It is unclear as to why the Mexican/Hispanic-looking and Black/Biracial-looking boys did not discuss gender, skin color, race/ethnicity, and language as pertinent factors in the making it process. Instead their definition of the making it process and articulation of the achievement ideology centered on education and individual effort as central to their perceptions of opportunity. However, the presence of Mexican/Hispanic-looking and Black/Biracial-looking girls warrants the speculation that the intersection of their gendered and racialized experiences and perspectives moderate the commitment they make towards the achievement ideology as well as the co-narrative they maintain of opportunity.

The Mexican/Hispanic-looking and Black/Biracial-looking girls maintained various co-narratives. First, within their discussion of making it and chance they argue that education, individual effort and orientation towards schools matter in the making it process. However they also argued that having a positive self-outlook is what defines whether anyone makes it or even can make it. This positive self-outlook 
they argue is necessary because of the barriers that girls like them experience in school and society. The second co-narrative contends that gender, skin color, and race/ethnicity mitigate an individual's opportunity. This co-narrative focuses on how they view these factors impinging on the making it process and the distribution of chance, substantiating why a positive self-outlook is necessary.

A positive self-outlook matters in the making it process. They not only discussed that everyone needs to study a lot and work hard to make it but they additionally considered self-outlook as significant to making it. This self-outlook did not operate as an addendum to individual effort and ambition but rather as a necessary orientation for making it. Their narratives not only introduced this notion of self-outlook but also a relationship between interpretations of opportunity, gender and skin color: how they interpret opportunity is structured around their social experiences of being female and identified as Mexican/Hispaniclooking and/or Black-looking. The ways in which they invoked selfoutlook further solidified this relationship. That is, the purpose of this outlook, according to these students, was to function as a barrier against negative "put-downs" from others. Meaning that this self-outlook orientation emerged from their social experiences as Mexican/Hispaniclooking and Black/Biracial-looking girls.

Maria, a Mexican/Hispanic-looking student, defined making it as getting an education in order to acquire monetary wealth. However, what it takes to get an education and make money involved characteristics other than effort and ambition. Self-confidence and selfesteem were the key characteristics that Maria perceived as necessary to make it. Maintaining such a belief in herself had always been a part of Maria. Although Maria knew that her mother wanted her to graduate from high school, she also felt that her mother wanted her to "stay home, get married and do housework." Such "old fashion ways," as Maria calls it, were some of the perspectives that she battled which required a positive self-esteem.

Interviewer: What does it mean to make it?

Maria: I think it means to be high class. Come out with the green. Go to college, go to grad school. Make money. Live in the suburbs. Have a car. Have a house. A fancy car and stuff like that.

Interviewer: What does it take to make it?

Maria: A positive self-esteem. You have to be really self-confident, because a lot of people always going to try to put you down and say things to make you feel low. And you got to be ambitious and stay in school. 
The need for self-esteem for Maria was not only in response to the low gendered expectations from home but also to battle the prejudice and racism that she believed prevents society from being equal; "to me everybody is equal. But in reality, the way, everybody keeps living, there's still stereotyping and prejudice and racism. It's just not shown, but it's in there. That's why we need the equal opportunity act and stuff like that." Maria does not designate having a positive self-outlook as alleviating inequality but rather she views it as a mechanism by which to psychologically operate within such societal constraints. Simultaneously, lacking a positive self-outlook also inhibits individuals from making it.

Interviewer: What do you think holds a person back from making it?

Maria: They get scared and they're self-conscious. They believe when people put them down. They don't even try.

Self-outlook and other's perceptions emerged as powerful agents in the making process of girls like Maria. The making it process involved contending with other's perceptions. Thus, what it takes to make it involved invoking a mechanism with which to deal with such negative perceptions.

A positive self-outlook intrinsically involved ambition or determination. In Beverly's definition of making it she focused on where you come from, appreciating "the journey" of making it and having determination. Beverly remembered her mom, a social worker, carrying her around to different places and exposing her to a variety of things when she was younger. This exposure Beverly recalled as significant in how her mother expressed the importance of education, which in turn resonated in her discussion of determination as important in making it.

Interviewer: What does it mean to make it?

Beverly: To graduate from high school, to go on to college and get a job and be able to come back and say, 'I graduated,' be able to talk to people and say, 'they have been through this neighborhood and still been able to get out of here.' It's not like you grow up and you go to college and you forget where you came from and you don't worry about nobody anymore, I mean if you are really going to make it you have to go to through all that stuff and then come back and see how long journey you've taken to get there. But if you are going to get all into success and just happy with your money, then you haven't made it.

Interviewer: What does it take to make it? 
Beverly: A lot of hard work, a lot determination. I mean 'cause people in this world going try and shoot you down; you gonna have to have enough will power to be able to look them in the eye and tell them you are not doing this to me. 'Cause you have to have determination, you have to have the heart and like yourself.

Determination was necessary to ensure that these "put-downs" did not diminish an individual's power. The above narratives on personal selfoutlook characteristics raised the possibility that issues of self-esteem and positive attitude are pertinent to Mexican/Hispanic-looking and Black/Biracial-looking girls' definitions of making it. In fact, they suggest that Mexican/Hispanic-looking and Black/Biracial-looking girls maintain co-narratives in which they assert that racial discrimination and sexism mitigate their opportunity to make it. In response to such conditions, these girls argue that they must maintain a positive selfoutlook. The presence of such a co-narrative among the Mexican/ Hispanic-looking and Black/Biracial-looking girls, and the absence of such a discussion among the White-looking girls, suggests that gender and skin color simultaneously moderates the perceptions girls have of opportunity. That is, the ways in which dark-skin girls think about the making it process involve issues that connect to how they perceive others situate them and interact with them as females and as Mexican/ Hispanic-looking and Black/Biracial-looking. This finding of gender/ gendered experiences having an impact on the opportunity and perceptions of opportunity girls is captured by other studies (e.g., Anyon, 1983; Borman, Mueninghoff, \& Piazza, 1988; Fordham, 1993). However these students complicate previous studies by suggesting that the interaction of their darker skin color with their gender constructs distinct experiences and perceptions, different from darker skinned boys and lighter skinned girls and boys. Additionally, their focus on positive self-outlook as an integral part of their commitment to the achievement ideology further solidifies this interaction of gender and skin color as informing their perceptions of opportunity.

These girls also articulated barriers, such as how others interpret skin color, gender, language, and names, as mitigating their opportunity. For instance, skin color or "darker complexion," minimal English skills, racial designation, not being a White female, having a Spanish surname and a female identity proved to be factors that these students perceived as being used to limit opportunity. Skin color was the dominant marker of race/ethnicity that these students discussed as limiting their opportunity. White skin color, which many of them did not have or were identified by others as not having, held value. Tara's response to 
the question of whether she perceived differences in opportunity between White women and Puerto Rican women, exemplified the students' interpretations that darker skin color is devalued by others. Tara stated, "Yeah, cause they're White. They look like business women and all sorts of stuff and lo blanco (Whites) they're all rich or whatever, so they get what they want." This perception of skin color as a barometer for making it was how these students considered race/ ethnicity as factors mitigating the making it process. In the following cases, we come to understand the nature of the gender and skin color conarrative that Maria and Beverly construct based on their own interpretations and experiences in the making it process.

According to Maria, White people have a better chance of making it than individuals with a darker complexion and minimal English skills. Even though she perceived that making it involved individual effort and having a positive self-outlook, skin color and language skills dictated the distribution of chance.

Interviewer: Who has the best chance of making it?

Maria: White people. Because this is the White man's world.

Interviewer: Who has the least chance of making it?

Maria: Non-Whites, have a tan or dark complexion and can't speak proper English.

When asked whether she considered herself as having the least chance, Maria stated she does not get the same chances because of her skin color. Additionally she did not perceive her Mexican/Latina peers as having a better chance of making it. Such an interpretation discloses that, because others situated her as Mexican/Hispanic-looking and her native language is Spanish, such factors limit her chances of making it. Part of why Maria perceived herself as having limited chances was also based on how she interpreted that her ethnic group "fits into" the United States binary paradigm of race. In response to questions about the distribution of advantage, Maria argued that the advantages not available to Puerto Ricans were related to how Blacks and Whites are unable to classify Puerto Ricans into a specific racial category.

Interviewer: Do you think that Puerto Ricans have more, less, or the same advantages as other groups?

Maria: I think we have less because the Puerto Ricans or Latinos, the White people see us as we're not White enough so forget you. And then the Black people say like, Well you're not dark enough, you're White just like them, so we go to...we're behind, in that we're trying to catch up to both of them. 
Maria's analysis of Puerto Ricans not fitting in raises very poignant issues regarding race/ethnicity, classification and the distribution of chance and the making it process. From her vantage point, racial classification is a hierarchical system with Whites holding the highest status because it is a "White man's world" while Blacks have a lower status because they are "non-White." This system, according to Maria, operates based on skin color and because Puerto Ricans like her who are identified by others as Mexican/Hispanic-looking fall outside the boundaries of such a paradigm, she receives fewer advantages than Whites and Blacks. Such a classification system, from Maria's interpretations, asserts that whatever group she is assigned to (or not) dictates the chances she receives and ultimately her ability to make it.

In addition to contending with such interplay, Maria also considered gender as dictating her making it process. Maria perceived her chances as limited because of how others view her gender along with her race/ ethnicity. She described a double-edged sword that operates in the making it process that minimizes the opportunity of women of color.

Interviewer: How do you think American society views you?

Maria: Being a woman and female, that's hard too. But being Puerto Rican, that's another thing, because I'm not also stereotyped by my gender, but also by being a minority. That means I have to do more than my regular performance. I have to do better, because I have to rise more.

Maria expressed that two social positions-Puerto Rican and female (or ethnicity and gender) - have a definite impact on how she views her opportunity. Her outlook on making it and chance operate from these two perspectives, not only by choice but also these were the two social positions she identified as others using to assign opportunity. Such a reality, she believed, mitigated the efficacy of individuals like her being able to actualize on the making it process and the distribution of chance.

Beverly also considered race/ethnicity as playing a dominant role in mobility. Beverly argued that her chances of making it were dictated by how others viewed her and subsequently stereotyped her ability to succeed. Beverly argued that her Spanish surname, along with what she circles as ethnicity when filling out information, is used to mitigate her opportunity.

Interviewer: How do you think American society views you?

Beverly: I don't think they think I'm going to make it. I don't believe that when I take the test, I believe that when they see my test or my name they don't expect me to score high, they expect me to be in 
that lowest percentile because of my last name, because of what circle I enter in the ethnicity. People out there are cruel people who do not want me to succeed, and they are willing to do anything to make one person fail.

Beverly believed the mobility structure is designed to purposely limit her chances of making it. The following narrative on the college admissions process is an example of how she perceived society stratified opportunity for people like her.

Interviewer: Are people equal in American society?

Beverly: Not everybody. If you are a college admissions officer and you get 20 applications and you're going through the applications and you see Detroit, Michigan, Southside, Bronx, New York and they'll see Bloomfields, Michigan or Chesterhill, what are you going to look at first? Before you even look at the qualifications before you even look at the recommendations and everything they have accomplished. You're going to look at where they came from. You're going to look how much they make a year, I mean what can they contribute to your college, they're going to look at in the long run.

Her example suggested that certain aspects of making it and the distribution of chance are not dictated by the individual but rather are coordinated by others perceptions of race/ethnicity and class. Although Beverly considered such perceptions as pervasive, she simultaneously thought that there is a specific determination towards making it that an individual must maintain because of such societal perceptions.

Interviewer: Do you agree or disagree that American society is a land of opportunity where everybody can get ahead and everybody gets everything they want out of life?

Beverly: I agree in some aspects but not all. I mean, I think everybody can get ahead, but it depends on how hard you're going to work for it because there always people who are going try and stop you. So it depends on your determination, but if you're coming here from another country and are going to look to our country to be able to make it better for themselves, they need to know that they need to go about it the right, If they going to come from Mexico, you shouldn't just start working in factory or construction, I mean people are coming from over there with Ph.D.s but don't speak English, they could go to college for a year and even a job in a hospital. But they're going to say 'I can't,' they're going to give up 
and work construction with their Ph.D., ten years of college and they're sitting there on the side of the road flagging down.

From Beverly's perspective everybody can get ahead, but the United States structure does not always allow for people to receive what they deserve. In order to contend with such a barrier, individuals like the Mexican doctors Beverly described need to exert a determination to succeed because the American dream of getting what you deserve out of life is not necessarily available for everyone. The dream is readily available for those with a wealthy background, from neighborhoods like Bloomfield Hills, with a United States education and the ability to speak English.

In sum, Maria and Beverly challenge the efficacy of the achievement ideology and the making it process by noting that the societal perceptions of low-income Mexican and Puerto Rican males and females mitigate the actualization of these groups being able to make it. That is, even though students like Beverly and Maria maintain an ideological commitment to what it takes to make it and how chance is distributed, they simultaneously construct a co-narrative of what it takes for someone like them to make it, and this conarrative is based on their racialized experiences as darker skinned females in and out of the classroom.

\section{SUMMARY}

The students' perceptions of making it and chance presented the various aspects of the achievement ideology they considered realistic, attainable, and resonated as something they believe in. Education resonated as the primary vehicle these students viewed as defining how to make it. However, these students also maintained co-narratives that in various ways expressed their lived experiences as White-looking, Mexican/ Hispanic-looking, and Black/Biracial-looking students. It was through such a discussion that we began to understand how these students reconcile their varying experiences as White-looking, Mexican/ Hispanic-looking, and Black/Biracial-looking within their perceptions of opportunity.

The co-narratives of the White-looking boys posed a relationship between gender and skin color that reflected in their explanation of social inequality and the inequitable distribution of opportunity. As Mexican and Puerto Rican boys living in a low-income neighborhood, they perceived the limited opportunity present in their neighborhood as the result of a limited educational background and their immigrant 
status. Further, they maintained that in order for individuals from their neighborhood to make it they needed to express a desire for and exert an effort towards making it. Race/ethnicity, from their vantage point, has not defined social outcomes. Such explanations of race/ethnicity as nonfactors are further complicated by their gender. Although they did not argue their gender as involved in this process, the absence of attention to gender suggests a relationship between gender and skin color. That is, within their social experiences as White-looking males, race/ethnicity may not have been organized or played a role in how they interpret opportunity.

The Mexican/Hispanic-looking and Black/Biracial-looking girls raised slightly different issues in their co-narratives of race/ethnicity. We came to understand from these girls that how they define themselves as Mexican and Puerto Rican females and how they perceive others situate their ethnicity and gender structured the ways in which they developed this co-narrative of opportunity. Maintaining a positive self-outlook mattered along with the individual effort they needed to engage the making it process. The self-outlook was significant because of the barriers they felt they needed to combat. To these girls, race/ethnicity and gender dictated making it and distribution of chance. As one girl stated, "it's a White man's worlds" and a positive selfoutlook is necessary to operate in such a world. Further, their opportunity to make was further complicated by the fact that they did not belong to the groups that they perceived as defining the structure of opportunity. And because they do not belong to those groups nor any other sanctioned racial category, like Black, their chance to make it is limited. Therefore, while they expressed a commitment to the achievement ideology, these girls maintained this co-narrative that explained how they perceived the making it process and the distribution of chance operating for them.

Overall, these findings suggest that the skin color and gender of these students has structured their experiences in and out of the classroom in ways that have influenced how they interpret their ability to actualize on the achievement ideology. This finding provides a backdrop for understanding the ways in which these students discuss their engagement and interpretation of schooling in the next chapter. 


\section{Chapter Six \\ Conceptualizing and Navigating the School Space}

Previous qualitative studies on academic variability argue that marginalized students' perceptions of the opportunity structure informs their academic orientations (e.g., Anyon, 1983; Fine, 1991; Foley, 1991; MacLeod, 1986; Mickelson, 1990; Ogbu, 1987; Suarez-Orozco \& Suarez-Orozco, 1995; Willis, 1977). Of course, not all marginalized students perceive opportunity in the same way, and numerous studies posit varying reasons for these differing perceptions in addition to their impact on student engagement in school (e.g., Flores-Gonzalez, 1999; Fordham, 1988; Fordham \& Ogbu, 1986; Hayes, 1992; Matute-Bianchi, 1986; Mickelson, 1990; O’Connor, 1997, 1999; Ogbu, 1987; Valenzuela, 1999). However, these studies operate on the assumption that identification is primarily a self-ascribed process, which presumes a commonality in experience and interpretation of the schooling experience.

The students in this book suggest such an assumption only illustrates part of the dynamic of racial/ethnic identification and its implications in their schooling experience. Marginalized students, like these Mexican and Puerto Rican students, experience racialization in which others situate them based on their skin color. The impact of such racialization moderated their articulation of opportunity as being available to everyone, but also how they conceptualized the significance of race/ ethnicity and gender followed along skin color and gender. In turn, this differential co-narrative of race/ethnicity underscored how these students discussed their academic orientation (i.e., the value and importance of school and engagement in school). What is illustrated throughout this chapter are the differences in experiences and interpretations of racialization (or lack of), and its significance to how and why they engage (or not) in the schooling process. How their African American peers and teachers read these students has significant implications in their academic orientation. 
Academic orientation is measured through various questions pertaining to the schooling process, including academic performance, educational and occupational aspirations, school engagement in curricular and extracurricular activities, attitudes towards school and its purpose, as well as how they perceived their school functions. These areas of academic orientation provided a rich landscape of how these students experienced and interpreted the schooling process. In looking at academic orientation from such a perspective, what emerged as salient was that academic performance across the phenotype groups was comparable. In fact, the majority of the students (15 out of 17 students) held average to above average GPAs (i.e., 2.5 to 3.8). ${ }^{1}$ Phenotype differences in educational and occupational aspirations also did not emerge. Students aspired to various degrees (i.e., diploma, bachelors, masters, doctorate, and juris doctorate) and a range of occupations, including white collar and/or professional occupations (e.g., doctor, lawyer) as well as blue collar/service industry occupations (i.e., police officer, military, construction) regardless of phenotype. However, phenotype differences emerged in the experiences they sustained in school as well as the ways in which they utilized such experiences to motivate and rationalize the purpose of school. Thus, this chapter argues that external interpretations of skin color do not have an apparent impact on aspirations and academic performance. However, the ways each phenotype group experienced school proved to moderate how they reasoned their motivation and engagement in school.

The chapter is divided into two sections. The first section attends to the similarities that emerged in the students' academic performance and aspirations. The second section focuses on their differential racialized experiences in school and their subsequent interpretations of these experiences as informing their orientation towards school.

\section{ACADEMIC PERFORMANCE AND ASPIRATIONS}

Performing well in school was a common belief among the students. Academic performance they perceived results in mobility. Additionally, the schooling process, in general, they perceived as providing benefits, such as mobility. They defined mobility as involving the opportunity to not work manual labor positions. Thus in order to discuss the students' academic performance, we must first contextualize it within the meaning and usefulness they attached to performance. For example, Don described mobility as being able to work with his brain, not his hands. He did not want to be employed as a factory worker like his 
father has been since they arrived in the United States from Puerto Rico in 1991. Don's parents' attitude towards school is for him to progress further than they did: "They say not to quit school because they don't want me to be like them and quit school in the 6th grade. They want me to do better." In fact, the importance he placed on his schooling was driven by his belief in working with his brain and his parents' desire for something better for him. In turn, he viewed a high school diploma as not providing as many benefits as a college education: "Like with a high school diploma you can not get the jobs that pay you better. With a college degree you can get better jobs." Don views a college education as providing that ultimate mobility of working with his brain.

Carola made a similar reference to blue collar work by stating that she does not want to have to work long days like those employed in a factory. This orientation defines the importance she places on education. Such importance also supported and/or defined by her parents focus on making sure she gets good grades; "If I bring home bad grades, they [parents] will ground me and tell me I have to do better, and if I don't they will try to help me find something so I could get a better grade in the class." Mobility also meant not having to work at Burger King flipping burgers for the rest of her life. Rather, it involved going to college, getting an education, and getting some type of white collar or professional employment. Such notions of mobility illustrated the importance these students placed on academic performance. That is, they perceived academic performance as the variable that would allow for many of them to be the first in their family to receive a college education and to not have to live in a low-income neighborhood. Therefore, academic performance was more than the grades the students achieved; it actually symbolized upward movement for themselves and in part their family.

Although they believed performing well in school results in mobility, such a belief did not translate to "good grades" for every student. For example, tenth grade students like Jeff and Keyla were the only students in the book with GPA's below 2.5. They achieved 1.2 and 1.8 GPAs respectively, but they maintained strong beliefs about schooling. On the other hand, the remainder of the students held GPAs above 2.5. Table 11 shows the distribution of GPAs among all the students.

Consistent with their mostly average to above average academic performance, the majority of students, regardless of skin color, maintained comparable aspirations for middle-class professions (see Table 11). Even though the White-looking, Mexican/Hispanic-looking and Black/Biracial-looking students differed in the efficacy with which they can actualize on the making it process, they similarly aspired to 
Table 11 Students' Achievement \& Aspirations

\begin{tabular}{|c|c|c|c|c|c|}
\hline & $\begin{array}{l}\text { Others } \\
\text { Identify as }\end{array}$ & $\begin{array}{c}\text { Self- } \\
\text { Identifies as }\end{array}$ & Grade & GPA & Aspirations \\
\hline Jeff & Arab & Mexican & 10th & 1.17 & $\begin{array}{c}\text { Police Officerl } \\
\text { Construction } \\
\text { Worker }\end{array}$ \\
\hline Alex & Black & Puerto Rican & 10 th & 3.00 & $\begin{array}{l}\text { Wrestler/Police } \\
\text { Officer }\end{array}$ \\
\hline Yami & Black and Mexican & Puerto Rican & $11 \mathrm{th}$ & 3.80 & Nurse \\
\hline Samantha & $\begin{array}{c}\text { Light-skin } \\
\text { Black/Arab/Indian }\end{array}$ & $\begin{array}{c}\text { Detroit-Rican \& } \\
\text { Puerto Rican }\end{array}$ & 12 th & 3.00 & Journalist \\
\hline Tara & Mexican & $\begin{array}{c}\text { Detroit-Rican \& } \\
\text { Boricua1 }\end{array}$ & 11 th & 2.80 & Pediatrician \\
\hline Maria & Mexican & Puerto Rican & $12 \mathrm{th}$ & 3.00 & Lawyer \\
\hline Beverly & Mexican & $\begin{array}{l}\text { Mexican-Puerto } \\
\text { Rican-Italian } \\
\text { and Boricua }\end{array}$ & $10 \mathrm{th}$ & 3.80 & Lawyer/Doctor \\
\hline Laura & Puerto Rican & Boricua & $12 \mathrm{th}$ & 2.80 & Military/lawyer \\
\hline Liv & Puerto Rican/Black & Puerto Rican & 11 th & 3.80 & Pediatrician \\
\hline Mellie & White & $\begin{array}{l}\text { Puerto Rican- } \\
\text { American }\end{array}$ & 10 th & 3.00 & Pediatrician \\
\hline Carola & White & Puerto Rican & 9th & 3.12 & Secretary \\
\hline John & White \& Mexican & $\begin{array}{c}\text { Mexican- } \\
\text { American-Italian }\end{array}$ & 11 th & 3.00 & $\begin{array}{l}\text { Aeronautical } \\
\text { Engineer }\end{array}$ \\
\hline Nori & White & Puerto Rican & 11 th & 2.80 & Lawyer/Teacher \\
\hline Keyla & White & $\begin{array}{c}\text { Mexican- } \\
\text { American-German }\end{array}$ & 10 th & 1.80 & Lawyer \\
\hline Paul & White & Chicano & $12 \mathrm{th}$ & 2.70 & $\begin{array}{l}\text { Mechanical } \\
\text { Engineer }\end{array}$ \\
\hline Edgard & White \& Mexican & Mexican & 10 th & 3.50 & $\begin{array}{l}\text { Track Coach' } \\
\text { Teacher }\end{array}$ \\
\hline Don & White \& Mexican & Puerto Rican & 10 th & 3.80 & Musician \\
\hline
\end{tabular}

attend college and even graduate school in the hopes of receiving masters, doctorate, medical, and/or law degrees. Many of the students wanted to be lawyers and doctors, while others desired to be teachers and police officers, and yet others desired professional athletic careers. These aspirations to them seemed attainable and for some of them stemmed from personal passions.

Keyla, with one of the lowest GPAs (1.8), desired to be a lawyer and believed she could because JROTC had helped her become more focused about school. Don, on the other side of the achievement 
spectrum, had a 3.8 GPA and aspired to be a musician. He grew up playing the congas and guitar and considered music his life passion. Maria aspired to be a lawyer, while Mellie and Liv both planned on becoming pediatricians. Both Mellie and Liv had taken this interest in pediatrics a step further and volunteered at a hospital and pediatrician's office. Edgard and Alex both aspired to enter professions that they currently find fascinating, track and wrestling. Edgard's interest in track stemmed from the support he received from his coach, who often took him fishing. Paul's aspiration to go to engineering school emerged from an eighth grade assembly where he met a mechanical engineer and realized what he wanted to be (during the pre-interview process he talked about applying to different engineering programs). Beverly could not decide between being a lawyer or doctor or even joining the military; she felt she had so many options, which could be attributed to her 3.8 GPA. Finally, Samantha spoke about her realization of wanting to be a journalist while working for her local church as the editor of the church newsletter. Each of their stories points to a desire for more and optimism towards the future.

The premise of discussing the academic performance and aspirations of these Mexican and Puerto Rican students was to provide a description of what they define their future to be, not to explain such renderings. Additionally, the premise for my discussing the students' aspirations was to demonstrate that, despite their differential perceptions of opportunity, these students expressed aspirations for something better. These aspirations also emerged in spite of their differential experiences of constraint and privilege. More specifically, the three phenotype groups differed in the kinds of things they reported happening in school as well as in their rendering of these experiences. In the following section, I explore the meaning making and interpretations they make regarding these differential experiences. The following discussion presents the dimensions of academic orientation moderated by external interpretations of skin color.

\section{SCHOOLING EXPERIENCES}

\section{White-looking students}

The White-looking students interpreted the making it process as guided by the educational process. Going to school, working hard and achieving good grades were the cornerstones to what they viewed as each individual's responsibility in the educational process. For many of them, that was how they explained their role in school and its utility in 
their lives. Some students looked forward to going to school with the hope of learning something new, while others viewed school as an opportunity to socialize. For example, Don considered the lunchroom as one of his favorite places to hang out with his friends. Simultaneously, he enjoyed the various teachers he had because, as he stated, "They're funny. They're interesting what they teach. Like, they teach in different ways to get your attention." Even though school meant different things for these students, they maintained a uniform perspective on the purpose of school, which was as a tool for mobility. Don perceived getting an education as enhancing his job prospects. This perspective of schooling not only coincided with how the students viewed the making it process, but also the overarching perspective they used to interpret their experiences in school.

Numerous questions posed to the students focused on their experiences in school. These questions focused on their perceptions of the importance of school, a typical day, whether discrimination occurs in school, likes and dislikes of school, perception of how opportunity is distributed in school, curricular and co-curricular activities, social groups in school, etc. The White-looking students' responses to many of the questions were typical of all the students in the book, but their discussions of opportunity in school and discrimination differed from the other phenotype groups. These White-looking students positioned school as a tool for mobility and performance defined by individual effort. Although many of the students recognized differential opportunity and discrimination, they maintained the belief that they effect their academic achievement through individual effort.

The discussion of external interpretations of skin color in chapter four alluded to school as an environment with various levels of racial tension and anxiety. The students' descriptions focused on what others were identifying them as and what that meant. However, these descriptions also involved whether the students viewed others' identification of them as having consequences and/or whether their own self-identification as Mexican, Chicano, Boricua, and Puerto Rican had consequences, such as discrimination. The students were asked whether they could recall experiences of discrimination. The majority of the students (5 out of 8 ) reported not experiencing discrimination. Paul, Carola, Nori, Edgard, and Don self-reported they did not recall experiences of discrimination. Part of why they held such a belief was because they defined discrimination as involving skin color: as Nori stated, "my skin color is not too dark." There were other signifiers that also defined discrimination, such as having Spanish names and/or speaking Spanish. However, the students perceived Spanish surnames 
and language as not part of mainstream perceptions of discrimination. Therefore, they did not perceive discrimination as happening to them. For those who did report experiencing discrimination, the discrimination they experienced involved the tension between African Americans, Mexicans, and Puerto Ricans in the school. Overall, although these students differed in their experiences of discrimination, they maintained their belief in school as a tool for mobility and as available to everyone who makes an effort. In the following discussion, I focus on the ways this interpretative viewpoint of school operated in their discussion of discrimination and opportunity.

Paul expressed an awareness of discrimination, even though he did not experience discrimination because of his skin color. Paul argued that if we follow a conventional definition of discrimination then it is not something he experiences; only when we included Spanish surnames does he suffer discrimination. Discrimination, according to Paul, occurs via external signifiers like skin color, but not signifiers like surnames and language.

Interviewer: Have your ever been discriminated against?

Paul: It's hard to say, because, like, for me to be discriminated against is kind of hard because people usually leave me alone. When you talking about discrimination you talking more about people coming up to you and bothering and following you because of your color and that's usually the discrimination we get today. The only discrimination I get is if they know my name or hear me speak and then they begin to judge me.

When asked about stereotypes held about Chicanos, Paul further delineated how he perceived skin color images were constructed and defined by others.

Interviewer: Do you think American society has stereotypes of Chicano?

Paul: Yeah I think they do. I think that White people have a stereotype for every race. When they think of Chicano they think gangbanger, they think illegal alien, they think of migrant workers, they think of drug dealers, they think of criminals-that's what they associate with Chicano. These people who steal, they think of us as criminals. If you ask someone about Colombianos they would say drug dealers and stuff. If you ask them about Mexicans they would say illegal aliens, criminals and that's about it. You assume Mexico with illegal aliens more than any other country in the world and so many other countries have illegal aliens.

Interviewer: Do you think that impacts how people interact with you? 
Paul: I would say for the most part my case not really. They would just, because I'm the type of person who would go up to someone and just like start...I'm not the type of person that fits that stereotype. I don't go out of my way to avoid it, but I just don't fit it. When people see me right away they don't think I'm Mexican, they think I'm White. They're more open with me, like if I were to conversate with a White person right now, I wasn't to say my name and they would start talking to me about Mexican culture. Yeah, the stereotype doesn't come to me, maybe if I was a dark-skin Mexican that most Mexican are then people would be scared of me or think of me as a criminal.

Paul argued that stereotypes of Mexicans and Colombianos exist in American society and these stereotyped groups are identified via skin color. In other words White-looking students, like Paul, do not experience discrimination nor are stereotyped similarly to other Mexicans because their skin color does not coincide with assumed images of Mexicans. They do not have people following them or making judgments about their skin color. Even though Paul personally had not experienced discrimination based on skin color, he maintained the belief that discrimination does occur, and it involves others making judgments about an individual. In his school, he perceived such judgments occurring in the hallways and in the classroom. These judgments that he perceived teachers making about Mexican students like him sometimes resulted in academic inequity.

Interviewer: Do you think that lighter skin students get better, same, or worse treatment than the darker skin students?

Paul: Yeah...[B]ut also in the classroom say, maybe they'll expect less, I mean, I really want a teacher that would challenge a [Latino] student to his potential, who will give me the same challenge as a White or Black person and will say, 'I believe in you, you can do it.' I want to compete. I want to write about stuff that is at the Harvard level.

From Paul's perspective, these judgments of Latino students' ability had an impact on the opportunity to receive challenging teachers. However, these judgments did not necessarily have such an impact on Paul. As a senior in high school, Paul was enrolled in pre-calculus and physics courses that he felt were important for him to get into a good mechanical engineering program. Though Paul maintained an interpretation of the classroom as not necessarily challenging, his academic achievement and course assignment did not coincide with the discrimination he perceived 
as happening to Latino students. As mentioned earlier in the chapter, Paul aspired to become a mechanical engineer and, thus, for him school was vitally important; "I think that it's very important, especially the point that I'm at where I will graduate soon. And I know that is not good enough even though I'm a minority. That's great, you graduated from college. But you're not going to get anywhere with a piece of paper. I need to keep getting educated in order to become successful." Therefore his academic trajectory and orientation towards schools did not necessarily signal that he was not challenged but rather his desire to be challenged at a "Harvard level" symbolizes his own academic expectation.

Part of Paul's schooling experience could be attributed to how others situated him as a White-looking Mexican, which subsequently means he did not experience discrimination of opportunity like other darker skin Mexicans. Paul experienced others assuming he was White and engaging him from that perspective. Such labeling in these predominantly African American high schools meant he was left alone by students and not ignored by teachers unlike the Mexican/Hispaniclooking and Black/Biracial-looking students. Therefore, what is important to understand from Paul's narrative is that skin color moderates some of the ways they experience school and subsequently affects the orientation they have towards school. Such a relationship also emerged among those few White-looking students who reported experiencing discrimination.

In response to whether they had ever been discriminated against, Keyla, John, and Mellie described experiences in which they felt African Americans treated them unfairly. In each of these students' descriptions each incidence of discrimination against them occurred due to their racial/ethnic group affiliation not necessarily skin color. However it could be argued that how they conceptualize others discriminating against their racial/ethnic group affiliation involves skin color designation. It is unclear from their discussion how identification was conducted; however, they do point to the discrimination as partly attributable to intra and inter-ethnic conflicts between African American, Mexicans, and Puerto Ricans.

When Keyla was in middle school, she had a violent encounter with a teacher.

Interviewer: Have you ever been discriminated against?

Keyla: Yeah, at middle school our teachers were Black, our principal was Black, we had maybe seven White or Mexican teachers and every time I got into a fight with a Black girl, she started it, the principal 
seen it [but] I got suspended for a week, she got to stay in school. Also I fought with a teacher and she told me to take my borderhopping butt back to Mexico. And I told her she needs to go back to Africa 'cause nobody wants you here. And then she called me the B word and I said it back to her. And there were other Black teachers and they are not stopping it, and then she pushed me into my locker and one of the Black teachers who is nice to me, she said, 'just get your stuff and go home.' And then the teacher I was fighting with said, 'you better not be talking about me little girl,' and I said, 'what if I am?' And then she tried to hit me, but I hit her first, and pushed her down. And so then the other teachers grabbed me and I was kicked out of that middle school.

Keyla's interpretation of these various experiences rests on the assumption that because school was primarily African American, as a Mexican she would always be a target. What she expressed as learning from that experience is that, if you are not African American, you will not receive fair treatment in that school. However, this belief was specific to her middle school because she did not express that about her high school. In fact, Keyla described her high school as a place she likes being because of her friends and ROTC. What she found challenging about school is waking up early. Unlike her middle school, Keyla felt that her high school teachers thought of her as a good student, and she stated, "It makes me feel proud that everybody looks at me that way." This greatly differs from her previous school where she perceived that others thought that she did not like Black students. She perceived her high school teachers as treating all students, including her, the same. Keyla stated, "No, they treat me based on who I am." This sense of fair treatment in school supported her belief in school as providing her better opportunities than other Mexican girls.

Although Keyla maintained such a firm belief in going to school, individual responsibility, and hard work, she did not perform at a level that would ensure her being able to get into the college or even the law school she wanted to go to. By her sophomore year, Keyla had a 1.8 GPA. She explained her low performance as due to her inability to complete and turn in homework assignments. However, this did not deter her from viewing school as the most important thing in her life. What Keyla's story presented was that the way in which she interpreted incidents of discrimination as non-systemic of the school environment suggests that schooling is not inherently stratified by ethnic/racial affiliation or skin color.

In sum, these White-looking students, although cognizant that discrimination occurs and differences in the distribution of opportunity 
may exist for Mexicans and Puerto Ricans like them, they did not relinquish the notion of school as open and available to those who put forth effort. These students likely maintained such an orientation because their experiences in school as White-looking Mexicans and Puerto Ricans rarely involve them being challenged by discriminatory practices. Instead, school was about putting forth individual effort and studying a lot for an end result of academic success and mobility. In the following section, the Mexican/Hispanic-looking and Black/Biraciallooking present a differing academic orientation that stems from their experiences of discrimination and opportunity.

\section{Mexican/hispanic-looking and black/biracial- looking students}

Schooling was also an important component of the Mexican/Hispaniclooking and Black/Biracial-looking students' lives. Many viewed getting an education as the means to becoming a lawyer, doctor, or pediatrician. However, their rationale as to why they needed to achieve such goals operated on the experiences they had around discrimination and opportunity in school. Similar to the White-looking students, these students also thought it important to be engaged in school, but their engagement did not always result in equitable rewards or opportunity. Instead, these students reported experiences in which teachers treated them as invisible members of the classroom while African American students received better treatment, and administrators made stereotypical comments about Mexicans and Puerto Ricans. They believed that their skin color was the basis of this mis-treatment and the lack of opportunity they received from teachers. Surprisingly, however, they interpreted these experiences of discrimination as reasons for continuing with school and placing value on its utility. That is, they described schooling as an ethnic and familial cause in which they needed to engage in order to ensure that they were not viewed as "another uneducated Hispanic" or another person in the family who dropped out of school.

Such an interpretation of schooling suggests that although they experience others cataloguing them into discrete categories like Hispanic and Black, and perceive opportunity structured along racial and gender lines, Mexican/Hispanic-looking and Black/Biracial-looking students interpret such conditions as the reason for continuing and believing in school. Their rationalizations varied slightly based on whether they were situated as Mexican/Hispanic-looking or Black/ Biracial-looking. Overall, they gathered around a similar orientation of school as a tool to help them be mobile for their ethnic group and 
family. Recent scholarship has captured such a phenomenon and theorized that, at times, oppression and/or acknowledgment of oppression, racism and discrimination can generate resilient personas and a cultural capital for success (O'Connor, 1997, 1999; Trueba, 2002). Further, Trueba argues that resiliency and the cultural capital of Latinos who speak both English and Spanish "create the psychological flexibility necessary to assume different identities in order to survive" (p. 8). Therefore, in the following cases, we are able to envision the process of students contending with their teachers' discrimination and racism which involves them assuming not only different identities (Hispanic and Black) but also a resilient persona in order to reconcile their experiences of constraint.

The Mexican/Hispanic-looking and Black/Biracial-looking students experienced discrimination based on their ethnicity and skin color. This discrimination received support through a hierarchical system of privileging the dominant racial/ethnic group and skin color at the school. In other words, these students perceived each ethnic group in the school as receiving certain privileges (or not) from teachers and administrators based on whether they were Black or not. Depending on who explained it, either Mexicans or Puerto Ricans received the worst treatment from teachers and administrators; Whites were barely noticed, and African Americans received the most favorable treatment regardless of the schooling context. According to the students, this system stems from inter-ethnic conflict that was present among the students and a disconnect the teachers felt towards the Mexican and Puerto Rican students. Although these students did not agree on who received the worse treatment, it was apparent from their accounts that those who looked "Hispanic" experienced the worst or most severe mistreatment from African American teachers and students.

Maria's experiences in being situated as Mexican/Hispanic-looking were part of her day-to-day dealings in school. So much so that she maintained a consciousness that she needed to assert her identification as Puerto Rican in order to not be deemed an "oreo" and to remind others that she is Puerto Rican. However, regardless whether she asserted her identification or was situated as Mexican/Hispanic-looking, Maria perceived that because she was not Black she would not receive favorable treatment.

Interviewer: Do you think that at your schools the lighter skin students get better, same, or worse treatment than the darker skin students?

Maria: Actually, the thing is, in my school, the majority of the school is all Black. More than $90 \%$ is Black students, and the teachers are all 
Black too, they give more of a preference to the Black students. And to the White students, um, a little, but to the Hispanic students, it's just, like, no, whatever.

Interviewer: What do you dislike about school?

Maria: Teachers. They like to stereotype over there and they do show favoritism. That bothers me, when they start. People say, oh, 'She's from Southwest...she's a little thug girl.' That gets me mad. Oh, and the other thing, I don't like it that they don't celebrate anything Latino. It's all about African Americans. And when I'm in class, it's like being Black is this, and being Black, and they just, like, forget about anyone who's not Black. But you get used to it. By senior year, you just go with the flow.

The favoritism of African American students is juxtaposed with Puerto Ricans being situated into categories like "Southwest thug girl" and made invisible by overlooking Puerto Rican culture within the school context. From such experiences, Maria has developed the psychological flexibility to know to just go with the flow as a Mexican/Hispaniclooking student. Such resiliency has, in part, allowed for her to attain a 3.0 GPA in a school where she does not feel affirmed as a Puerto Rican or comfortable demonstrating her racial/ethnic affiliation.

These experiences of discrimination, as Maria described above, rest on certain stereotypes of Puerto Ricans. In addition, others maintained images of Hispanic as code for Mexican.

Interviewer: Can you think of time when someone has assumed you from another race or ethnic group?

Maria: Yeah, you know, like, Black people do it too, they see a Hispanic person, 'oh you're Mexican,' that's first thing, like, they ask, 'can you speak Mexican?' I be like, 'what?'

Interviwer: Speak Mexican?

Maria: Yeah, that cracks me up I just come back with, 'oh yeah, well do you speak Jamaican?'

These stereotypes sometimes were the first things others assumed about her ethnicity, which at times led to assumptions about her intellect.

Interviewer: Do you think that people judge you based on your skin color?

Maria: If you just look at me, they judge by saying I'm Mexican, 'she don't know about this and that,' but once people get to know me, they're all like, 'yeah, Maria, you're the bomb, come do this.' 
Such experiences of discrimination and stereotyping were a continuous element of the schooling experiences of the Mexican/Hispanic-looking and Black/Biracial-looking students. How their African American peers and teachers situated them was the basis of their experiences of discrimination and stereotyping. Current research on school environment and responsiveness to culturally diverse groups asserts that ethnic minority students have difficulty engaging in school when they feel school personnel discriminate against their own ethnic group (Davidson, 1999). Students like Maria often discussed feeling somewhat separate from the majority group in the school because she was not African American. However, many of these students placed a high importance on school not only for its value towards providing mobility but also in its impact on stereotyped images and the ability to breakthrough barriers. The latter issue emerged as a prevalent explanation as to why schooling was important to these students. Their renderings of how and why schooling is important illustrated the way in which these students utilized experiences of discrimination to develop a resilient persona.

Interviewer: How important is being in school to your life right now?

Maria: Very important, because if I don't, I don't want to be, like, a statistic, like, another Hispanic didn't go to school. I don't want to be another housewife. I got to break the tide - somebody got to do it.

School was also important for Maria because of her family's beliefs. Maria wanted to break the mold of her mother's belief that Hispanics are limited in how far they can go.

Interviewer: What kind of attitudes do your parents have about education?

Maria: She wants me to finish high school. She doesn't want me to drop out or anything like that. It took her a while to graduate so... She still wants me to graduate. She wants me to at least finish high school. It's like, high school is, like, the top level that Hispanics see. Like, yeah, high school you're out.

As a senior at Crestwood, Maria has focused her energies on graduating and going to college and some day becoming a lawyer. As noted earlier, Maria was keenly aware that she had to work a little harder in school in order to receive the same opportunity as the African American students or even to get attention from her teachers. Even though Maria named several teachers she felt listened to her and encouraged her school 
work, that was not the norm. Maria stated that sometimes teachers would think of her as a gangbanger because of the neighborhood she was from. Even with such a difficult educational environment, Maria had achieved a 3.0 GPA by her senior year. Part of her ability to achieve such an above average GPA has to do with her resolve that as a Puerto Rican she refused to be another statistic. Instead she'd rather challenge the stereotypes and assumptions her peers and some teachers placed upon her.

Some of the discrimination the students described they perceived as part of their daily routine in school. Maria discussed the circumstances of the school (i.e., population) and the stereotypes that led to feeling discrimination in the school. On the other hand, Beverly discussed how these stereotypes manifested themselves in the classroom and impacted academic performance. Beverly, as a tenth grader, had only been at Westwood for a year and several months, but during that time she had had various encounters with teachers that she perceived as minimizing her opportunity. This limited opportunity has not necessarily had an impact on her 3.8 GPA but more on how she views her engagement in school.

Interviewer: Have you ever been discriminated against?

Beverly: I feel as if I am discriminated against in school. It's mostly an African American population, and I was in student government last year, and this year also, and it seems as if, to me, I wouldn't get notification of meetings if I didn't go up to the teacher or the person advisor and ask for it. If I wasn't right behind her, its like I wasn't even there, it's always the Black kids, the Black kids this, the Black kids that. So I had to stay on top it, but there was this, it wasn't against me, but it was a comment that was worded very ugly, and it was taken as racist. In my algebra class my teacher was absent, and the department head was filling in. She was so happy, she's an African American woman, and she was so happy that she had just hired a teacher and this one girl asked her is she Black and she said of course.

Interviewer: What did you get from that?

Beverly: There is only two Hispanic kids in my first hour in my algebra class and we just looked at each other and we knew that was not right. She standing right in front of me and she says of course she's Black, like of course the person has to be Black. Like there is no other way to go.

Beverly's argument was that the interests of the chair of the department did not coincide with her desire for a Latino teacher. And the teacher's 
comfort in proclaiming "of course it's a Black teacher" further demonstrated to Beverly that her needs were invisible within this context. Such indifference Beverly noted as shaping the grades she received.

Interviewer: Teachers often have ideas about their students, how do you think teachers see you?

Beverly: In some of my classes there are a lot of students so we don't get to have that much perspective of the kids, but biology teacher 'cause I got my progress report three days ago, and my mom called the second she got it, because I got a B+, and it said my study habits can be improved. So my mom says the least thing, what are we doing wrong, what can we do better? So Ms. Little, my biology teacher, she knows that now I know that she sees me in a different light now. Cause she, when she works, it's mostly with the Black students, so its like she doesn't travel over to our neck of the woods. So mostly she doesn't speak to us [Latinos], maybe if we're speaking to her, she'll smile or laugh but not really come over and interact with us.

Beverly was not only outspoken about receiving an unfair grade, but she also did not tolerate other people judging her based on her skin color, especially when some of these judgments were based on assumptions about her language abilities.

Interviewer: Do you think that people judge based on skin color?

Beverly: I do think sometimes. They see me in class, they probably right away those new teachers wouldn't even think I knew English. And they would be very surprised if they learned I had a 4.0 average. I think some people think that oh you know don't even worry about that, they'll look over it. I'm not quiet, I'm not going to let them just get away with that.

Challenging such assumptions and stereotypes defined some of Beverly's views of schooling as important. As a tenth grader with a 3.8 GPA, her aspiration to be a doctor or lawyer was not only about her own dreams, but she also wanted to demonstrate that Latinos were upwardly mobile.

Interviewer: Do you think there are benefits to having a higher degree?

Beverly: I think in the long run people are going to look at the letters after your name. They are going to want to see the doctor, the Ph.D., the B.A. or whatever. That's what they are going to look at. So that for me to do anything in life so I am positive and make a dent in this 
barrier that is blocking us, you have to have that education for them to even consider it because you are just another person who's trying and is going to fail.

Interviewer: What barrier are you talking about?

Beverly: I think people, they don't want us to succeed, so when they see us succeed its like what are they doing wrong...for us to like move forward, it's like you have this one person who I don't even have to know that but I can read about them in the news paper its like yeah. They're doing it. That's what I want to do.

Beverly's story further solidified the complexity of how these students interpret the purpose of schooling. Instead of circumscribing their aspirations and expectations based on limited opportunity in school, as various ethnographies note occurring with low-income students (e.g., Hollingshead, 1975; MacLeod, 1986; Willis, 1977), these students assert a resilient persona. They utilize their perceptions of limited educational opportunity in school and the making it process as motivation and rationale for engaging in and interpreting school as a purposeful endeavor.

The Black/Biracial-looking students also reported experiencing discrimination. However, they additionally reported experiencing a dual life of discrimination and social acceptance. That is, while they perceived themselves as being discriminated against, they also recognized that African American students treated them as part of their ethnic minority community. It was not an acceptance resulting in better treatment in the classroom, but it suggested the possibly that these students had better social relations with African American students than other Mexican and Puerto Rican students who did not look like they had "Black in them." Furthermore, the absence of such a discussion from the Mexican students underscored the significance of skin color as a tool of social acceptance within this predominantly African American context.

Liv experienced discrimination that was similar to Maria and Beverly. Liv reported that her African American peers made stereotyping comments about Puerto Ricans that sometimes referenced her.

Interviewer: Have you ever been discriminated against?

Liv: Yeah.

Interviewer: What kinds of things have happened to you?

Liv: Whites, or somebody that's not Puerto Rican, they be like, 'oh that

Puerto Rican girl, you know they are lazy.' Or they be like, 'you're

Puerto Rican right?' They always talk bad about Puerto Ricans.

Interviewer: How do they talk bad about Puerto Ricans? 
Liv: Like, they talk about people, like people being rude, they be like, 'oh, Puerto Ricans are always rude and they always loud.' They always say stuff like that.

Interviewer: Do you think people judge you based on skin color?

Liv: Yeah.

Interviewer: In what way do you think they judge you?

Liv: They always like, 'oh there goes that loud girl.' Because me being Puerto Rican, not because I'm Puerto Rican, but I just don't take nothing from nobody. If they got to say something, say it my face, if I got to say something I'll say it flat out. I don't like people talking behind my back. So they do...they be like, 'oh yeah, there goes that blonde.' They call me blunt girl. They say I say things flat out. I don't care if they are bigger than me and they'll beat me up.

However, Liv also experienced social acceptance from her African American peers, which Maria and Beverly did not. This social acceptance occurred because her peers viewed her as having "some Black in her." Thus, there was a level of social acceptance based on her darker skin color that may have allowed her not to experience the degree of discrimination Maria and Beverly dealt with.

Interviewer: Do other students treat you differently based on your racial/ ethnic background?

Liv: No, it depends on who is the student. Like, if it's a Mexican, they be talking behind your back, most of them, not all of them. And if it's like a Black, they just get along with us you know 'cause Puerto Ricans have like all kinds of races in them, they have Black in them you know. They be like, 'oh there's my Puerto Rican girl.' And White, they just be, like, they don't really say nothing.

Although Liv did not view herself as being treated differently or even discriminated against by her African American peers, this did not mean that she received similar preferential treatment as her African American peers. She understood that she was not part of the privileged group, but rather more of an ally, which is why she distinguished that the Black students received first choice.

Interviewer: Do you think that in your school students who are lighter skin get better, same, or worse treatment than darker skin students?

Liv: It's like, the darker students are better. Like, mostly this whole school is, like, Black, and they get the first choice always. 
This social acceptance from her African American peers did not translate to better treatment from her teachers and school administrators. Liv, like many of the Mexican/Hispanic-looking and Black/Biracial-looking students, recognized that having "some Black in you" does not equal bountiful opportunity in a predominantly African American context. Teachers and administrators, from Liv's viewpoint, made ethnic and racial distinctions between African American and nonAfrican American students. Such distinctions were the things Liv disliked about school.

Interviewer: What do you dislike about school?

Liv: A lot of things. The racism, the nastiness, the food when I have lunch, the overflowing toilets, and that they never have toilet paper, the teachers, sometimes they are racist. I don't really have a problem with kids being racist, but the principal, Carmen Strom (pseudonym), she is racist. And the secretary, she is racist. I haven't seen her talk to anybody else other than a Black person. And when you ask her something she busts out with the attitude, just out of nowhere. A lot of teachers are racist there, and it's mostly the Black teachers - they are racist.

This differential treatment Liv also recalled occurring in her classroom and having an impact on her grade in the class.

Interviewer: Do you feel comfortable talking to your teachers?

Liv: Yeah, whenever I have problems I tell them. Like the other day I got a $\mathrm{C}$ in Global Issues, and I'm not a $\mathrm{C}$ person, so I went up to him, I was like, 'why did I get a C? Explain to me, because I want to make it up.' And he said, 'don't argue with me,' I'm like, 'I'm not arguing, I just want to know why I got a C. You marked nothing wrong.' and he made a big ol' $\mathrm{X}$ on 5 problems, and I'm like, 'are they all wrong? He's like, 'no, just something of them,' and I'm like, 'why did you mark them all wrong?' He was like, 'just cause, go sit down,' and I'm like, 'no, 'cause I want to get an A in this class, and I need to know what I need to improve, what do I need to do so I can get my grade?' And he was like, 'don't worry about it.' So I brought my mom in, and she went up there and he was like, 'no, she's doing fine.' And he told her all this mess that he didn't tell me. He tells her that I'm a very good student, but in class he's always telling me Liv do this, do that, don't do this or that.

Although Liv experienced some level of social acceptance with her African American peers because they felt she had "some Black in her," 
this did not translate to positive interactions with teachers and administrators. Instead, Black/Biracial-looking students, like Liv, faced some teachers and administrators who dictated the academic outcome of Latino students by ignoring them or giving them lower grades. Such a hostile environment would be difficult for any Latino student to prevail against, but students like Maria, Beverly and Liv expressed the importance of schooling because of what it would do to relinquish them from such situations.

The discrimination that teachers and administrators made towards Liv did not minimize her aspiration to become a doctor. Instead, Liv viewed graduating from high school and going to college as important to her family and enabling her to circumvent experiences of discrimination. As an eleventh grade student with a 3.8 GPA and a member of the National Honor Society (NHS), becoming a doctor seemed realistic to Liv.

Interviewer: Do you think there are benefits to having a higher degree?

Liv: Yeah, there are a lot of benefits

Interviewer: What kind of benefits?

Liv: Oh, I don't know.

Interviewer: For example, what kind of benefits do you think you are going to get by being a doctor? What kind of benefits do you think a person would have if they don't go to medical school?

Liv: Somebody who doesn't go to medical school, they not going to have the more opportunities I'm going to have. You know, I'm going to have a lot of chances of going to get a job and easy job because that they need it. And somebody who didn't go to college, they're going to be out there in a little town.

Liv's story illustrates that while she experienced a dual life of social acceptance and discrimination, her interpretation of school, as an important tool for her family's mobility and disrupting stereotypes, allowed for her to utilize such experiences of discrimination as further reasoning for continuing with school.

In sum, the differences in experiences and perceptions between the White-looking, Mexican/Hispanic-looking and Black/Biracial-looking students illustrates that the school environment operates differently for each group, and subsequently they interpret it differently and maintain distinct orientations as to why it is important to their future. While experiencing differential treatment and opportunity, these Mexican/ Hispanic-looking and Black/Biracial-looking students valued education and the schooling process for the mobility that it could bring them, their families, and the symbolism of being a Mexican or Puerto Rican with an education. They felt the need to "represent" for their ethnic group and 
family by achieving academically and having economic success. As one student stated, she did not want to be another Hispanic that does not succeed nor another member in the family without a high school or college education. Education has a familial and ethnic/political significance to these students. They perceived that whatever they decided to do with their life, education was the key variable that could minimize the social barriers they perceived exists for Latinos/as.

\section{SUMMARY}

The academic orientation of these students emerged from various axes of experience, including reported parental influence, engagement in school, racial discrimination by administrators and teachers, and limited academic opportunity in the classroom for those that look Mexican/ Hispanic or "some Black in them." Although the students maintained differing experiences, they each rallied around the notion of education and schooling as important to their occupational aspirations and, for most of the students, such an orientation coincided with average to above average academic performance. However, though these students articulated similar orientations of education and schooling, how they construct such an orientation matters in understanding the role skin color plays in the school environment. Each phenotype grouping proved the ways in which they perceived others situated them racially and ethnically, and their subsequent experiences in and out of the classroom, moderated the meaning and interpretation they made of education and the schooling environment.

The White-looking students proved to have varying experiences of discrimination in school, but they maintained a perspective of school as an institution which operates on a reward system of objective markers (i.e., individual effort, ability, interest in school). Some reported experiences of discrimination in which African American teachers and students made remarks to them or had physical altercations fueled by the students' Mexican and Puerto Rican affiliation. While other Whitelooking students did not experience discrimination, they recognized its existence. Even understanding that their schools contain discriminatory practices that they experience or recognize happening, they perceived the utility of schooling as a tool for mobility in which students earn their grades based on effort and ability. These students did not articulate school as an environment that maintained pervasive discriminatory practices that minimized the achievement and opportunity of Mexican and Puerto Rican students. Instead, they perceived education and the schooling process as focused on providing students who demonstrate 
effort by "studying a lot," trying hard, and participating in classroom discussions with the academic achievement and opportunity they deserve.

The Mexican/Hispanic-looking and Black/Biracial-looking students also considered education as an endeavor in which individuals need to show effort and a desire to learn. However, based on their experiences of racial discrimination in and out of the classroom, they constructed a different viewpoint of the schooling process which in some ways informed their notion of education. These students perceived their school environment as limiting opportunity and purposefully mistreating individuals like them based on skin color and ethnic affiliation. Unlike the White-looking students, these students felt that African American teachers treated them differently in the classroom by ignoring them, giving them grades and progress notes that some students felt were unfounded, and in one instance minimizing their participation in student government activities. In addition, these students felt that the administration also participated in the discrimination by refusing to have interaction with Mexican and Puerto Rican students. Even though these students felt that such discrimination was operating in various aspects of the school environment, they maintained a positive orientation towards education. Their orientation towards education as an important accomplishment stemmed from their experiences of discrimination and their desire to be the first to go to college. That is, education was important because they needed to disprove the stereotypes that were the basis of discrimination and to demonstrate to themselves and their family that Latinos are able to make it.

The differences between the groups center on the experiences and interpretations they made about their school environment. The Whitelooking students expressed an awareness of discrimination, but not as a pervasive mechanism that minimized their academic achievement and opportunity within school. On the other hand, the Mexican/Hispaniclooking and Black/Biracial-looking students considered discrimination as focused towards them because of their ethnic affiliation. Additionally, the fact that the Black/Biracial-looking students reported greater social acceptance on the part of their African American peers did not mitigate their reported accounts of discrimination in school. Instead, similar to Mexican/Hispanic-looking students it was the mistreatment they experienced in school that informed, in part, the logic by which they 
engaged in school. Such a difference between the phenotype groups establishes that the ways in which these students perceived that others situated them racially and ethnically informed how they interpreted and experienced the school environment and reasoned the utility of schooling. 
128 SKIN COLOR AND IDENTITY FORMATION 


\section{Chapter Seven \\ Toward an Understanding of the Educational Implications of Skin Color Variation}

The story of this book is one of complexity. This complexity involves three constructs - external interpretations of skin color and identification, perceptions of opportunity, and academic orientationwhich interact to introduce, on the one hand, complex explanations and, on the other, layers of additional questions. These explanations and layers of complexity arise from the five main questions, which guided this book: 1) How do Mexican and Puerto Rican students of different phenotype construct their ethnic identification? 2) How do these students perceive that others identify them? 3) Do these identifications coincide (or not) with the students' identification? 4) Are the students' perceptions of opportunity a function of how they self-identify or how they perceive others identify them? and 5) Does the students selfidentification, external identification, and/or perceptions of opportunity inform their academic orientation? In this chapter, I provide an overarching discussion of the complexities which emerged in answer to these five guiding questions as well as the theoretical arenas to which they relate.

This book proposes several theoretical expansions about how we think about Latinos and their educational process. Previous discussion on the education of Latino/a students - which include academic achievement, immigrant adaptation process, language adaptation and acquisition, and ethnic identification - explain such phenomenon with the assumption that uniformity exists within national Latino/a groups and across these groups. However, such assumptions operate with an unspoken understanding that each national Latino/a group has a unique experience within the United States that is common among all group members. However, several studies of national Latino/a groups assert that that is not necessarily accurate. These studies illustrate that within national Latino/a groups, such as Mexicans and Puerto Ricans, how skin color is perceived has a relational impact on educational attainment as well as on the identification they select (e.g., Murguia \& Telles, 1996; 
Rodriguez, 1992, 2000; Rodriguez \& Cordero-Guzman, 1992). These studies not only substantiate the need to explore variation within national Latino/a groups but also the significance of this book in exploring skin color and its moderating affect on experiences of opportunity, mobility, and academic orientation. This book interjects skin color as a guiding mechanism in how these Mexican and Puerto Rican students perceive the opportunity available to them and others like them, and aspects of their academic orientation. In other words, how the students perceive others situating their skin color moderates how they conceptualize opportunity and mobility for themselves, as well as informs, in part, their orientation towards education and the schooling process. Thus, assumptions of uniformity overlook the significant impact of skin color variation among Latinos.

The other major discussion this book engages is the role and meaning of skin color in racial/ethnic identification. Within the United States context, race/ethnicity is primarily situated based on skin color. Categories such as White, Black and, in the last 30 years, Hispanic operate with specific perceived notions of who fills those identifications (Omi \& Winant, 1994; Rodriguez, 2000). With that said, identification involves not only self-identification but also what many scholars define as the notions of race/ethnicity and subsequent expectations others maintain (e.g., Bashi, 1998; Hall, 1990; Hall \& du Gray, 1996; Nagel, 1994). The process of identification is a negotiation not only of whose identification or labeling has more power but also centers on the interaction between two actors - the individual and external agentsand how they individually and together outline the variables that define ethnic/racial identification. Stuart Hall (1990, 1996), in labeling skin color as a "floating signifier" of race/ethnicity, offers a useful analytical example to understanding how this interaction between actors occurs. Hall argues that the genetic definitions of race appear in everyday interactions/discourses. For example, the Census 2000 asserted a genetic definition through its distinguishing of national Latino groups from identifications such as Black, White, Asian/Pacific Islander, and Native American. The census form required a national identification as well as a racial (or genetic) identification in which Black and White did not include the phrase "Black/White, not of Hispanic descent" [See Appendix E]. Such separation exemplifies a significant movement in how we recognize or label race and national identification among Latino groups. More importantly, in the context of this book, the census example provides a nation-state approach and designation of skin color as a signifier of racial identification. In sum, these two areas of thought, the education of Latinos and meaning of racial/ethnic identification are 
necessary to consider as we re-capture some of the major findings of this book.

\section{SELF-IDENTIFICATION AND EXTERNAL AGENTS}

Identification and culture are critical mechanisms of how individuals think of themselves and how these shifts in turn guide their lives in various ways (e.g., Baumann, 1996; Calhoun, 1995; Cornell, 1988; Davidson, 1996; Erickson, 1987; Espiritu, 1992; Flores-González, 1999; Gibson \& Ogbu, 1991; Gutierrez, 1995; Hall, 1990; Hall \& du Gray, 1996; Lee, 1994; Matute-Bianchi, 1986; Nagel, 1986, 1994; O'Connor, 1997, 1999; Ogbu, 1987). However, much of this discussion centers on identification and culture as end products. The focus of this book was to capture the complexity and meaning making that has been absent in considerations of identification and explore it as a continuous process of adding and subtracting relevant attributes. The students' selfidentification emerged as a function of their immigrant generation, as well as their own interpretation of what matters to identification. They presented varying identifications that coalesced around three forms of identification: 1) hyphenated, 2) ancestral/national, and 3) cultural identification. Although the three identifications were not mutually exclusive, the students did express usage of one over the other, which suggests that the meaning and interpretations of that identification operated as the construct of how they viewed themselves most often. For example, the students who utilized a hyphenated identification defined themselves primarily by the differing locales and ethnicities the hyphen embodied. Such identification can be attributed to their third generation status. In other words, they viewed themselves as bridging borders between differing locales and ethnicities, a trait, which is generally found among third generation immigrants who are making meaning from (re)constructed homeland in the U.S. and a newly constructed representation of homeland made in the U.S. However, such hyphenating also involved competing ways of knowing. More specifically, some students consciously hyphenated their Mexican or Puerto Rican identification with an American identification, which among the collective Latino group is an assimilated identification. That is, such hyphenation was considered as a form of assimilation among their Latino peers because it implied an affiliation with Whites. ${ }^{1}$ Thus, this hyphenated identification represented a merging of differing, and at times competing, racial/ethnic locales. 
Ancestral/national identification, on the other hand, was characteristic of the second-generation students. This identification defined for the students their ancestral/national connection to Mexico and Puerto Rico. The students characterized such identifications as inescapable representations of who they are. In other words, students who identified as Mexican or Puerto Rican utilized these identifications because either they or their parents were born in Mexico or Puerto Rico, thus for them it was a true and inescapable fact. Cultural identifications, on the other hand, were used by a cross-section of students that defined themselves as embodying an orientation that is characteristic of Mexicans or Puerto Ricans. The students' use of the term culture not only made it a cultural identification, but also the meaning of culture centered on an orientation or perspective that represents a "real" Boricua or Chicano way of thinking. This identification was reminiscent of Anzaldua's (1987) discussion of how conceptualization of Mexican at times emerges as "a state of soul—not one of mind, not one of citizenship" (p. 26). In other words, this cultural identification went beyond a citizenship claim-like the hyphenated and ancestral/national identifications make - but rather pointed to a perspective of the world as indicative of their Chicano or Boricua cultural identification.

The students' discussion of their self-identification argues for more elaborate investigations which focus on understanding identification selection via the meaning and interpretations students make of their identification. Their discussion allows us to conceptualize selfascription as built on the meanings and interpretations individuals make of what they consider valid about their identification. Such conceptualization of identification makes it a process in which the individual defines the validity of their identification. However, what also becomes apparent about the students' identification are the challenges others make to how the students define their identification, or how others define race/ethnicity in conflict with their own definition.

The students perceived others situating them into discrete racial/ ethnic categories based on their skin color: White-looking, Mexican/ Hispanic-looking, and Black/Biracial-looking. Their accounts of how they perceived that others interpreted their skin color into these three categories established two operating dynamics. First, these students, although they identified similarly, had differing social experiences. These differences include varying treatment from teachers and students, as well as experiences of discrimination. The second dynamic involved the students being situated into categories that at times were inconsistent with their own identification as Puerto Rican, DetroitRican, Boricua, Mexican, Chicano or Mexican-American. Although 
these categories were externally situated and resulted in specific experiences, the students responded to these categories by modifying their self-identification according to how others viewed them. In other words, their experiences of being externally situated resulted in modification of identification. For example, the Mexican/Hispaniclooking students expressed that they had to assume a Hispanic identification at times because that is how they were situated based on skin color. However, they also recognized that such identification operated as code for Mexican. Such coding did not pose a significant problem for the Mexican students but assuming a Hispanic identification for the Puerto Rican students meant accepting, to a certain degree, that others would situate them as Mexican. Such interplay between these students' self-identification and others' external interpretations of skin color established that identification was not a discrete or static process of them selecting Mexican or Puerto Rican as an identifier, but rather was being reconstituted by the students and other's interpretation of skin color as a signifier of race/ethnicity. As such, this negotiation posits identification is a layered dynamic (Nagel, 1994; Padilla, 1985; Pedraza, 1992) that is simultaneously optional (Hein, 1994; Nagel, 1994; Waters, 1990) and mandatory (Nagel, 1994). Additionally, this discussion further solidifies that skin color is a floating signifier of race/ethnicity (Hall, 1996) in which individuals make assessments of self-identification based on external factors like skin color (Hall, 1996; Rodriguez, 2000). More importantly, the students exemplified what Bashi (1998) argues as the power relations that exist in the identification process between the individual and external agents.

\section{SKIN COLOR AND PERCEPTIONS OF OPPORTUNITY}

The significance of the power differential and negotiations between selfidentification and external agents was further exemplified in the ways in which these external interpretations of skin color moderated the students' perceptions of opportunity. In other words, how the students experiences of racialization moderated their interpretations of how social mobility occurs. Many of the students, regardless of skin color, shared in what Mickelson (1990) and others deem as an abstract attitude towards education in which school and patterns of engagement define an individual's mobility or chance of making it. They believed that by studying a lot and working hard they would achieve academic success, which in turn would result in social mobility and the acquisition of 
making it markers (e.g., children, house, and marriage). However, differential experiences of identification moderated whether they perceived themselves and others like them as being able to make it. The three phenotype groups developed different co-narratives of opportunity in order to explain social inequality. Additionally, gender emerged as defining the nature of these co-narratives. For example, the Whitelooking male students expressed that race and skin color do not explain why some people are rich and others are poor. Instead they attributed the wealth that Whites maintain to their educational background and immigrant status. In contrast, they imagined that Latinos were poor because of their immigrant status and lack of transferable skills from their homeland to the United States.

This co-narrative suggests social factors like race and skin color do not mitigate the efficacy with which ethnic groups like Mexicans and Puerto Ricans are able to actualize on the American dream. On the other hand, the co-narrative of the Mexican/Hispanic-looking and Black/ Biracial-looking students situated a different perspective of opportunity. These students simultaneously argued opportunity was available to those who pursued educational success but was stratified by race/ ethnicity, skin color, gender, and language skills. They reasoned social inequality exists because such social factors are used to stratify the opportunity/chances different social groups have of making it. They maintained this co-narrative of opportunity because of its usefulness as a motivating tool for pursuing their occupational aspirations. In sum, external interpretations of skin color and gender prove to have a moderating impact on the type of co-narratives of opportunity the students maintained. What such a finding contributes to the dearth of studies on perceptions of opportunity is that external interpretations of skin color along with gender result in social experiences that inform these students' renderings of opportunity and the opportunity structure.

\section{SKIN COLOR AND ACADEMIC ORIENTATION}

Based on previous cultural ecological research, marginalized students like the Mexican/Hispanic-looking and Black/Biracial-looking students, who perceive opportunity as limited would be most likely to disengage from the schooling process. The reasoning is that such perceptions inform the ways in which they elect not to participate in the classroom. Only a few studies complicate this argument by stating that students also are able to recognize social barriers and simultaneously engage in school (Flores-Gonzalez, 1999; O'Connor, 1997, 1999). The students in 
this book substantiate such an argument, but their narratives also offer their reasoning as to why they would engage in school.

Although these students maintained comparable academic performance and aspirations, they differed in their social experiences in school and the opportunity they perceived available to them in school. Such experiences and perceptions of opportunity in school and society informed the ways in which they rationalized their orientation towards in school. The White-looking students expressed having varying discriminatory experiences in school but maintained a perspective of school as an institution that operates on a reward system of objective markers (i.e., individual effort, ability, and interest in school). There was no visible pattern as to why some White-looking students reported discrimination and others did not. Some reported having experienced discrimination in which African American teachers and students made remarks to them or had physical altercations that were fueled by the students' Mexican and Puerto Rican affiliation. On the other hand, some White-looking students did not recall experiencing discrimination, though they recognized its existence. Even with their perspective of their schools as containing discriminatory practices which they either experienced or recognized happening, their perspective did not taint or appear as significant in how these students perceived schooling as a tool for mobility. Consistent with how these students viewed opportunity structured in society, they viewed school as an environment employing pervasive discriminatory practices which minimized the achievement and opportunity of Mexican and Puerto Rican students. They imagined these experiences as isolated incidents. Instead they perceived education and the schooling process as focused on providing students who demonstrate effort by studying a lot, trying hard, and participating in classroom discussions with the academic achievement and opportunity they deserve.

The Mexican/Hispanic-looking and Black/Biracial-looking students' academic orientation involved different experiences from the Whitelooking students. They also considered education as an endeavor in which individuals needed to show effort and a desire to learn. However, their experiences of racial discrimination in and out of the classroom informed their viewpoint of the schooling process. These students perceived their school environment as limiting opportunity and purposely mistreating individuals like them based on skin color and ethnic affiliation. Unlike the White-looking students, these students felt that African American teachers treated them differently in the classroom by ignoring them, giving them grades and progress notes that some students felt were unfounded, and minimizing their participation in 
extra-curricular activities. In addition, these students felt that the administration also participated in the discrimination by refusing to have interaction with Mexican and Puerto Rican students. Even though these students felt discrimination was pervasive in the school environment and limited the educational and subsequent life chances of persons like themselves, they pursued their educational and occupational goals. They reasoned education was important because they needed to disprove the stereotypes that were the basis of discriminatory practices and demonstrate to themselves and family members that Latinos are able to make it. These students' academic orientation demonstrates a psychological flexibility and resilient persona (Trueba, 2002) in their ability to interpret discriminatory practices as a motivating factor in pursuing educational goals. This finding points to external interpretations of skin color among Mexican/Hispanic-looking and Black/Biracial-looking students as moderating their engagement in school as well as how they interpret the purpose of school. Although this book is not intended to make generalizable statements, the Mexican/ Hispanic-looking and Black/Biracial-looking students ability to demonstrate such resilient interpretations offers substantive evidence that within Latino groups, some individuals, exemplify a resilient perspective. Additionally, this resilient behavior/orientation may explain why many of these students performed academically average to above average. In sum, external interpretations of skin color emerged as moderating the ways students engaged in school and perceived its utility. In other words, how these students constructed the purpose of school and how they accounted for their engagement in school depended on whether the students were classified as White-looking, Mexican/Hispanic-looking, or Black/Biracial-looking. Such a finding contributes a unique understanding of how Latino students' orientation towards school is moderated by the ways in which members of school communities, like that of students in this book, interpret skin color variations among ethnic groups.

\section{THEORETICAL SIGNIFICANCE}

The theoretical significance of this book is its re-examination of how we look at academic variability among Latino groups. Traditional arguments explaining the academic variability among ethnic minority groups overlook the relevance and impact of skin color. The typologies that explain academic variability center on fictive kinship, immigrant experience, and interpretations of discrimination as informing the ways in which marginalized students engage in school. However such 
typologies operate on the assumption of uniform or at least common social experiences and interpretations among ethnic minority groups. More specifically, Ogbu's cultural ecological model and subsequent typologies' uniform/macro treatment of marginalized groups as having distinct, if not common social experiences creates an analytical limitation on the concept. This model and its typologies rest on the assumption that students who maintain similar social group affiliation have common social group experiences, hence interpreting them in a like manner and constructing dispositions towards students' life chances and school engagement. However as discussed in chapter three, phenotypically distinct Mexicans and Puerto Ricans do not necessarily have common social experiences that permit them to have similar ethnic identification processes. In fact, many of these experiences are more the result of how they perceive that others situate them racially and ethnically versus how they perceive the socio-historical conditions of their racial/ethnic group. I am not implying that socio-historical conditions do not play a role, but it is not the only variable that registers as pertinent in their racial/ethnic identification.

This book also challenges the ecological model's assumption that marginalized students perceive the opportunity structure as maintaining the same social barriers for their ethnic group as for them. In actuality, ethnic group affiliation did not appear as the most significant relationship; instead, their experiences around skin color and gender resonated with how they interpreted race/ethnicity, gender and language as mitigating (or not) the making it process and the distribution of chance. Such a finding raises significant questions as to the viability of Ogbu's model and typologies in being able to fully capture marginalized students' engagement in school and resulting academic performance. In fact, this finding suggests that marginalized students make interpretations of their life chances based on individual treatment as well as understanding of socio-historical group experiences.

Academic orientation also did not emerge as a result of sociohistorical conditions and interpretations of the opportunity structure as limited. Although the students' perceptions of opportunity differed along phenotype lines, academic performance did not follow along such lines. However, the ways in which the students experienced and interpreted their schooling experiences as well as perceived the purpose of school followed along phenotype lines. As a result, the ways in which others situated them along racial and ethnic lines moderated elements of their academic orientation. More specifically, these students perceived schooling in relation to how they were treated in school, how they 
perceived opportunity was dispensed, and how they interpreted racial/ ethnic discrimination.

Aside from raising questions about cultural ecological model and typologies, this book interjects the significance of skin color in the educational experiences of Latino groups, the racial/ethnic relations among students of color, and the way teachers function in making students invisible in the classroom/school, and/or how the students interpret such events. Research on the schooling experiences of Latino groups has primarily centered on how the role of first and second language, culturally relevant pedagogy, immigrant status and adaptation process, academic placement practice, and social differences with White teachers operates in the engagement, experiences and academic performance of Latino students (Cazden, John, \& Hymes, 1972; Portes \& Schauffler, 1996; Suárez-Orozco \& Suárez-Orozco, 1995; Trueba, 1987, 1989; Valenzuela, 1999). A few studies in educational research and other disciplines have interjected that Latino groups sustain differing social experiences based on skin color, which inform adaptation to the United States context (Murguia \& Telles, 1996; Rodriguez, 1992). This book interjects the significance of skin color in informing social experiences as well as moderating perceptions of how opportunity is distributed and rationalizing the purpose of school. Additionally, this book raises poignant questions about the racial/ethnic relations between ethnic minority groups. What are ethnic minority students allowed to be? What are the racial politics of skin color in school? What are racial politics of schools with predominantly ethnic minority populations? Coupled with these questions are concerns as to the involvement of teachers in the displacement of educational opportunity in relation to the ways in which they racialize students. The Mexican/Hispanic and Black/Biracial-looking students reported experiences of being made invisible points to racial politics between students and teachers as not only how do students and teachers identify race but also what consequences are attached to the assignments and interpretations each makes about race/ethnicity. Overall, the narratives of these students raise significant doubt as to whether the cultural ecological model and other typologies rest on conclusive assumptions. In addition, the findings raise considerations as to the significance of skin color among Latino groups in the school context.

In sum, this book offers new complications in how we discuss the educational process of Mexican and Puerto Rican students specifically, and Latinos in general. Ogbu's cultural ecological model has always presented a fascinating approach in which to observe students' interpretations of the relationship between schooling and social 
outcomes, and its relevancy to academic variability. However, this model and subsequent clarifications leave questions unanswered as to its applicability to ethnic groups with internal variations such as skin color. More importantly, the intent of this book is to begin deconstructing how various Latino populations in the United States make sense of their social world. That is, how do they interpret and respond within a societal context that racializes everyone based on skin color? I offer an initial foray into skin color as a significant factor in how Mexicans and Puerto Ricans view opportunity and develop their academic orientation. In addition, I situate the important role external agents play in the ethnic identification process and subsequently in moderating how these students view their future and its affect within the school context.

Finally, much of the educational research on Latino groups explores their experiences in school based on the decades of research on African Americans. More specifically, discussions of curriculum, teacher quality, cultural difference/discontinuity, status attainment, cultural deprivation, bilingual/bicultural issues, etc., rest on the assumption that, like African Americans, Latinos have a unifying racial/ ethnic experience. However, similar to how skin color variation among African Americans has not been explored in a systematic fashion, empirical educational research regarding the moderating effect of skin color variation among Latinos has not been conducted. Although it is common knowledge that Latinos comprise the full spectrum of skin color, and it has been researched in other fields (e.g., Duany, 1998; Murguia \& Telles, 1996; Rodriguez, 1992), the exploration of skin color within the schooling context has been absent within educational research. Thus, the outcomes from this book are not only in conversation with arguments regarding the academic variability of minority youth, but also will generate points of departure from which to further explore the development of ethnic and racial identification among Latino students and its significance to the educational process. 
140 SKIN COLOR AND IDENTITY FORMATION 


\section{Appendix A \\ Interview Measure}

Respondent Name:

Respondent Age:

Respondent Date of Birth:

Respondent Address:

Date of Interview:

Site of Interview:

\section{INTERVIEW SCRIPT}

\section{FAMILY}

[First, I'd like to ask you questions about your background-how your family arrived to the U.S., what kind of education have your parents/guardians received, etc.]

1. Who do you live with?

2. Who is mainly responsible for raising you?

3. Where were you born?

A. If born in native country, when did you arrive in U.S.?

B. If born in U.S., what city and state?

4. How much education has your mother completed? [If student is being raised by someone other than their biological parents, phrase this question to reflect that fact]

A. If presently pursuing a degree, what kind of degree?

5. How much education has your father completed? [If student is being raised by someone other than their biological parents, phrase this question to reflect that fact]

A. If presently pursuing a degree, what kind of degree?

6. Does your mother work?

A. If yes, what does she do? 
B. If yes, how long has she worked?

7. Has your mother ever been unemployed?

A. If yes, for how long?

B. What did she do for a living?

8. Does your father work?
A. If yes, what kind of work does he do?

B. If yes, how long has he worked?

9. Has your father ever been unemployed?

A. If yes, for how long?

B. What did he do for a living?

10. Do you get reduced lunch or free lunch?

A. If yes, how long have you been on reduced lunch or free lunch?

11. Where was your mother born?

A. If born outside of U.S., when did she migrate to U.S.?

12. Where was your father born?

A. If born outside of U.S., when did he migrate to U.S.?

13. Are you an American citizen?

A. If not, what country are you a citizen of ?

14. Are your parents American citizens?

A. If not U.S. citizens, have your parents applied for citizenship?

B. If not U.S. citizens, do your parents talk about becoming citizens?

C. If U.S. citizens, how did they become citizens?

15. Do you have any siblings?

A. If yes, how many? How old is he/she/they?

[If no, GO TO Question 17]

16. Tell me about your brother(s)/sister(s).

A. Do you look like your siblings?

B. Do you think your parents treat you the same or different from your siblings?

C. If different, how?

17. What kind of relationship do you have with your father/male guardian?

18. What kind of relationship do you have with your mother/ female guardian?

\section{Attitudes and Constructs of Race and Ethnicity}

1. Do your parents/guardians ever talk about discrimination?

A. What kinds of things do they say? 
2. Do your parents talk to you about what it means to be [insert ethnic group affiliation]?

A. If yes, what kinds of things do they say?

3. Do your parents ever talk about other Latina/o groups?

A. If yes, what kinds of things do they say?

\section{COMMUNITY COMPOSITION}

[Explore student's knowledge of surrounding community and level of en gagement.]

1. Describe your neighborhood.

2. Tell me about the things you see on the way to school/from school.

3 . What do you do in your neighborhood on the weekend?

4. Describe some of the things you like about your neighborhood.

5. Describe some of the things you dislike about your neighborhood.

6 . Tell me about the people who live in your community.

A. What is the racial and ethnic make-up?

B. What language(s) is spoken in your community?

7. Are most of the adults in your neighborhood employed/ unemployed?

A. If employed, what kinds of jobs do they have?

B. If unemployed, why do you think they are unemployed?

9. How long have you lived in your neighborhood?

\section{ETHNIC IDENTITY}

[Note to Researcher: Inquire into how student describes themselves to oth ers-family, friends, teachers, community; what student thinks others think of them; does it differ from their own description of self.]

1. How would you describe yourself in terms of race or ethnicity? [If they focus on one of the two then probe about the othen.]

A. Do you ever describe yourself in racial term, e.g., Black or white?

B. Do you ever describe yourself in ethnic terms, e.g., Asian, Hispanic/Latino, African-American?

C. When do you describe yourself in these terms?

2A. [State this question if respondent is of Mexican descent.] There are a number of ethnic terms which are associated 
with people of Mexican descent, e.g., Mexican, Mexican-American, Chola/o, and Chicana/o. What comes to mind when you think about each of these terms. [State each term to the participant.]

A. Do you identify with any of these terms? Why?

2B. [State this question if respond is of Puerto Rican descent.] There are a number of ethnic terms which are associated with people of Puerto Rican descent, e.g., Puerto Rican, Nuyorican, and Boricua. What comes to mind when you think about each of these terms. [State each term to the participant.]

A. Do you identify with any of these terms? Why?

3. Would you say that being __ is important to you? [Fill the blank with whatever ethnic category student chooses from above]

If so, why?

4. Can you think of times in your life that being has been more or less important? [In the blank fill in the term the student used in ques tion $\# 2$; also, if student talks about one term ask about more important and vice versa.]

5. You indicated that you see yourself as a . Do your friends see you in this way? Do they identify you in other ways?

A. If no, how do you feel about that?

6. You indicated that you see yourself as a . Do your teachers see you in this way? Do they identify you in other ways?

A. If no, how do you feel about that?

7. If you had the opportunity to stand in front of a classroom of White students, how would you describe yourself?

8 . Would you describe yourself differently if you were standing in front of a classroom of minority students?

A. Why? Or why not?

9. Can you think of a time in your life when someone has assumed you were of another race or ethnic group?

A. If yes, can you describe the situation?

B. If yes, have you ever identified yourself as part of that race or ethnic group?

10. Do you think that Americans have a stereotype of what being [Insert ethnic group affiliation] is?

A. If yes, what do you think they are? 
B. If yes, do you think those stereotypes impact how people interact with you?

C. If no, why?

11. Does your family want you to marry someone who is [Insert ethnic group affiliation]?

A. Why? Or why not?

B. How do you think that they would react if you wanted to marry some one who is not

[Insert ethnic group affiliation]?

12. Have you ever been discriminated against?

A. If yes, how did you handle the situation?

B. Have there been any situations in which you felt as if you were treated unfairly?

13. Do you think that in your school students who are lighter skinned get better, same, or worse treatment than darker skin students?

A. Why?

14. Do you think that in society people who are lighter skin get better, same, or worse treatment?

A. Why?

15. Do you think that people judge you based on your skin color?

A. If yes, in what way?

B. If yes, why do you think so?

C. If no, why?

16. Do you consider yourself American?

A. If yes, why?

B. If no, why not?

17. Are there students who treat you differently because of your cultural background?

A. If yes, how does that make you feel?

\section{Knowledge of Ethnic Group Affiliation}

1. Do you speak another language besides English?

A. If yes, what do you consider your first language?

2. What language do you feel most comfortable speaking?

3 . What language do your parents/guardians speak?

4. Is this the language most spoken at home?

5. If Spanish is first language: When did you learn English?

A. Who was responsible for helping you learn English?

6. If English is first language: When did you learn Spanish?

A. How? 
7. What language do you usually speak with your friends?

8. If you had the opportunity to stand in front of a classroom, how would you describe your culture?

A. Some students say that language, music, food, religion and family are important things in Latina/o culture, do you agree or disagree?

9. Do you see your culture similar to or different from American culture?

A. Explain why?

10. Is there anything about American culture that makes life hard for people like you?

A. If yes, what is it?

\section{Social Group Affiliation}

1. At school, do you usually hang out with Mexicans, Puerto Ricans, African Americans, Whites or a mixture?

A. [If interact with one specific group] What do you enjoy about hanging out with these people?

2. Outside of school, do you hang out with the same group of people or different group?

A. If different, why?

3. When you get together with other [insert ethnic group affiliation], do you ever talk about other Latina/o groups?

A. If yes, what do you talk about?

4. Can you name any famous affiliation] that you would like to be like?

[insert ethnic group A. What do you like about that person?

5. If you could pick anybody, who would you like to look like?

A. Why that person?

6. What kinds of things do you talk with your friends about that are important to you?

\section{SCHOOLING ORIENTATION}

\section{Educational Aspirations and Expectations}

1. What do you want to be when you get older?

A. Why? 
2. Do you think you will complete high school? College? Graduate or Professional school?

3. How important is being in school to your life right now? Very important somewhat important not important at all

4. What do you plan to do when you graduate from high school? Get a job go to college take a break undecided
A. [If they select anything other than "go to college" ask the following]
Do you want to go college?

5. Do you think that there are benefits to getting a lot of education?
A. If yes, what benefits?
B. If no, why not?

6. What do you think your parents want/hope for you to be?

A. Did they ever indicate how much education they wanted you to achieve?

7. Do you think what you are learning now in school is important for your future?
A. If yes, why?
B. If no, why?

8. What kind of attitudes do your parents/guardians have about your education?

9. Do they discuss the importance of your education with you?
A. If yes, why do you think they did?
B. If no, why do you think they did not?

10. Do you have any other relatives that had an impact on how you think about your future?
A. If yes, who?
B. How did they affect your thoughts about your future?

11. Do you have any people in your life that have felt that you were talented?
A. If yes, what kind of things did they tell you?

12. Do you have any people in your life that made you feel that you did not have any talents or were not good at something?
A. If yes, how did they express those feelings?
B. How did that make you feel?

\section{Engagement in school related activities}

1. Are you a member of any clubs, teams, or social organizations at school?
A. If yes, what are they? 
B. How long have you been involved?

C. Do you hold any positions?

2. What is special about these organizations?

A. Why is it important to you to be part of these organizations?

3. Throughout your time in high school and middle school, what other activities have you been a part of ?

4. Have your ever been an office aide or teacher's assistant?

5. Do you stay after school for academic help?

\section{Accommodation to schooling norms}

1. What's your favorite class?

A. Why?

2. What's your least favorite class?

A. Why?

3. How often do you go to school?

A. Do you ever skip school? Skip classes? When? How often?

4. Teachers often have ideas about their students, how do you think teachers see you?

A. How does that make you feel?

5. What do you like about school?

A. Why?

6. What do you dislike about school?

A. Why?

7. Do any other teachers stand out in high school? How about before getting to high school?

8. Do you study outside of school?

A. How often?

B. Whenever you're about to have a test, when do you usually start studying for the test?

C. Do you usually study at home, library, a friends' house, or somewhere else?

9. Do you complete your homework some of the time, most of the time, or hardly ever?

10. Do you participate in classroom discussions?

A. Why?

11. What types of grades do you receive in school?

12. What is your current GPA?

13. What classes are you taking right now? 
14. Have you ever thought or talked about dropping out of school?

A. If yes, when was this?

15. Have your friends ever talked about dropping out of school?

A. If yes, when?

16. Tell me about your [Fill in class year] year.

\section{Opportunity and Differential Treatment in School}

1. Do you think your school is divided into groups?
A. If yes, why?
B. If no, why? [Go To Question 3]

2. What kinds of groups are they divided into?
A. What kinds of people belong to each group?
B. How would you order these groups (from lowest to highest)?
C. How can you tell what group someone belongs to?

3. Is there racism in your school?
A. If yes, can you describe an incident?
B. If no, why not?

4. Do [insert teachers, principal, counselors] treat students similarly or differently?

A. If different, why do you think they do?

5. In your school, do you think that everyone has the same opportunity to get good grades?
A. If yes, why?
B. If no, why not?

6. Do you think that in your school girls get better, same or worse treatment than boys?
A. Why?

7. Do your teachers ever talk about issues of race/culture in the classroom?
A. If yes, what do they talk about?
B. If no, why do you think they don't?

8. Do the students who have high GPAs get treated better, same or worse than students with lower GPAs?
A. If better or worse, why?
B. If same, why?

9. In your school, do you think there is equal opportunity to participate in extracurricular activities?

A. If yes, why? 
10. Do you think that a rich and a poor student going to the same school receive the same opportunities in school?
A. If yes, why?
B. If no, why?

\section{PERCEPTIONS OF SOCIETAL OPPORTUNITY}

1. Why do you think some people are rich and others are poor?

2. Why do you think some students stay in school and others drop out?

3. What do you think it means to "make it" in this society?

4. Do you believe that it is important to do well in school? Why?

5. What do you think it takes to "make it" in this society?

6. Are people equal in American society?
A. If so, why?
B. If not, why?

7. What kinds of jobs do you feel are good jobs in American society?
A. Why?

8. Can anybody get a good job in American society?
A. Why do you feel that way?
B. Why not?

9. Do you agree or disagree that America is a land of opportunity where everybody can get ahead, and that everybody gets what they deserve out of life?
A. Why or why not?

10. Do you think there is more or less opportunity for people to get ahead today than in the past?

A. Why or why not?

11. Which people have the best chance for getting ahead?
A. Why?

12. Which people have the worst chance for getting ahead?
A. Why?

13. Which of those groups does your immediate family fit into?

A. Why do you think so?

14. Which of these groups do your friends fit into?
A. Why do you think so?

15. What holds a person back from getting ahead in society?
A. Why do you feel this way?

16. Do you know anyone personally that has not gotten ahead in life that should have? 
A. Why do you think that they didn't get ahead?

17. Do you think people in [insert city] have an equal opportunity to get a job?
A. If yes, why?
B. If no, why?

18. You said earlier that you want to be a [insert occupational aspiration], do you think that is a good job?
A. If yes, why?
B. If no, why?

\section{Self and Group Opportunity}

1. As a [insert respondent's race and gender] how do you think American society views you?

2. Do you believe that African Americans, Puerto Ricans/ Mexicans, or Whites have more advantages than [insert respon dent's race and gender]?

A. Why do you think they have more advantages?

3. Do you believe that African Americans, Puerto Ricans/ Mexicans, or Whites have less advantages than [insert re spondent's race and gender]?

A. Why do you think they have less advantages?

4. Do you believe that you have a better, worse or same chance at making as other [insert respondent's race and gender]?

5. Do you believe that [insert respondent's race and gender] have more or less advantages than [insert respondent's race and gender]?

6. Do you personally expect to move up in the world?
A. If not, why?
B. If yes, how do you plan to do so?

7. Do you think that in the future your life will be better than the life your parents had?
A. If not, why not?
B. If yes, why? Also, how are you going to make sure it is better?

8. Do you think that all [insert ethnic group affilia tion] have the same opportunity to get ahead?
A. If yes, why?
B. If no, why not?

9. Do you think that lighter skin [insert ethnic group affiliation] have better, same or worse 
opportunity to make it than darker skin

[insert ethnic group affiliation]?

\section{SOCIAL GROUP AFFILIATION AND ATTITUDES}

1. Are your [insert friends then family] attitudes about getting ahead in life similar or different from yours?

A. If similar, would it matter to you if they were different?

B. If different, would it matter to you if they were similar?

2. Do your friends tend to be wealthier, poorer than you, or the same?

A. If wealthier or poorer, does the difference affect how you talk to each other?

3. Do you think that other [insert ethnic group affil iation] have similar attitudes about making it like you?
A. If no, why?
B. If yes, why? 
Name:

Date:

[I am going to go over a list of things with you that concern getting ahead in life. Please rank these items, one at a time, on a scale of 1 to 5 ; 1) extremely important, 3 ) somewhat important, and 5) not important at all]

\begin{tabular}{|c|c|c|c|c|c|}
\hline & $\begin{array}{l}\text { remely } \\
\text { rortant }\end{array}$ & & $\begin{array}{l}\text { somewhat } \\
\text { important }\end{array}$ & & $\begin{array}{c}\text { not important } \\
\text { at all }\end{array}$ \\
\hline Education & 1 & 2 & 3 & 4 & 5 \\
\hline Money in the family & 1 & 2 & 3 & 4 & 5 \\
\hline Skin color & 1 & 2 & 3 & 4 & 5 \\
\hline Hard work & 1 & 2 & 3 & 4 & 5 \\
\hline Knowing the right people & 1 & 2 & 3 & 4 & 5 \\
\hline Luck & 1 & 2 & 3 & 4 & 5 \\
\hline Ethnic or racial heritage & 1 & 2 & 3 & 4 & 5 \\
\hline Intellectual ability & 1 & 2 & 3 & 4 & 5 \\
\hline Neighborhood one lives in & 1 & 2 & 3 & 4 & 5 \\
\hline Being male or female & 1 & 2 & 3 & 4 & 5 \\
\hline \multicolumn{6}{|c|}{$\begin{array}{l}\text { Is there anything missing from this list that should be included? } \\
\text { If so, what is it? }\end{array}$} \\
\hline & 1 & 2 & 3 & 4 & 5 \\
\hline & 1 & 2 & 3 & 4 & 5 \\
\hline & 1 & 2 & 3 & 4 & 5 \\
\hline
\end{tabular}

\section{CONCLUSION}

[This should be an open-ended session in which the student has an opportunity to answer as freely as possible]

1. Do you have questions or issues about the interview that you would like raise with me?

2. Is there anything that you left out of our discussion that you feel like saying now? 
154 APPENDIX A 


\section{Appendix B \\ Letter to Parents of Respondents}

Dear Parent or Guardian:

I am a graduate student at the University of Michigan and I am conducting a study on Latino adolescents. The intent of my project is to better understand how Latino adolescents understand and perceive their education and future outcomes. The intent of this project is to understand why some Latino students fail and others succeed. My findings will hopefully assist educators, policy makers, and community organizations in their attempts to improve the educational opportunities available to Latino youth residing in urban communities.

My intent is to interview the students individually and tape-record our conversation. I hope that you will grant me permission to speak with your child. Your child's participation will be completely voluntary and he/she can decline to answer any of the interview questions. Please be assured that all information derived from the interviews will be held in strict confidence. After the interviews, the tapes will be transcribed and stored in a locked cabinet. Also, when reporting my findings neither the school nor the students' name will be identified.

If you are willing to let your child speak with me, please sign the attached consent form and have your child return it to me. If you would like to ask me some questions or get additional information before making up your mind, I can be reached at home (XXX)-XXX-XXXX. I hope that I will get the opportunity to speak with your child. Thank you for your time and consideration.

Estimados Padres:

Mi nombre es Eduardo Fergus y soy un estudiante asistiendo en la Universidad de Michigan para conseguir un doctorado. Estoy dirigiendouna investigación de estudiantes Latinos y las percepciones 
quo ello tiene sobre su educación. La intención de esta investigación es para entender porque algunos estudiantes Latinos fracasan y otros tienen éxito. Los resueltos de esta investigación espero que ayude maestros, principales y organizaciones mejora la oportunidades y educación para estudiantes Latinos.

Yo quisiera interviù su hijo/a. El interviù se va grabar. La participación de su hijo/a es completamente voluntario y el o ella puede rehusar de responder cualquiera pregunta. Toda la información conseguido de el interviù es confidencial. Nombre de el estudiante y la escuela va se confidencial.

Con su permiso yo quisiera hablar con su hijo/a. También, me gustaría tener una copia de la ultima notas de se hijo/a. Cada estudiante va recibir un certificado de $\$ 15$. Los interviù van ser hecho en la agencia de Adelante. Si usted esta de acuerdo que su hijo/a participe, por favor firme el permiso y devuélvelo con su hijo/a ha Adelante. Si tiene mas preguntas o quiere mas información sobre esta investigación, por favor deme una llamada en casa $(\mathrm{XXX}) \mathrm{XXX}-\mathrm{XXXX}$. Espero que yo tenga la oportunidad de hablar con su hijo/a. Gracias por su tiempo y consideración.

Sinceramente, Eduardo Fergus 


\section{Appendix C Assent Form}

I am giving consent to participate in the study being conducted by Edward Fergus. I understand that all interviews will be conducted by Eddie Fergus, a doctoral student at the University of Michigan-Ann Arbor. I understand that this study will explore how Latino adolescents understand and perceive their education and future outcomes. I have been informed that as a consequence of participation in this study I will be interviewed on one occasion. I also understand that the interviews will be recorded with a tape recorder and I agree to its usage.

I have entered into this agreement with the understanding that at any time during the process I may refuse to participate in the study. I also understand that the taped interviews will be transcribed and then the tapes will be stored in a locked cabinet. Finally, the results, when available, will be reported to me upon my request.

I hereby authorize Eddie Fergus to use the information from my participation in this study for research purposes.

Name(Print)

signature

Date Age: Grade: Date of Birth: 


\section{Appendix D \\ Consent Form}

As the parent/guardian of

I am giving consent to have my child participate in the study being conducted by Eddie Fergus. I understand that all interviews will be conducted by Edward Fergus, a doctoral student at the University of Michigan-Ann Arbor. I understand that this study will explore how Latino adolescents understand and perceive their education and future outcomes. I have been informed that as a consequence of participation in this study my child will be interviewed on several occasions. I also understand that the interviews will be recorded with a tape recorder and I agree to its usage.

I have entered into this agreement with the understanding that at any time during the process I may refuse to have my child participate in the study. Also, if my child at any point chooses to decline participation they may do so. I also understand that the taped interviews will be transcribed and then the tapes will be stored in a locked cabinet. Finally, the results, when available, will be reported to me upon my request.

I hereby authorize Eddie Fergus to use the information from my child's participation in this study for research purposes.

Name

Signature

Date 


\section{PERMISO}

Como el padre de yo doy permiso que mi hijo/a participe en la investigación dirigido per Eduardo Fergus. Yo entiendo que toda la entrevistas va ha ser hecho por Eduardo Fergus un estudiante de la Universidad de Michigan. También entiendo que esta investigación es para entender las percepciones que estudiantes Latinos tienen sobre su educación y futuro. Me han informado que la entrevistas se van grabar.

También se que ha cualquier tiempo yo puede rehusar que mi hijo/a participe en la investigación y el/ella también puede rehusar. Se que la grabaciones van ha ser transcribiendo y guardado en un caja con cerradura. Finalmente los resueltos de esta investigación van ha ser disponible cuando yo lo quiera.

Yo doy permiso que Eduardo Fergus hable con mi hijo/a para esta investigación.

Nombre (letra)

Firme

Fecha 


\section{Appendix E}

PLEASE DO NOT FILL OUT THIS FORM.

This is not an official census form. It is for informational purposes only.

United States
This is the official form for all the people at this address. It is quick and
easy, and your answers are protected by law. Complete the Census and
help your community get what it needs - today and in the future!

\section{Start Here/}

1. How many people were living or staying in this house, apartment, or mobile home on April 1, 2000?

\section{Number of pecple}

INCLUDE in this numbor

- foster children, roomers, or housemates

- people stayng here on Apal 1, 2000 who have

no other permanent place to star

- people hing here most of the time while working.

even if they have ancther piace to live

\section{DO NOT INCLUDE in this number}

- college students living away while attending college - peopie in a correctional facility, nursng home, or mental hosptal on April 1, 2000

- Armed forces personnel living somewhere else - people who live a stay at another place most
of the time

2. Is this house, apartment, or mobile home Mark $\mathbb{Q}$ ONE box

$D$ Onned by you or sconecone in the hausenold with a mortigage or loan?

Owred by vou or someone in ths howsehcid free and clear (minthout a mertgage or laani)?

Rented for cash rent?

Occapied without peyment of cash rent? 3. Ploase angwer the following questions for each
person living in this house, apartmont or mobile home. Start with the name of one of the people iving hore who owns is buying or rents this house, apartmont, or mobiio home. If there is no such person, start with any adut living or staving What is this person's name? Print name below Last Name

Frst Name
4. What is Person 1's telephone number? We may calf this person if we don't understand an answer Area Code + Number

5. What is Person 1's sex? Mark \ ONE box. Male $D$ Fomale

6. What is Person 1's age and whit is frerson 1 's date of birth? Age on April 1, 2000

Pnnt numbers in bcias

Month Day "Ysar of brth

$\rightarrow$ NOTE Please answer BOTH Ousstions 7 and 8.

7. ts Parson 1 Spanizh/Hispanic/Latino? Mark $ه$ the "No" tux if not Spanish/Hispanic/Latono

No, not Spanish/Hispanc/latno $\square$ Yes. Puerto fican

Yes, Mexien, Merocan Am, Chicano $D_{\text {Yes, Cuben }}$

$\square$ Yes, other Spenish/Hepenie/Latono - Pint group, $\boldsymbol{Z}$

8. What is Person 1's raee? Mark $\triangle$ one or more races to indicate what this person considers himselt/herself to be $\square$ White

Black. Alrian Am, a Negro

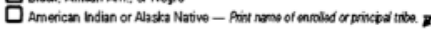

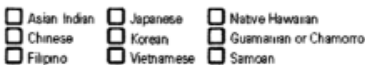

Filiono $\square_{\text {Vietramese }} \square_{\text {Samoen }}$

$\square$ Otiar Asan - Pint nace. $\boldsymbol{Z} \quad \square$ Other Pachic Islander - Print racer $\boldsymbol{Z}$

D Some other race - Pint race. $\mathbb{Z}$

$\rightarrow$ If more people live here, centinue with Person 2. 


\section{Appendix F \\ Across and Within Case Data Matrix by \\ Student}

Participant 1: Participant 2: Participant 3:

Socioeconomic class

Gender

Generation

Identity as self-choice

Identity as external

perception

Educational Aspirations

Importance of Schooling

Co-Curricular Activities

School norms;

Academic Performance

Reasons for social

inequality

Making it in society

Job opportunity

Fqual society

Perceptions of self-opportunity, ethnic group opportunity, and other ethnic groups' opportunity

Importance of School 


\title{
Appendix G \\ Across and Within Case Data Matrix by \\ Phenotype
}

\author{
White Mexican/Hispanic Black/Biracial \\ -looking: -looking: -looking:
}

Socioeconomic class

Gender

Generation

Identity as self-choice

Identity as external

perception

Educational Aspirations

Importance of

Schooling

Co-Curricular Activities

School norms;

Academic Performance

Reasons for social

inequality

Making it in society

Job opportunity

Equal society

Perceptions of self-opportunity, cthnic group opportunity, and other ethnic groups' opportunity

Importance of School 


\section{Appendix $\mathrm{H}$ \\ Conceptually Clustered Data Matrix}

Black/Biracial

White/Biracial

(Black \& White;

(White \&

Hispanid

Hispanic and

Mexican)-looking Mexican-looking Black)-looking

Gender

Generation

Hyphenated, Ancestral/

National, and Cultural

IdentificationCulture

Treatment by Other

Students:

Treatment by Teachers

and Administration

Aspirations

Academic performance

Utility of Schooling

Experiences of

Discrimination-

Self and Group

Perceptions of how

one makes it

(achievement ideology)

Perception of social

inequity/equity:

Advantages and

disadvantages 


\section{Appendix I Are You Latina/o? Are You in High School?}

IF YOU SAID YES TO BOTH QUESTIONS, THEN YOU ARE ELIGIBLE TO TAKE PART IN A STUDY WITH A UNIVERSITY OF MICIHIGAN GRADUATE STUDENT, EDDIE FERGUS.

PURPOSE OF STUDY: THE STUDY IS ON LATINO STUDENTS AND HOW THEY THINK ABOUT EDUCATION, THEIR FUTURE, AND THEMSELVES.

REQUIREMENTS: PERMISSION SLIP

WHEN:

MONDAY, TUESDAY OR WEDNESDAY OF ANY WEEK

REWARD: $\quad$ \$15 GIFT CERTIFICATE TO SAM GOODY, MUSICLAND, MEDIAPLAY OR BORDERS

IF YOU ARE INTERESTED, PLEASE TALK TO AT ADE-

LANTE (PHONE NUMBER), GET A PERMISSION SLIP.

PLEASE SIGN UP!!!!!!

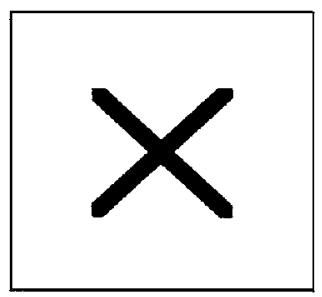




\section{Notes}

\section{NOTES TO CHAPTER TWO}

1. This book investigates high school students which permits the primary method of data collection to be open-ended interviews. The maturity of this population speaks to their verbal ability and intellectual development, which allows for application of this methodology with greater certainty. Also, their lengthy schooling history may provide insight into shifts in schooling orientation that might have occurred.

2. Gender is introduced for several reasons. First, research focusing on perceptions of opportunity does not generally attend to gender differences; meanwhile status attainment research notes differences in educational attainment and schooling experience between males and females. Such inconsistent attention to gender ignores the possibility that gender is a factor in how students perceive opportunity.

3. N/A is used for students that were born in the United States.

4. Immigration research has for the last 25 years offered numerous benchmarks of what should be considered a first and second generation immigrant (Rumbaut, 1996). Within this book I adopt the definition that second generation immigrants are either born in the United States or arrived prior to the age of 10. I use ten as the benchmark because developmentally the child's identification would be formed with memories of homeland and adaptation experiences in the new context.

5. Each interview was tape-recorded in order to ensure accuracy in data collection.

6. The interview measure has been adapted from a 1997-1998 pilot study conducted for this project. It has been modified to ensure the language is accessible and the questions are soliciting useful data. 


\section{NOTES TO CHAPTER THREE}

1. "Represent" is used by various ethnic minority groups - mainly younger individuals - to imply that an individual should demonstrate who they are and what they have allegiance to.

2. Although much of immigration research does not identify Puerto Ricans as an immigrant group because they have US citizenship status, within this book my reference to Puerto Ricans as immigrants does not reflect such a definition. My reference to immigrant generation implies a process, whether segmented or linear, that immigrants experience which involves an adaptation to the U.S. economic, political, and social context.

3. Ogbu defines such a historical context as an example of the involuntary minority status of Mexican Americans.

4. I borrow this concept from Gloria Anzaldúa (1987) who uses it as a reference to the convergence between the Border Patrol that is trying to keep out the "mojados" (wetbacks) and coyotes (smugglers), and farming combines that desire Mexicans for cheap labor.

5. This notion of Mexicans being the representative group of Hispanics in Detroit will be elaborated upon in chapter four.

6. The term 'Boricua First' was a campaign slogan created for the purpose of advocating for Puerto Rican political power.

7. Puerto Rican hip-hop artists like Fat Joe, K7, and the deceased Big Pun have used the term.

8. These terms are used in various capacities in multiple Latino/a and Hispano communities. The difference in these terms from terms like Black and White is their reference to a skin color and not necessarily a cultural group. However these terms also have their own racialized undertones that in some countries references class position.

9. Beverly's narrative is situated within the section on Mexicans because as I will discuss in chapter four, she is classified as others as Mexican/ Hispanic-looking.

\section{NOTES TO CHAPTER FOUR}

1. Two of the three high schools' student populations were primarily African American; while the third high school's student population had a large percentage of Latino/a students. However, many of the students interviewed identified it as predominantly African American.

2. I borrow from Cornell and Hartmann's (1998) analytical distinction between race and ethnicity. The authors explain that race is a classification that is typically assigned or externally imposed, while ethnicity is internally asserted. Such an explanation allows us to explore 
the difference in power positions of having an identification imposed versus constructing one.

3. The description of the groupings' appearances is only to provide a general picture of what these students looked like from the perspective of the investigator and what features others may have used to situate these students as White-looking, Mexican/Hispanic-looking and Black/ Biracial-looking.

4. Edgard's reference to his slicked-back Black hair as a symbol of his Mexican identification is consistent with gang literature on Mexican males and how part of their identification as a Cholo or gang member involves donning a specific dress, speech, tattoos, and graffiti that reflects and is solely embodied by that identification (Vigil, 1988).

5. Some theoretical arguments surrounding the racial classification of Latinos stipulate that the term Hispanic as been defined to "subtly" reference a stereotype image of "tan" or "light-skinned" (Rodriguez, 2001).

\section{NOTES TO CHAPTER FIVE}

1. See Appendix A for the full-range of questions.

2. In chapter six I discuss these students experiences of not feeling judged based on skin color or race/ethnicity in school.

\section{NOTES TO CHAPTER SIX}

1. I defined an average GPA as a C, or 2.5, thus anything above a 2.5 is above average.

\section{NOTES TO CHAPTER SEVEN}

1. Students in the book often referred to American as the way of describing Whites. 
174 NOTES TO CHAPTER FOUR 


\section{Bibliography}

Aggleton, P.J., and G.Whitty. "Rebels Without a Cause? Socialization and Subcultural Style Among Children of the New Middle Classes." Sociology of Education , 58 (1985):60-72.

Arce, Carlos, Murguia, E. and W.Frisbie. "Phenotype and Life Chances Among Chicanos." Hispanic Journal of Behavioral Sciences. 9 (1987):19-32.

Anyon, Jean. "Intersection of Gender and Class: Accommodation and Resistance by Working Class and Affluent Females to Contradictory Sex Role Ideologies." In Gender, Class and Education edited by S.Walker and L.Barton. Sussex, England: Palmer, 1983.

Anyon, Jean. "Social Class and School Knowledge." Curriculum Inquiry 11 (1981):2-42.

Barth, Frederik. Ethnic Groups and Boundaries: The Social Organization of Culture Difference. Boston: Little, Brown, 1969.

Bashi, Vilna. "Racial Categories Matter Because Racial Hierarchies Matter: A commentary." Ethnic and Racial Studies. 21 (1998):959-968.

Bates, Nancy, et al. "Research on Race and Ethnicity: Results from Questionnaire Design Test." Paper presented at the U.S. Census Bureau's annual research conference, Rossyln, VA (1994, March).

Baumann, G. Contesting Culture: Discourses of Identity in multi-ethnic London. New York: Cambridge University Press, 1996.

Blau, P.M., and O.Duncan. The American Occupational Structure. New York: Wiley, 1967.

Bloom, B., Davis, A., and R.Hess. (1965). Compensatory Education for Cultural Deprivation. New York: Holt, Rinehart, and Winston, 1965.

Blumer, Herbert. Symbolic Interactionism. Los Angeles, CA: University of California Press, 1969.

Borman, Kathryn, Mueninghoff, \& Piazza, Shirley. "Urban Appalachian Girl and Young Women: Bowing to No One." In Class, Race, and Gender in American Education edited by L.Weis. New York: SUNY Press, 1989.

Bourdieu, P. "Cultural Reproduction and Social Reproduction." In Power and Ideology in Education edited P.Bourdieu. London: Oxford University Press, 1977.

Bourdieu, P., and J.C.Passeron. Reproduction in education, society and culture. London: Sage, 1977.

Calhoun, Craig. "Social Theory and the Politics of Identity." In Social Theory and the Politics of Identity edited by Craig Calhoun. New York: Ballantine Books, 1995. 
Caplan, N., Choy, M., and J.Whitmore. Children of the Boat People: A Study of Educational Success. Ann Arbor: University of Michigan Press, 1991.

Cardenas, E. "Hispanic Influence Keeps Growing in Metro Detroit." The Detroit News. September 2000.

Carpenter, P.G., and J.A.Fleishman. Youth Achievement and the Structure of Inner-City Communities. Chicago: University of Chicago, 1987.

Carter, T.P., and R.Segura. Mexican Americans in School: A decade of Change. New York: College Entrance Examination Board, 1979.

Cazden, C.B., John, V., and D.Hymes. Functions of Language in the Classroom. New York: Teachers College Press, 1972.

Christian, K. Show and Tell: Identity as Performance in U.S. Latina/o Fiction. Albuquerque, NM.: University of New Mexico Press, 1997.

Codina, G., and F.Montalvo. "Chicano Phenotype and Depression." Hispanic Journal of Behavioral Sciences. 16 (1994):296-306.

Coleman, J., et al. Equality of Educational Opportunity. Washington, D.C.: U.S. Government Printing Office, 1966.

Constantino, Rebecca, and C.Faltis. "Teaching against the grain in bilingual education." In Ethnic Identity and Power edited by Yali Zou and Enrique Trueba. New York: SUNY Press, 1998.

Cornell, Stephen. The Return of the Native: American Indian Political Resurgence. New York: Oxford University Press, 1988.

Cornell, Stephen. "The Variable Ties that Bind: Content and Circumstance in Ethnic Processes." Ethnic and Racial Studies. 19 (1996):266-289.

Cornell, Stephen and Douglas Hartmann. Ethnicity and Race: Identities in a Changing World. Thousand Oaks, CA: Pine Forge Press, 1998.

Danziger, S., Sandefur, G., and D.Wienberg. Confronting Poverty: Prescriptions for Change. New York: Russell Sage Foundation, 1994.

Davidson, Ann Locke. Making and Molding Identity in Schools: Student Narratives on Race, Gender, and Academic Engagement. Albany: SUNY Press, 1996.

Davidson, Ann Locke. "Negotiating Social Differences." Urban Education. 34 (1999):338-369.

Davis, James. Who is Black? One Nation's Definition. University Park: Pennsylvania State University Press, 1992.

Delgado-Gaitan, Concha, and H.Trueba. Crossing Cultural Borders: Education for Immigrant Families in America. London: Falmer Press, 1991.

Detroit Public Schools District Data, "School Data," Detroit Public Schools, http://www.detroit.k12.mi.us

Duany, Jorge. "Reconstructing Racial Identity: Ethnicity, Color, and Class Among Dominicans in the United States and Puerto Rico." Latin American Perspectives. 25 (1998):147-172.

Erickson, E.D. "Transformation and School Success: The Politics and Culture of Educational Achievement." Anthropology and Education Quarterly 18 (1987):335-355 . 
Erickson, E, and J.Mohatt. "Cultural Organization of Participant Structure in Two Classrooms of Indian Students." In Doing the Ethnography of Schooling: Educational Anthropology in Action edited by G.D.Spindler. New York: Holt, Rinehart \& Winston, 1982.

Espiritu, Y. Asian American Panethnicity: Bridging Institutions and Identities. Philadelphia, PA: Temple University Press, 1992.

Evans, Nicola. (1998). "Identity in question." The Quarterly Journal of Speech 84 (1998):94-109.

Fine, M. Framing Dropouts: Notes on the Politics of an Urban Public High School. Albany: SUNY Press, 1991.

Flores-González, N. "Puerto Rican High Achievers: An Example of Ethnic and Academic Identity Compatibility." Anthropology \& Education Quarterly 30 (1999):343-362.

Foley, Douglas. "Reconsidering Anthropological Explanations of Ethnic School Failure." Anthropology and Education Quarterly. 22 (1991):60-86.

Fordham, Signithia. "Racelessnees as a Factor in Black Students' School Success: Pragmatic Strategy or Phyrric Victory?" Harvard Educational Review. 58 (1988):54-84.

Fordham, Signithia. "Those Loud Black Girls: (Black) Women, silence, and gender "passing" in the Academy." Anthropology and Education Quarterly. 24 (1993):3-32.

Fordham, S. and John Ogbu. "Black Students' School Success: Coping with the Burden of Acting White." Urban Review. 18 (1986):176-206.

Fox, Geoffrey. Hispanic Nation. Arizona: University of Arizona Press, 1996.

Gans. Herbert. The Urban Villagers: Group and Class in the Life of Italian Americans. New York: The Free Press, 1961.

Gans, Herbert. "Symbolic Ethnicity: The Future of Ethnic groups and Cultures in America." Ethnic and Racial Studies. 2 (1979):1-20.

Gibson, Margaret. "The School Performance of Immigrant Minorities: A Comparative view." Anthropology and Education Quarterly. 18 (1987): $262-275$.

Gibson, Margaret. "Ethnicity, Gender and Social Class: The School Adaptation Patterns of West Indian Youths." In Minority Status and Schooling edited by Margaret Gibson and John Ogbu. New York: Garland Publishing, 1990.

Gibson, Margaret. "The Dynamics of Educational Decision Making." In Minority Status and Schooling edited by Margaret Gibson and John Ogbu. New York: Garland Publishing, 1990.

Gibson, Margaret and John Ogbu. Minority Status and Schooling: A Comparative Study of Immigrant and Involuntary Minorities. New York: Garland Publishing, 1991.

Glazer, Nathan and Daniel Moynihan. Beyond the Melting Pot. Cambridge, MA.: MIT Press, 1970. 
Gomez, Christina. "The continual significance of skin color: An exploratory study of Latinos in the Northeast." Hispanic Journal of Behavioral Sciences. 22 (2000):94-103.

Gordon, Milton. "Assimilation in America: Theory and Reality." DAEDALUS: Journal of the American Academy of Arts and Sciences. 90 (1961):263-285.

Gurin, P., Hurtado, A., and T.Peng. "Group contacts and ethnicity in the social identities of Mexicanos and Chicanos." Personality and Social Psychology Bulletin 20 (1994):521-532.

Gutierrez, D. Walls and Mirrors: Mexican Americans, Mexican Immigrants and the Politics of Ethnicity. Los Angeles: University of California Press, 1995.

Hall, Stuart.“Cultural Identity and Diaspora.” In Identity: Community, Culture, Difference edited by Jonathan Rutherford. London: Lawrence \& Wishart, 1990.

Hall, Stuart and Paul du Gray. Questions of Cultural Identity. Thousand Oaks, CA: Sage, 1996.

Heath, Shirley Brice. Ways With Words: Language, Life and Work in Communities and Classrooms. Cambridge, MA: Cambridge University Press, 1983.

Hayes, Katherine G. "Attitudes Toward Education: Voluntary and Involuntary Immigrants from the Same Families." Anthropology and Education Quarterly 23 (1992):250-267.

Hein, Jeremy. "From Migrant to Minority: Hmong Refugees and the Social Construction of Identity in the United States." Sociological Inquiry. 64 (1994):281-306.

Heller, C. Mexican American Youth: The Forgotten Youth at the Crossroads. New York: Random House, 1966.

Hirschman, C. "Studying Immigrant Adaptation from the 1990 Population Census: From Generational Comparisons to the Process of Becoming American." In The New Second Generation edited by Alejandro Portes. New York: The Russell Sage Foundation, 1996.

Hochschild, Jennifer. Facing Up to the American Dream: Race, Class and the Soul of the Nation. Princeton: Princeton University Press, 1995.

Hollingshead, A. Elmtown's Youth and Elmtown Revisited. New York: Wiley, 1975.

Hughes, M., and B.Kertel. "The significance of color remains: A study of life chances, mate selection, and ethnic consciousness among Black Americans." Social Forces. 68 (1991):1105-1120.

Hurtado, A., and C.Arce. "Mexicans, Chicanos, Mexican Americans, or pochos... ¿Que somos? The impact of language and nativity on ethnic labeling." Aztlan 17 (1986):103-130.

Hurtado, A., and P.Gurin. "Ethnic Identity and bilingualism attitudes." Hispanic Journal of Behavioral Sciences. 9 (1987):1-18. 
Hurtado, A., Gurin, P., and T.Peng. "Social Identities-A Framework for Studying the Adaptations of Immigrants and Ethnics: The Adaptations of Mexicans in the United States." Social Problems , 41 (1994):129-151.

Isaacs, Harold. "Basic Group Identity: Idols of the Tribe." In Ethnicity: Theory and Experience edited by N.Glazer and D.P.Moynihan. Cambridge, Mass.: Harvard University Press, 1975.

Jensen, A.R. "How much can we boost IQ and scholastic achievement?" Harvard Educational Review. 3 (1969):1-123.

Keith, Verna and C.Herring. "Skin Tone and Stratification in the Black Community." American Journal of Sociology. 97 (1991):760-778

Kerckhoff, A. and R.Campbell. "Black-White Differences in the Educational Attainment Process." Sociology of Education. 50 (1977):15-27 .

Kockman, T. Black and White Styles in Conflict. Chicago: University of Chicago, 1981.

Lee, Stacey J. "Behind the Model-Minority Stereotype: Voices of High- and Low-Achieving Asian American Students." Anthropology and Education Quarterly 25 (1994):413-429.

Lewis, Amanda. Race in the Schoolyard. Rutgers, NJ: Rutgers University Press, 2003.

Lewis, O. The Children of Sanchez. New York: Random House, 1961.

Lieberson, Stanley. A Piece of the Pie: Blacks and White Immigrants Since 1880. Berkeley: University of California Press, 1980.

Lieberson, Stanley. "Unhyphenated Whites in the United States." Ethnic and Racial Studies. 8 (1985):159-180.

MacLeod, J. Ain't no makin' it: Leveled aspirations in a low-income neighborhood. Boulder, Colorado: Westview Press, 1995.

McQuillan, P.J. Educational Opportunity in an Urban American High School. Albany, NY: SUNY Press, 1998.

McRobbie, A. "Working Class Girls and the Culture of Femininity." In Women Take Issue: Aspects of Women's Subordination. Hutchinson Publishing, 1978.

Marini, M.M., and E.Greenberger. "Sex differences in educational aspirations and expectations." American Educational Research Journal. 5 (1978): 147-179.

Martin, E., DeMaio, T., and P.Campanelli. "Context effects for census measures of race and Hispanic origin." Public Opinion Quarterly. 54 (1990):551-66.

Massey, Douglas. "Latinos, poverty, and the underclass: A new agenda for research." Hispanic Journal of Behavioral Sciences. 15 (1993):449-475.

Massey, D. and N.Denton. "Racial Identity and the Spatial Assimilation of Mexicans in the United States." Social Science Research. 21 (1992): 235-260.

Matute-Bianchi, M.E. "Ethnic Identities and Patterns of School Success and Failure among Mexican-descent and Japanese American Students in a 
California High School." American Journal of Education. 95 (1986): 233-55.

Mickelson, R. "The attitude-achievement paradox among Black adolescents." Sociology of Education. 63 (1990):44-61.

Miles, M. and A.Huberman. Qualitative Data Analysis. New York: Sage, 1984. Moynihan, Daniel P. The Negro Family: The Case for National Action. Washington, D.C.: United States Department of Labor, Office of Policy, Planning, and Research, 1965.

Murguia, Edward and E.Telles. "Phenotype and Schooling among Mexican Americans." Sociology of Education. 69 (1996):276-289.

Nagel, Joane. "The political construction of ethnicity." In Competitive Ethnic Relations edited by S.Olzak and J.Nagel. New York: Academic Press, 1986.

Nagel, Joane. "Constructing Ethnicity: Creating and Recreating Ethnic Identity and Culture." Social Problems. 41 (1994):152-176.

National Center for Education Statistics. The Educational Progress of Hispanic Students. Washington, D.C.: United States Department of Education, Office of Educational Research and Improvement, 1995.

National Center for Education Statistics. October Current Population Survey. Washington, D.C.: United States Department of Commerce, Bureau of the Census, 1996.

Nieto, Sonia. "Causes and Effects of the Puerto Rican Diaspora," Sonia Nieto, http://www-nix.oit.umass.edu/ nyal/papers/diaspora\%20presentation.htm

Oboler, S. Ethnic Labels, Latino Lives: Identity and the Politics of (Re)Presentation in the United States. Minneapolis, MN.: University of Minnesota Press, 1991.

O’Connor, Carla. "Dispositions Toward (Collective) Struggle and Educational Resilience in the Inner City: A Case Analysis of Six African American High School Students." American Educational Research Journal. 34 (1997): 593-629.

O'Connor, Carla. "Race, Class, and Gender in America: Narratives of opportunity among low-income African American youths." Sociology of Education. 72 (1999):137-157.

O'Connor, Carla. "Making sense of the complexity of social identity in relation to achievement: A sociological challenge in the new millennium." Sociology of Education (2001): 159-168.

Oliver, M. and T.Shapiro. Black Wealth/White Wealth: A New Perspective on Racial Inequality. New York: Routledge, 1997.

Ogbu, John. Minority Education and Caste: The American System in CrossCultural Perspective. New York: Academic Press, 1978.

Ogbu, John. "Anthropology and Education." In International Encyclopedia of Education: Research and Studies. Oxford: Oxford University Press, 1982. 
Ogbu, John. "Variability in Minority School Performance: A Problem in Search of an Explanation." Anthropology and Education Quarterly. 18 (1987): 312-334

Ogbu, John. "Immigrant and Involuntary Minorities in Comparative Perspective." In Minority Status and Schooling: A Comparative Study of Immigrant and Involuntary Minorities edited by Margaret Gibson and John Ogbu. New York: Garland Publishing, 1991.

John Ogbu. "Understanding Cultural Differences and School Learning." Paper presented at the $83^{r d}$ Annual Meeting of the Special Library Association, San Francisco, CA, 1992.

Olsen, L. Made in America: Immigrant Students in our Public Schools. New York: The New Press, 1997.

Omi, M. and H.Winant. Racial Formation in the United States: From the 1960s to the 1990s. New York: Routledge, 1994

Padilla, Felix. Latino Ethnic Consciousness. Notre Dame, IN: University of Notre Dame Press, 1985.

Park, Robert. "Racial Assimilation in Secondary Groups." In Race and Culture. Glencoe, IL: The Free Press, 1950.

Patchen, M. Black-White Contact in Schools: Its Social and Academic Effects. West Lafeyette, IN: Purdue University Press, 1982.

Patterson, Orlando. "Context and Choice in Ethnic Allegiance: A Theoretical Framework and Caribbean Case Study." In Ethnicity: Theory and Experience edited by Nathan Glazer and Daniel Moynihan. Cambridge, Mass.: Harvard University Press, 1975.

Patton, Michael. Qualitative Evaluation and Research Methods. Newbury Park, CA: Sage Publications, 1990.

Pedraza, Silvia. "Ethnic Identity: Developing a Hispanic-American Identity." Paper presented at the 5th Congreso Internacional sobre las Culturas Hispanas de los Estados Unidos, Madrid, Spain, 1992.

Phoenix, Ann. "Dealing with Difference: The Recursive and the New." Ethnic and Racial Studies. 2 (1988):859-880.

Pizarro, M., and E.Vera. "Chicana/o ethnic identity research: Lessons for researchers and counselors." Counseling Psychologist. 29 (2001):91-117.

Portes, Alejandro. "The New Second Generation." International Migration Reviewm. 28 (1994):1-10.

Portes, Alejandro. The New Second Generation. New York: Russell Sage Foundation, 1996.

Portes, A., and R.Bach. Latin Journey: Cuban and Mexican Immigrants in the United States. Berkeley: University of California Press, 1985.

Portes, A., and D.MacLeod. "What Shall I Call Myself? Hispanic identity formation in the second generation." Ethnic and Racial Studies. 19 (1996a):523-547. 
Portes, A., and D.MacLeod. "Educational progress of children of immigrants: The roles of class, ethnicity and school context." Sociology of Education. 69 (1996b):255-275.

Portes, A., and R.Shauffler. "Language and the Second Generation: Bilingualism Yesterday and Today." In The New Second Generation edited by Alejandro Portes. New York: Russell Sage Foundation, 1996.

Portes, A., and Ruben Rumbaut. Immigrant America. Berkeley: University of California Press, 1996.

Portes, A., and Min Zhou. "The New Second Generation: Segmented Assimilation and Its Variants Among Post-1965 Immigrant Youth.” Annals of the American Academy of Political and Social Sciences. 530 (1993): 74-96.

Rodriguez, Clara. Puerto Ricans: Born in the U.S.A. Boulder, CO.: Westview Press, 1991.

Rodriguez, Clara. "Race, Culture, and Latino "Otherness" in the 1980 Census." Social Science Quarterly. 73 (1992):930-937.

Rodriguez, Clara. Changing Race: Latinos, the Census, and the History of Ethnicity in the United States. New York: New York University Press, 2000 .

Rodriguez, Clara and Hector Cordero-Guzman. "Placing Race in Context." Ethnic and Racial Studies. 15 (1992):523-542.

Rodrgiuez, J. and P.Gurin. "The relationship of intergroup contact to social identity and political consciousness." Hispanic Journal of Behavioral Sciences. 12 (1990):235-255.

Rumbaut, Ruben G. "The Crucible Within: Ethnic Identity, Self-Esteem, and Segmented Assimilation Among Children of Immigrants." International Migration Review. 28 (1994):748-794.

Saenz, R. and B.Aguirre. "The dynamics of Mexican ethnic identity." Ethnic Groups 9 (1991):17-32.

Santiago, Roberto. Boricuas: Influnetial Puerto Rican Writing-An Anthology. New York: One World Ballantine Books, 1995.

Sewell, W.H., Haller, A.O., and A.Portes. "The educational and early occupational attainment process." American Sociological Review. 34 (1969):82-92 .

Solomon, R.P. Black Resistance in High School: Forging a Separatist Culture. Albany: State University of New York Press, 1992.

Standard \&; Poor's School Evaluation Services. "Detroit Public Schools," Standard \& Poor's, http://www.ses.standardandpoors.com

Suárez-Orozco, Marcelo. "Immigrant Adaptation to Schooling: A Hispanic Case." In Minority Status and Schooling: A Comparative Study of Immigrant and Involuntary Minorities edited by Margaret Gibson and John Ogbu. New York: Garland Publishing, 1991. 
Suárez-Orozco, Carola and Suárez-Orozco, Marcelo. Trans-Formations: Migration, Family Life, and Achievement Motivation Among Latino Adolescents. Stanford, California: Stanford University Press, 1995.

Trueba, Henry. Success or Failure? Learning and the Language Minority Student. Cambridge, Mass.: Newbury House, 1987.

Trueba, Henry. Raising Silent Voices: Educating the Linguistic Minorities for the 21st Century. Cambridge, Mass.: Newbury House, 1989.

Trueba, Henry. "Multiple Ethnic, Racial, and Cultural Identities in Action: From Marginality to a New Cultural Capital in Modern Society." Journal of Latinos and Education. 1 (2002):7-28.

U.S. Bureau of the Census. Census of Population: Person of Hispanic Origin in the United States. Washington, D.C.: Government Printing Office, 1999.

U.S. Bureau of the Census. Census of Population: Person of Hispanic Origin in the United States. Washington, D.C.: Government Printing Office, 2000.

U.S. Department of Education. The Condition of Education 2001. Washington, D.C.: Government Printing Office, 2001.

Valenzuela, Angela. Subtractive Schooling: U.S.-Mexican Youth and the Politics of Caring. Albany: SUNY Press, 1999.

Vazquez, L., Garcia-Vazquez, E., Bauman, S. and A.Sierra. "Skin color, Acculturation, and Community Interest among Mexican American Students: A research note." Hispanic Journal of Behavioral Sciences. 19 (1997):77-386.

Vigil, James Diego. Barrio Gangs: Street Life and Identity in Southern California. Texas: University of Texas Press, Austin, 1988.

Waters, Mary. Ethnic Options: Choosing Identities in America. Berkeley, CA: University of California Press, 1990.

Waters, Mary. "The Role of Lineage in Identity Formation Among Black Americans." Qualitative Sociology. 14 (1991):57-76.

Waters, Mary. "Ethnic and Racial Identities of Second-Generation Black Immigrants in New York City." International Migration Review. 28 (1994):795-821.

Weis, Robert S. Learning From Strangers: The Art and Method of Qualitative Interview Studies. New York: Free Press, m 1994.

Whyte, W. Street Corner Society: The social structure of an Italian slum. Chicago: The University of Chicago Press, 1943.

Willis, Paul. Learning To Labor: How working class kids get working class jobs. London: Saxon House, 1977

Willis, P. "Cultural Production is Different from Cultural Reproduction is Different from Social Reproduction is Different from Reproduction." Interchange. 12 (1981):49-67

Wilson, W.J. The Declining Significance of Race: Blacks and Changing American Institutions. Chicago: University of Chicago Press, 1980.

Wilson, W.J. The Truly Disadvantaged: The Inner City, The Underclass, and Public Policy. Chicago: University of Chicago Press, 1987 
Wilson, W.J. When Work Disappears: The World of the New Urban Poor. New York: Vintage, 1996.

Winant, H. Racial Conditions: Politics, Theory, Comparison. Minneapolis, MN: University of Minnesota Press, 1994.

Wojtkiewicz, Roger and K.Donato. "Hispanic Educational Attainment: The effects of family background and nativity." Social Forces. 74 (1995):2-15.

Yancey, W., Ericksen, E., and J.Richard. "Emergent Ethnicity: A Review and Reformulation.” American Sociological Review. 41 (1976):391-403

Zhou, Min. "Segmented Assimilation: Issues, Controversies, and Recent Research on the New Second Generation." International Migration Review. 31 (1997). 


\section{Index}

A

Absolute success, 83

Academic identity, 7-8

Academic orientation, 105 academic performance, 105-107 aspirations, 105-107 interpretations of school, 109-124

Academic variability, xviii-1 explanations of, xviii-9

Achievement ideology, 79 commitment to, 90-91

Across-case analysis, 31-32

Afro-Latino, 70

Algarín, Miguel, 43

Ancestral/national identification, 46 as inescapable, 46-51 second-generation, 46

Anzaldúa, Gloria, 39

\section{B}

Barth, Fredrik, 10

Bashi, Vilna, 9, 14, 73

Black/biracial-looking, 63

dual-life, 121

experiences of discrimination,

115-124

interpretations of making it,

96-103

physical congruence with blacks, 73-75

racial affiliation with blacks,

73-75
Black Caribbean immigrants, 14-15

Boricua, 52, 70, 74

C

Calhoun, Craig, 8-9, 64

Chance, 81

distribution of, 94 tool for mobility, 95

Chicano identification, 53

Co-narratives of opportunity, 91 erasing race/ethnicity, 92-93 gender, skin color, and race/ ethnicity-based, 96-103

Cordero-Guzman, Hector, 15

Cornell, Stephen, 10-13

Cultural capital, 1

Cultural deprivation theory, 1-3

Cultural difference model, 3-4

Cultural ecological model, 4-7 limitations of, 7-9

Cultural identification, 52-55

Culture, 34 content, 55

Mexican culture, 59-60

Puerto Rican culture, 55-59

Culture of poverty, see Cultural deprivation theory

D

Detroit, 20

census, 20-21

public schools, 26-29 
Detroit-Rican, 43-44

\section{$\mathbf{E}$}

Ethnic minority students, xii academically troubled, 4 multiple social positionings, 91

Espiritu, Yen Le, 11

Evans, Nicola, 45

External identification, 62

F

Flores-Gonzalez, Nilda, 7

Fox, Geoffrey, 11

H

Hall, Stuart, 10, 14, 69

Heller, Carl, 1

Hochschild, Jennifer, 83

Hoya, de la, Oscar, 71

Hyphenated identification, 39

hyphen as a border, 42-44

incorporate multiple locales,

39-42

multiple ethnic lineage, 44-45

I

Identity politics, 8-9

Immigrant minorities, 5

Involuntary minorities, 5

secondary cultural differences,

5-6

$\mathbf{L}$

Lewis, Oscar, 1

M

MacLeod, Jay, 81

Making it, 81

interpretations of, 83-91

and a positive self-outlook, 96-99

Matute-Bianchi, Maria, 7

Mexican-American, 41-43

Mexican culture, 59-60

Mexican/Hispanic-looking, 63 experiences of discrimination,

115-124

interpretations of making it,

96-103

physical congruence with

Mexicans, 73, 75

racial affiliation with Mexicans,

73

Mexicans, 1

braceros program, 21

census population, 20-21

identification by generation, 6

Mexican-American identity,

41-43

repatriation program, 21

as representative of Hispanic, 73

use of Latino/Hispanic, 11

use of skin color, 15

Mickelson, Rosyln, 90

$\mathbf{N}$

Nagel, Joane, 11-13, 55, 61

Nuyorican Poet's Café, 43

$\mathbf{O}$

O'Connor, Carla, 91

Ogbu, John, 3-7

$\mathbf{P}$

Padilla, Felix, 11, 13

Pan-ethnicity, 11-12; see also Racial/ethnic identification

Perceptions of opportunity, 79

Phenotype, see Skin color

Puerto Rican-American identification, 39-41

Puerto Rican culture, 55-56

and skin color, 57-58

based on context, 57

family interaction styles, 56-57

Puerto Ricans, 1

census population, 20-21

and culture, 55-59 
Detroit-Rican identification,

43-44

high-achieving, 7

Nuyorican identification, 43

Operation Bootstrap, 21

Puerto Rican-American

identification, 39-41

use of Latino/Hispanic, 7

use of skin color, 15

\section{$\mathbf{R}$}

Race/ethnicity, 35

erasing of, 92

Racelessness, 8, 16

Racial/ethnic identification, 9

agency, 12-16

boundary construction, 10

circumstantial factors, 11

language as signifier, 70-71

as mandatory, 14

pan-ethnicity, 11

as performance, 70

process of gain and loss, 69

"representing," 70-71

use of markers, 14

Racialization, 63

new category, 73

Relative success, 83

Resilient personas, 115

Rodriguez, Clara, 15

\section{S}

Self-identification, 34

ancestral/national identification,

46-52

cultural identification, 52-54

hyphenated identification, 39-46

use of race and ethnicity, 35

Skin color, 10

as a floating signifier, 10

as a marker, 14-15

in Puerto Rican culture, 57-58

selection of students, 22-23

Social inequality, 84-85, 87
Suárez-Orozco, Carola, 6

Suárez-Orozco, Marcelo, 6

\section{$\mathbf{T}$}

Trigueño. 63

Trueba, Henry, 115

V

Vigil, James, 71

Voluntary minorities, 5

primary cultural difference, 5

\section{W}

Waters, Mary, 14

White-looking, 63

differences in privilege, 64

experiences of discrimination,

110-114

interpretations of making it, 92

96

performing identification, 70

physical congruence with whites,

67-68

power of skin color, $69-70$

racial affiliation with whites,

67-68

situated based on skin color, 66

use of language, 70-71

Within-case analysis, 31-32 